Supporting Information

\title{
Ruthenium Metathesis: a Key Step to Access a New Cyclic Tetrasubstituted Olefin Platform
}

\author{
Clément F. Heinrich ${ }^{[\mathrm{a}]}$, Didier Durand ${ }^{[\mathrm{b}]}$, Jérôme $\operatorname{Starck}^{[\mathrm{b}]^{*}}$, Véronique Michelet ${ }^{[\mathrm{a}, \mathrm{c}]^{*}}$
}

[a] PSL Research University, Chimie ParisTech-CNRS, Institut de Recherche de Chimie Paris, 11 rue P. et M. Curie, 75005 Paris, France

[b] Institut de Recherches Servier, 125 Chemin de Ronde, 78290 Croissy-Seine, France. jerome.starck@servier.com

[c] University Côte d'Azur, Institut de Chimie de Nice, Parc Valrose, Faculté des Sciences, 06100 Nice, France.

veronique.michelet@univ-cotedazur.fr

Note: Dienes 1a-q, tetrahydropyridines 8a-q, amide 17 and reductive amination products 18a and 18b expressed a rotameric behaviours due to the Boc moiety. In all spectra $\left({ }^{1} \mathrm{H},{ }^{13} \mathrm{C}\right.$ and $\left.{ }^{19} \mathrm{~F}\right)$ a splitting pattern could be noticed, which decrease the overall resolution. 
${ }^{1} \mathrm{H}$ and ${ }^{13} \mathrm{C}$ spectra for compounds 1a-r, 2a-d, 3, 4a-b, 5a-c, 6a-e, 7a-c
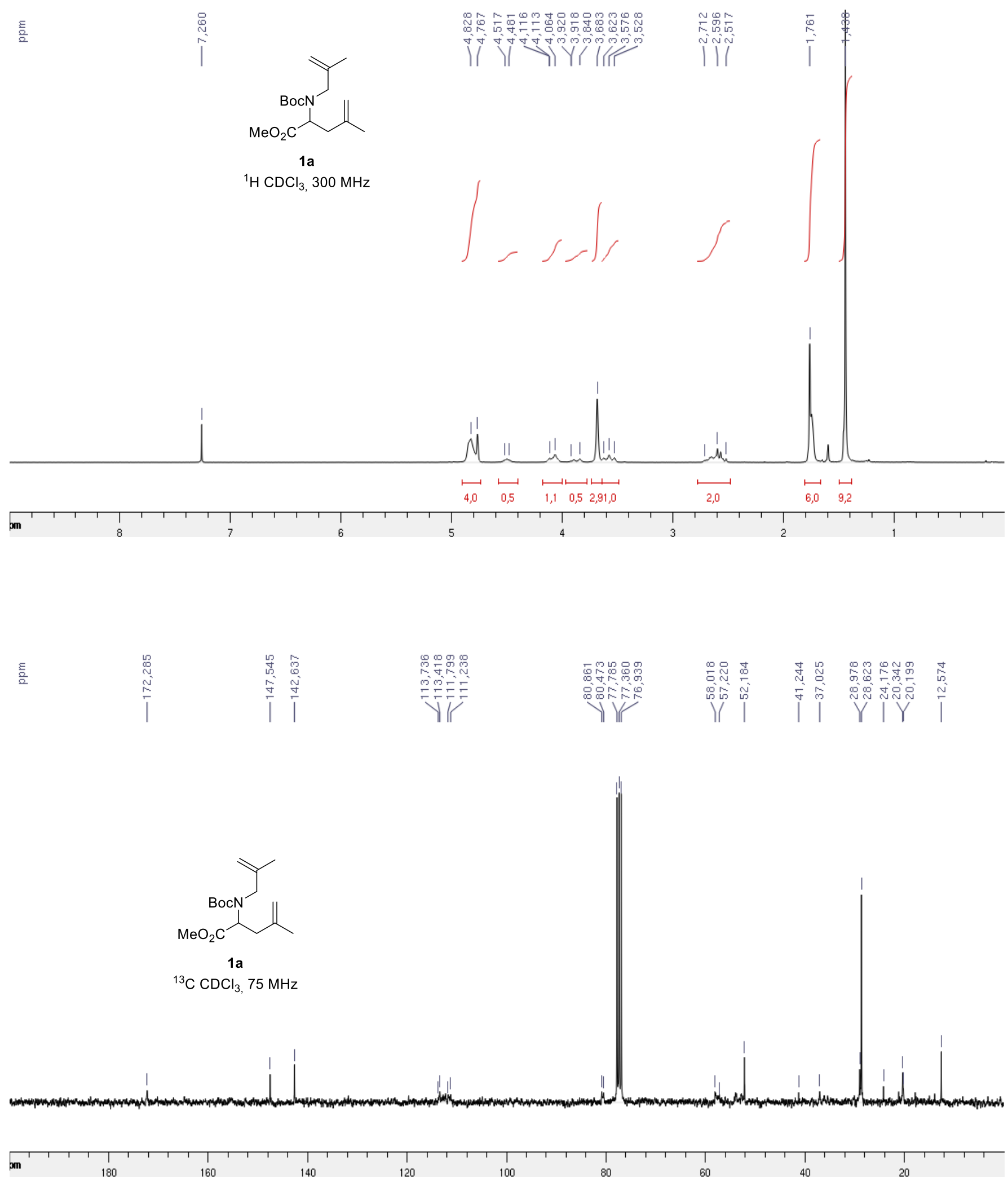

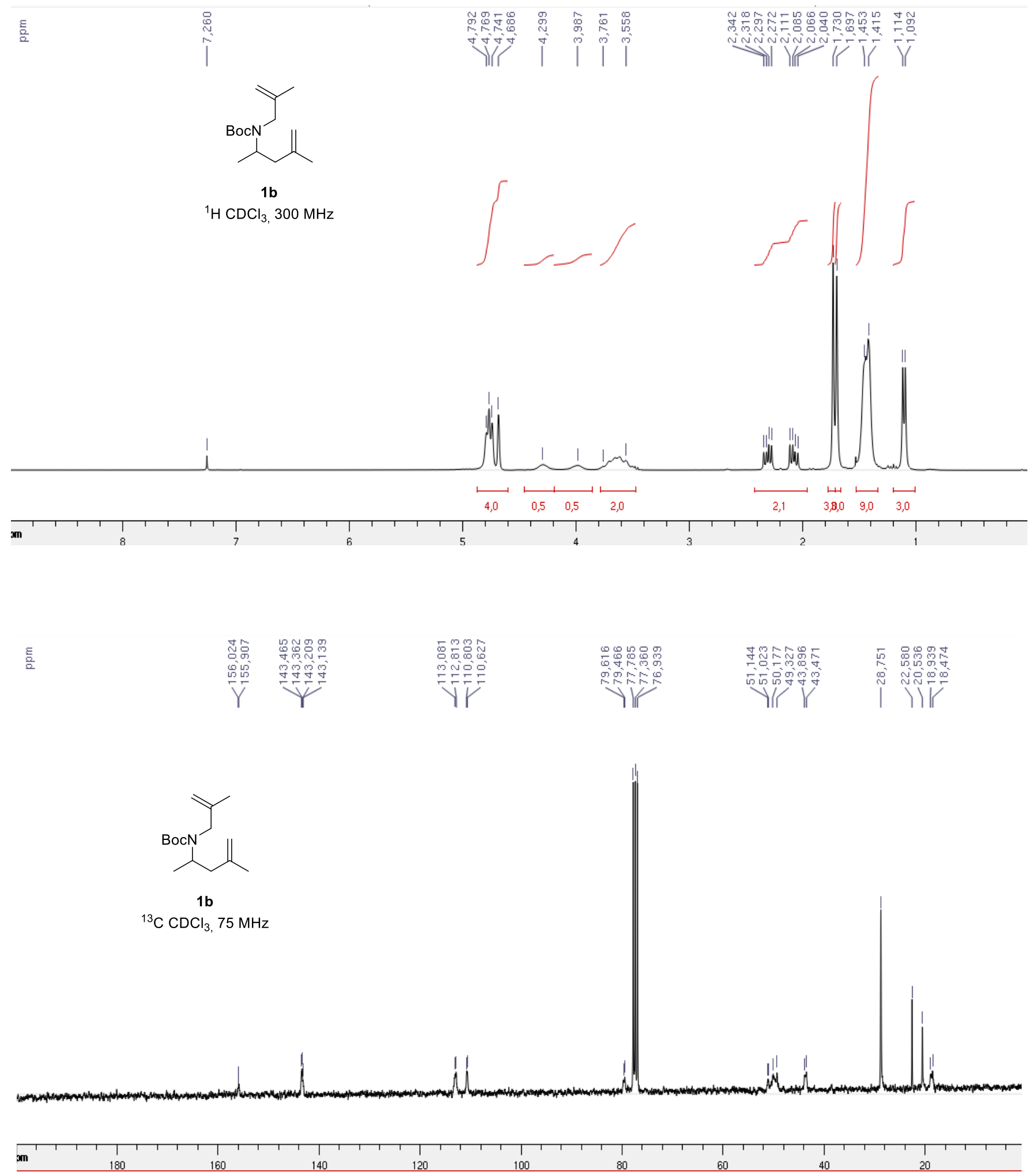

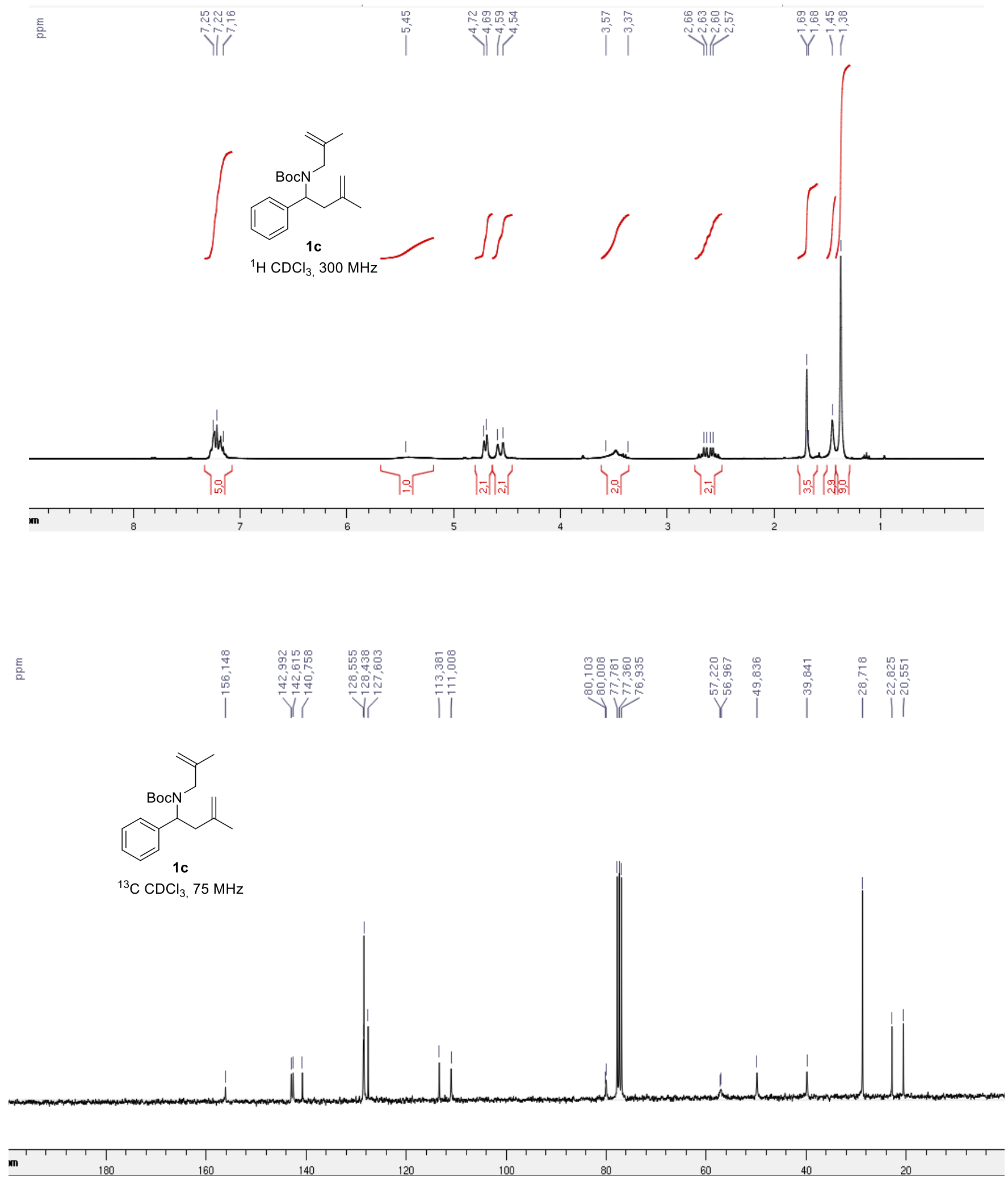

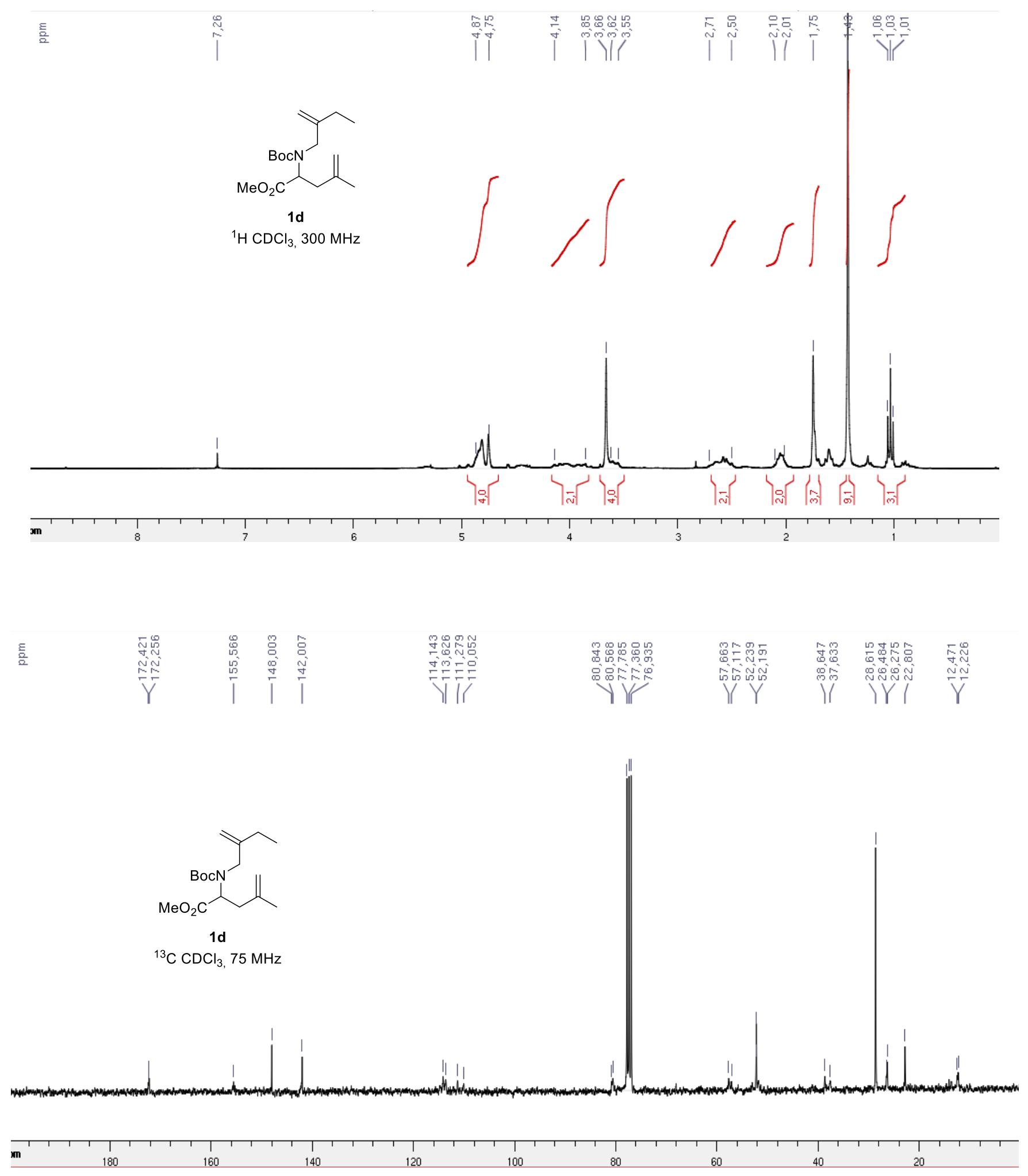

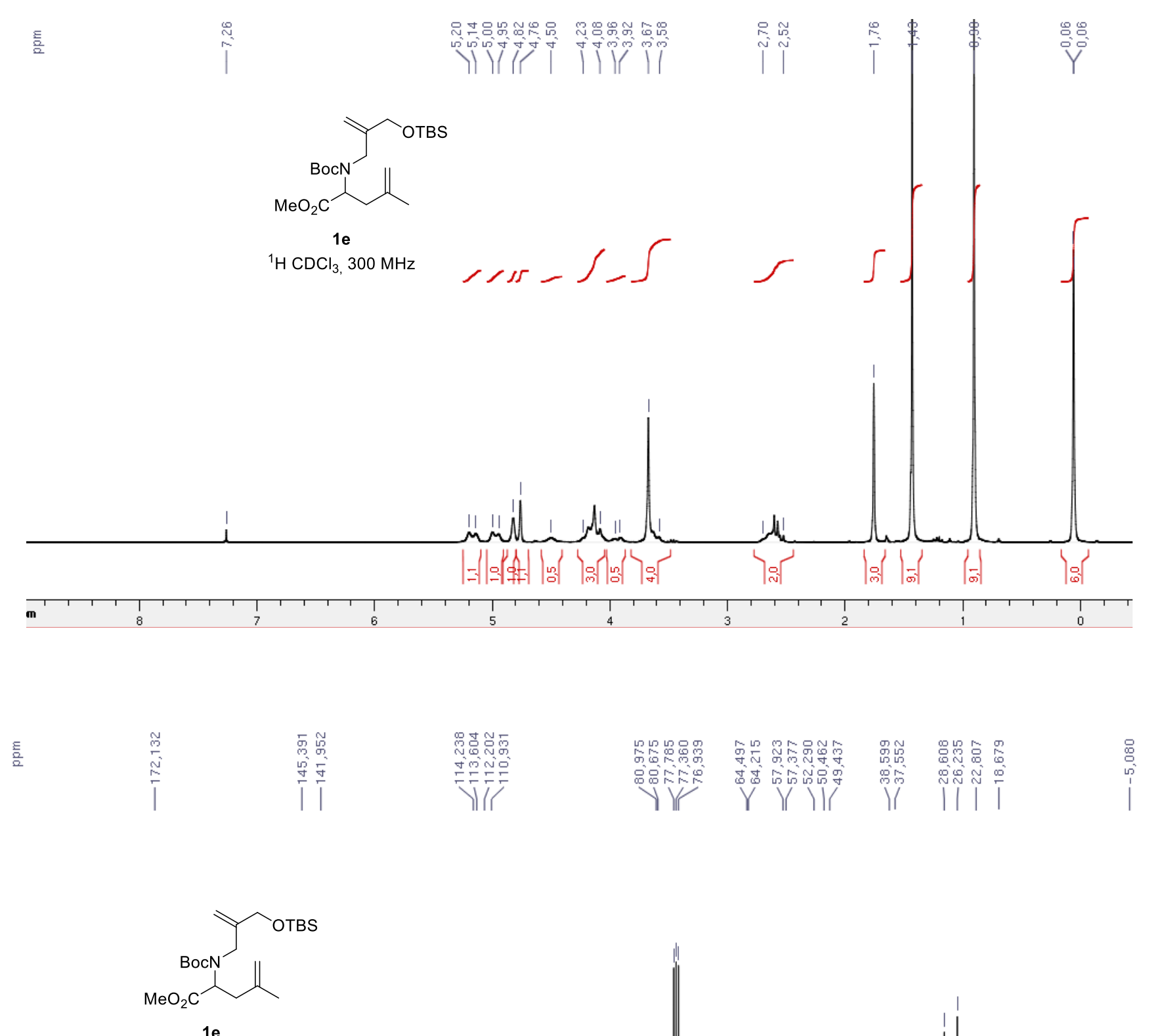

${ }^{13} \mathrm{C} \mathrm{CDCl}_{3}, 75 \mathrm{MHz}$ 

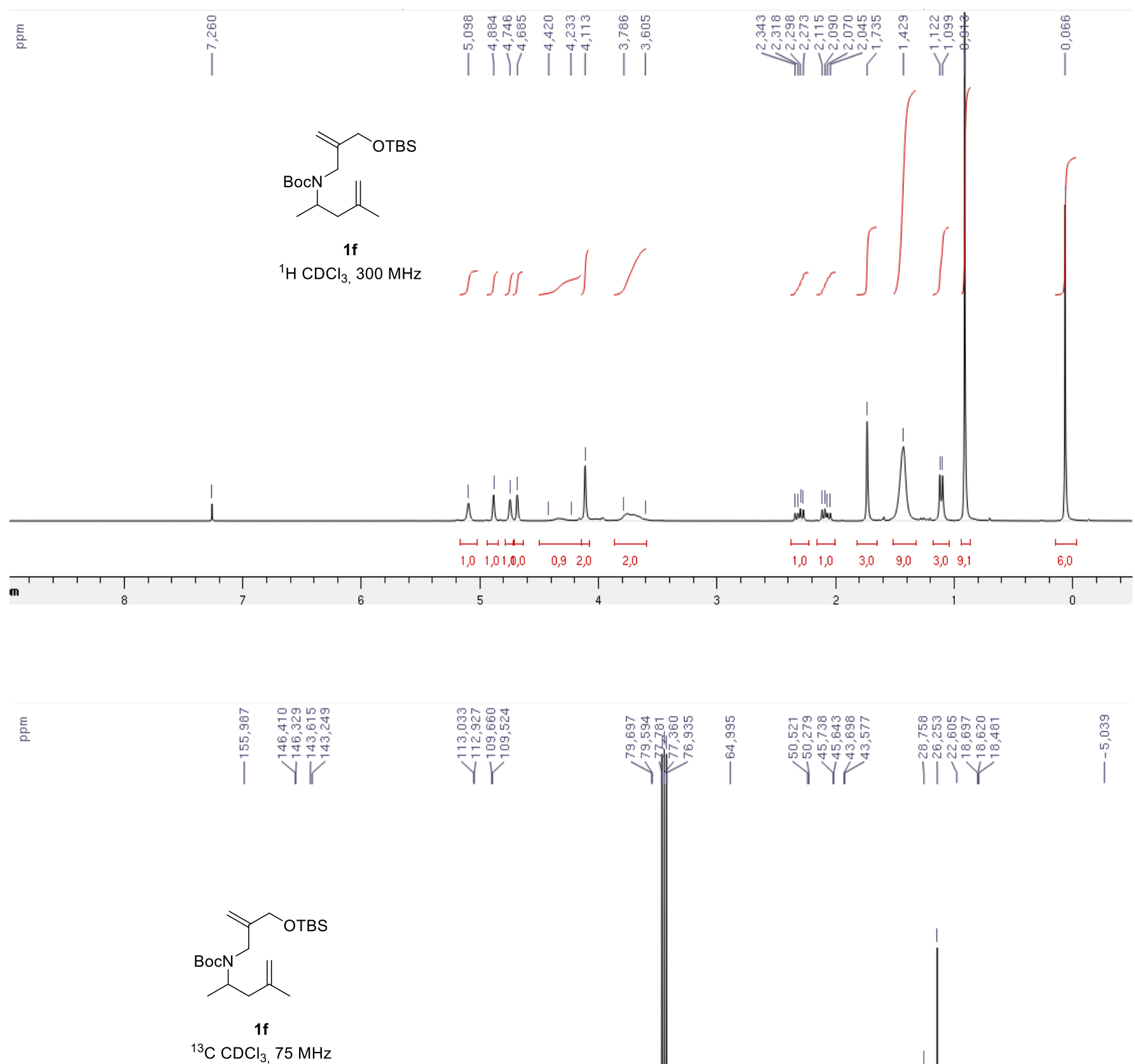

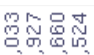 \\ Y}

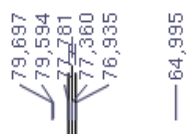

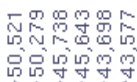

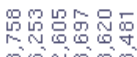

yYy

กับง

$\| \mid Y$

${ }^{13} \mathrm{C} \mathrm{CDCl}_{3}, 75 \mathrm{MHz}$

m.t.

m

180

160

140

120

100

80

60

40

20 

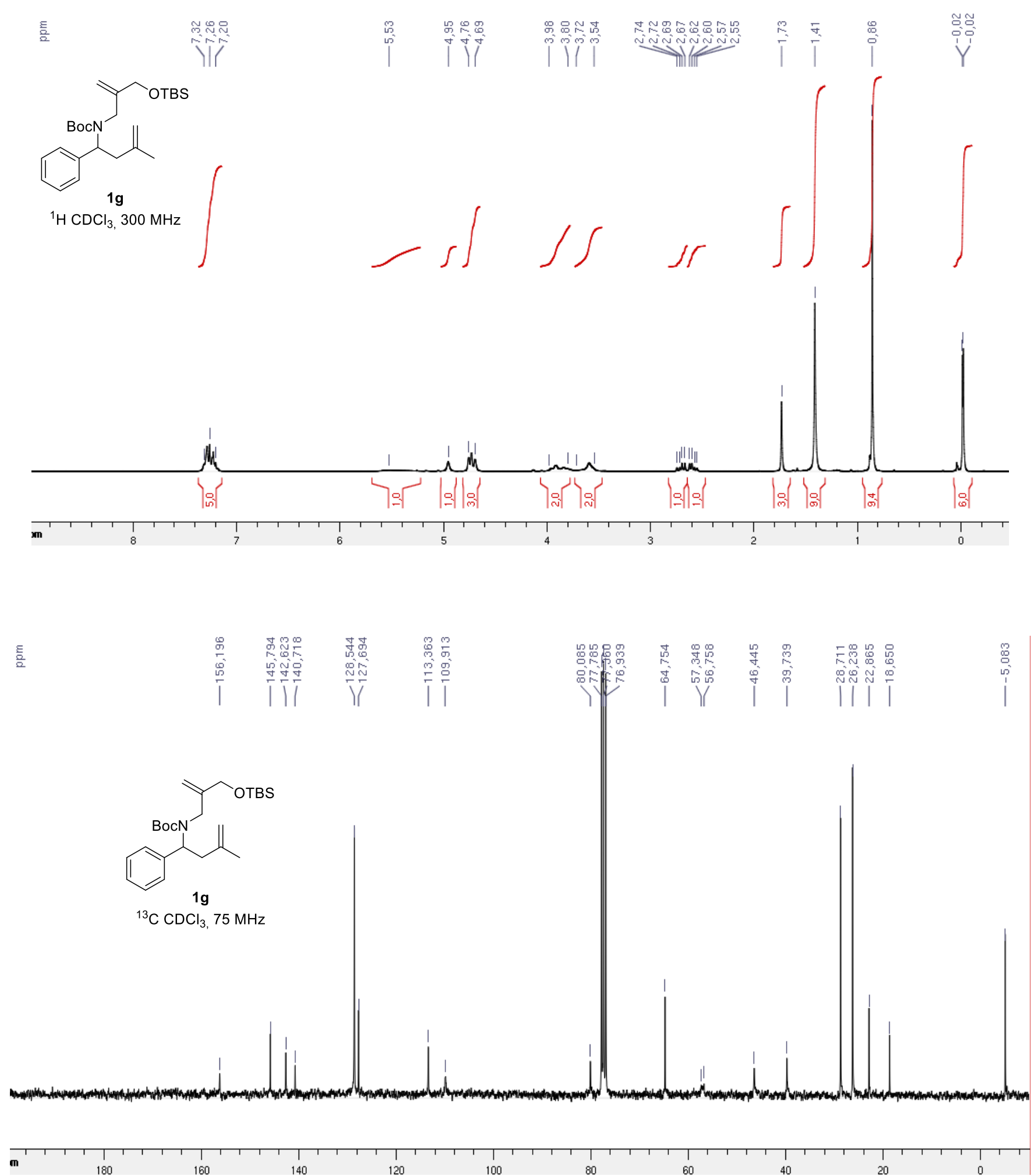


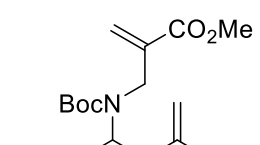

$1 \mathrm{~h}$

${ }^{1} \mathrm{H} \mathrm{CDCl}_{3}, 300 \mathrm{MHz}$

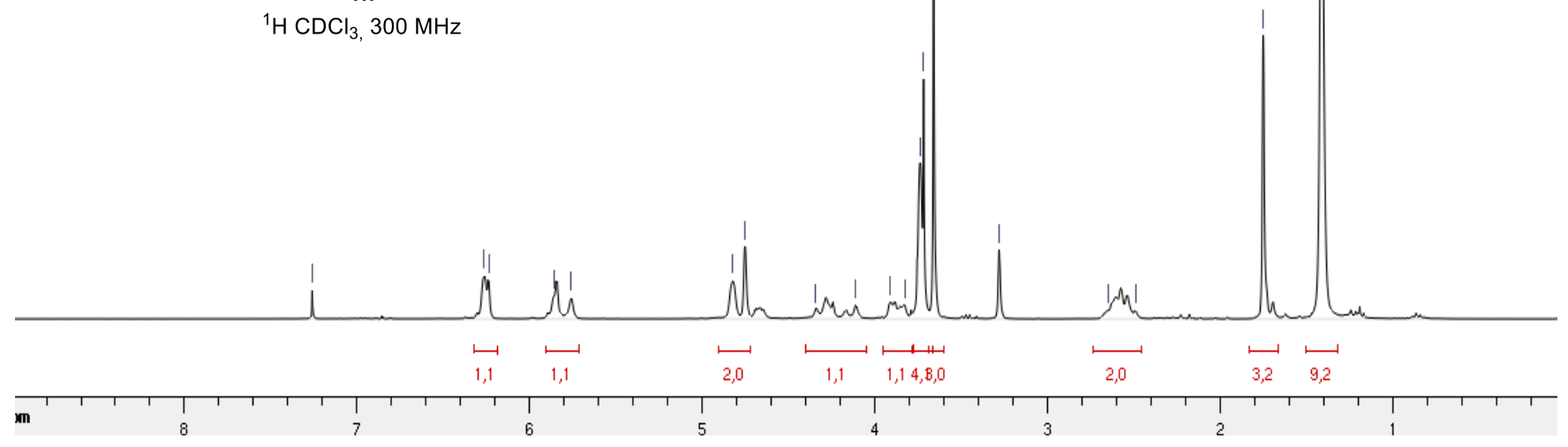

I

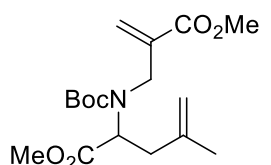

$1 \mathrm{~h}$

${ }^{13} \mathrm{C} \mathrm{CDCl}_{3,75 \mathrm{MHz}}$ 

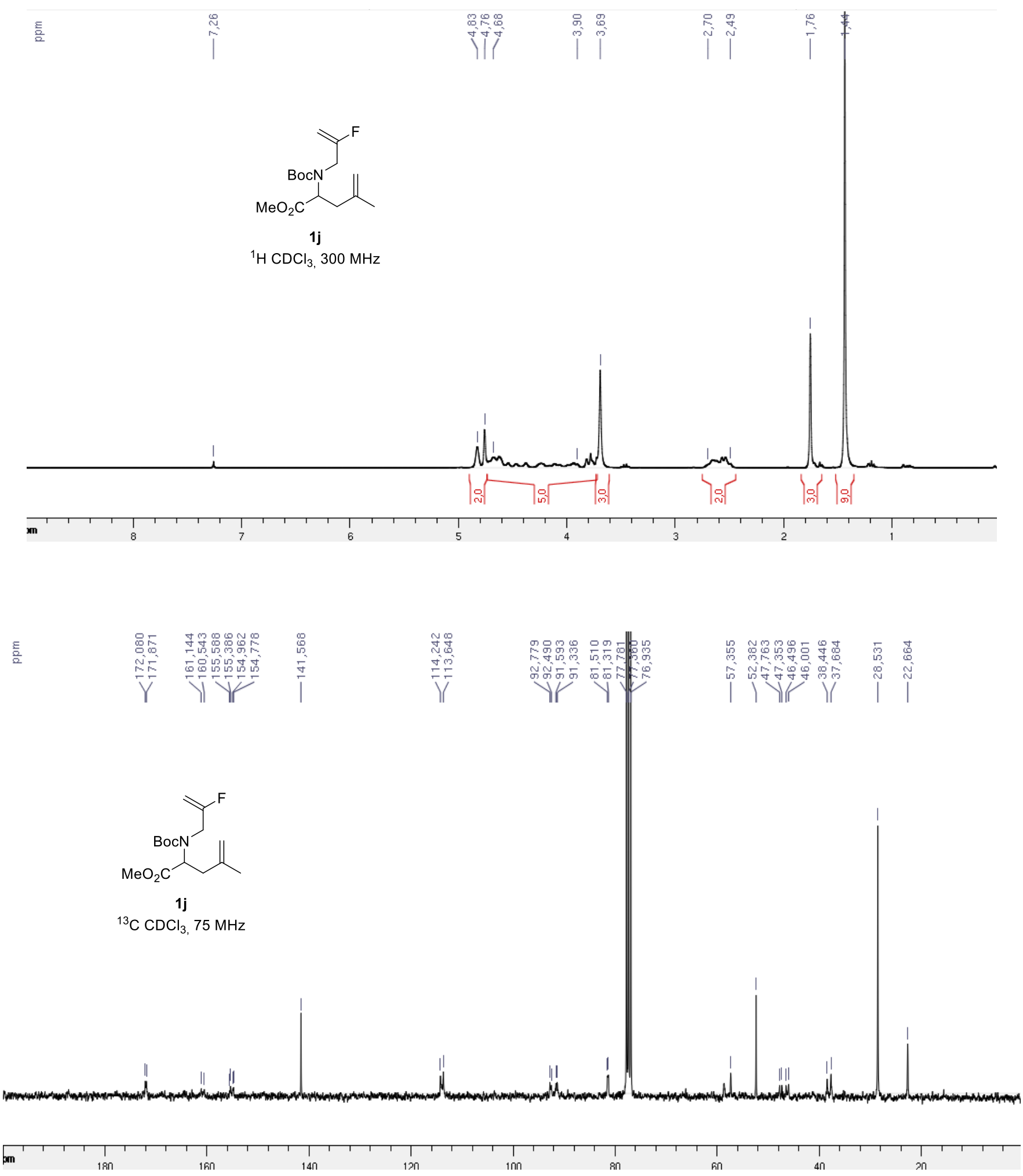

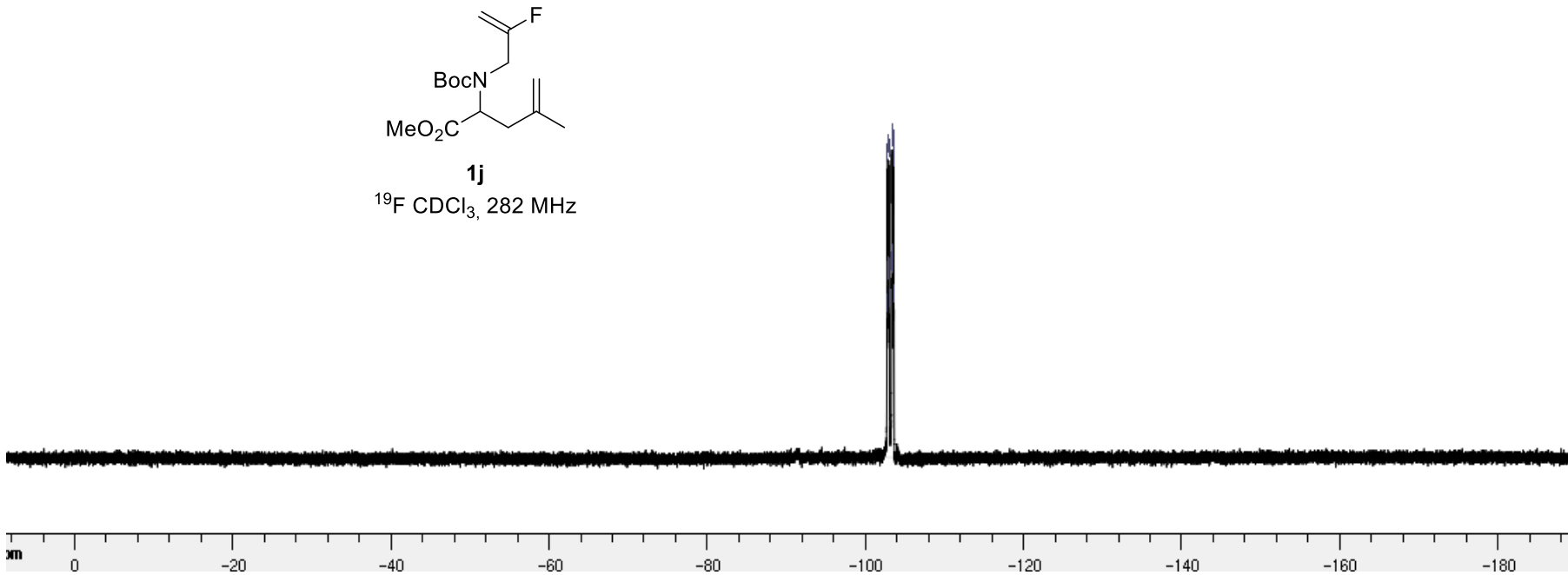


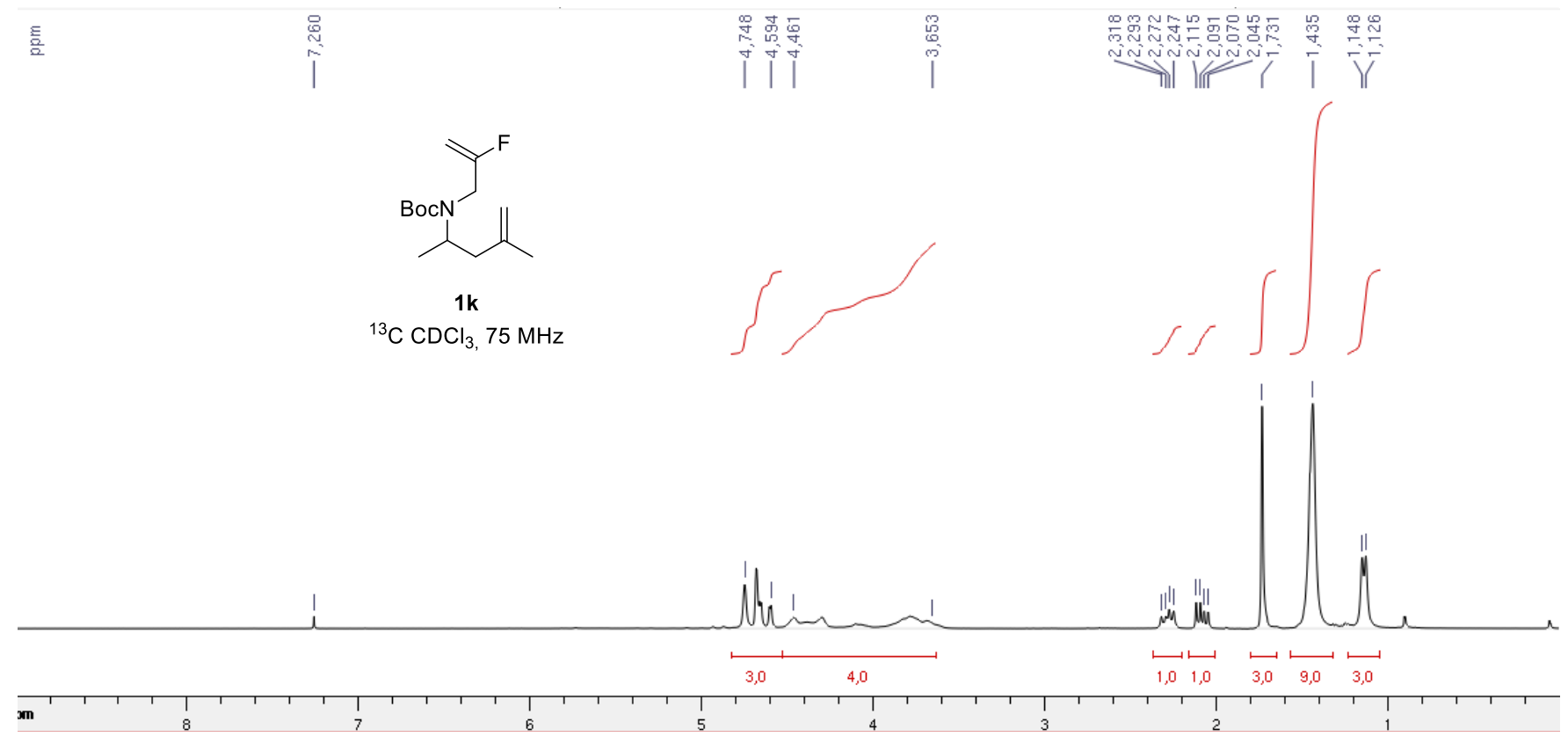

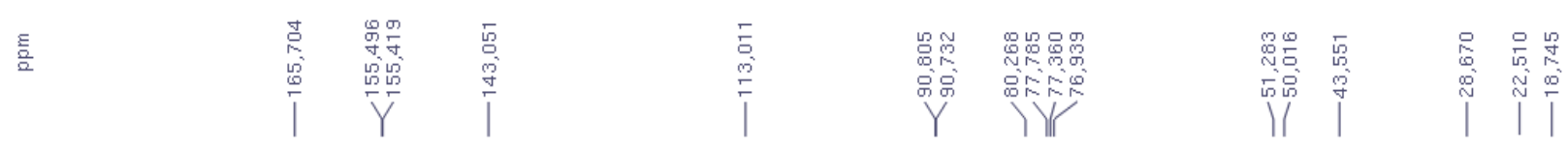

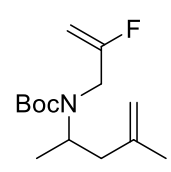

$1 \mathrm{k}$

${ }^{13} \mathrm{C} \mathrm{CDCl}_{3}, 75 \mathrm{MHz}$
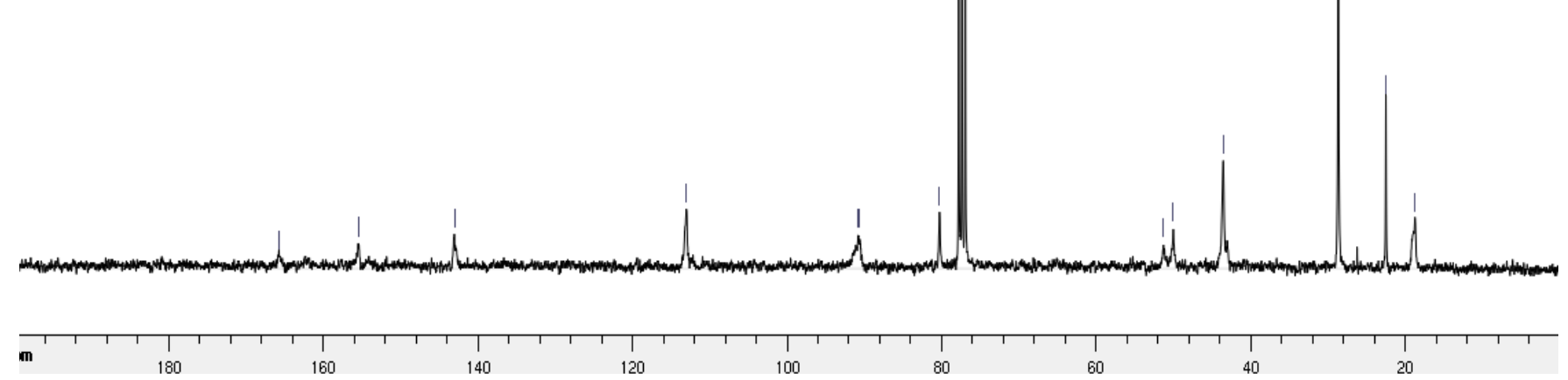


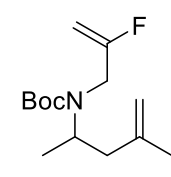

$1 k$

${ }^{19} \mathrm{FCDCl}_{3}, 282 \mathrm{MHz}$
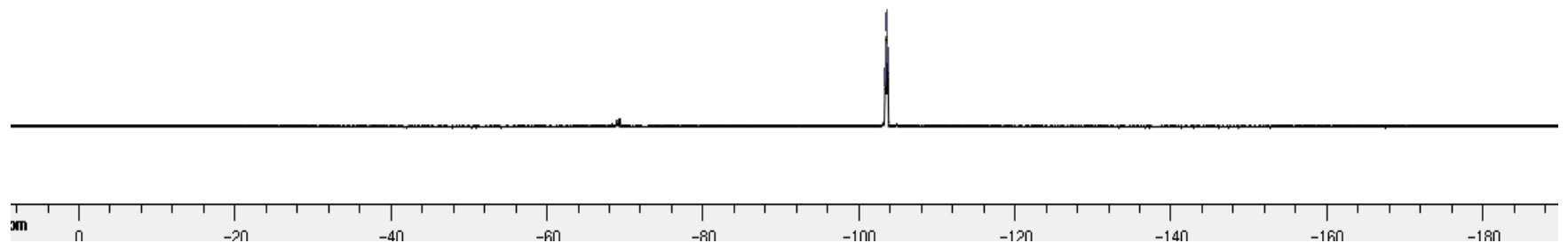

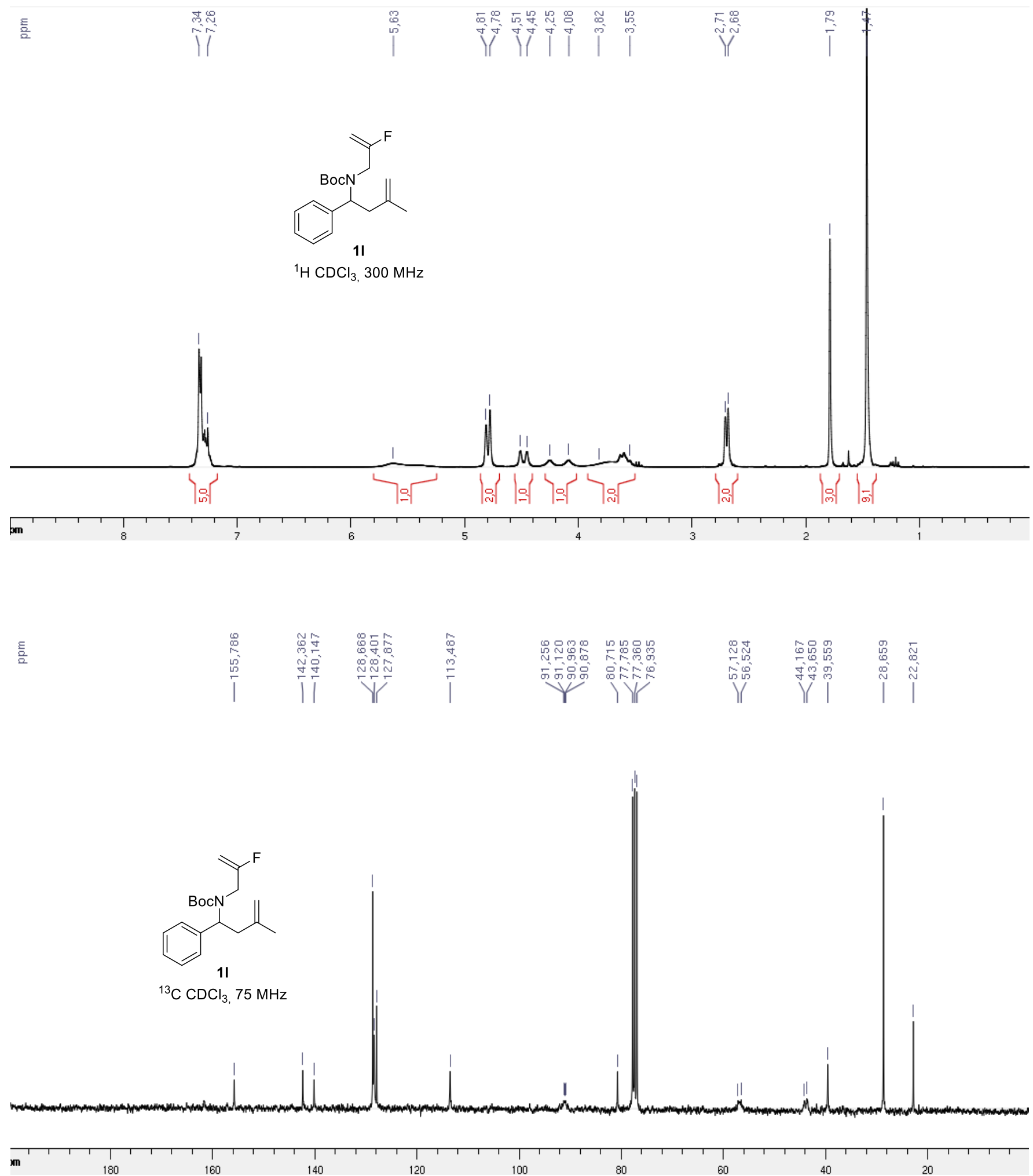


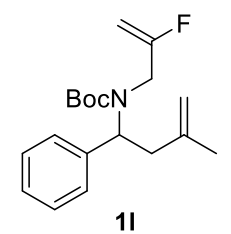

${ }^{19} \mathrm{~F} \mathrm{CDCl}_{3}, 282 \mathrm{MHz}$

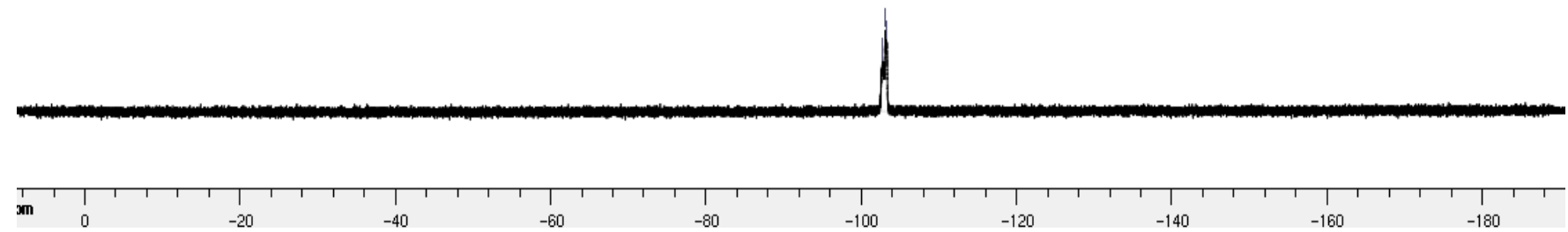



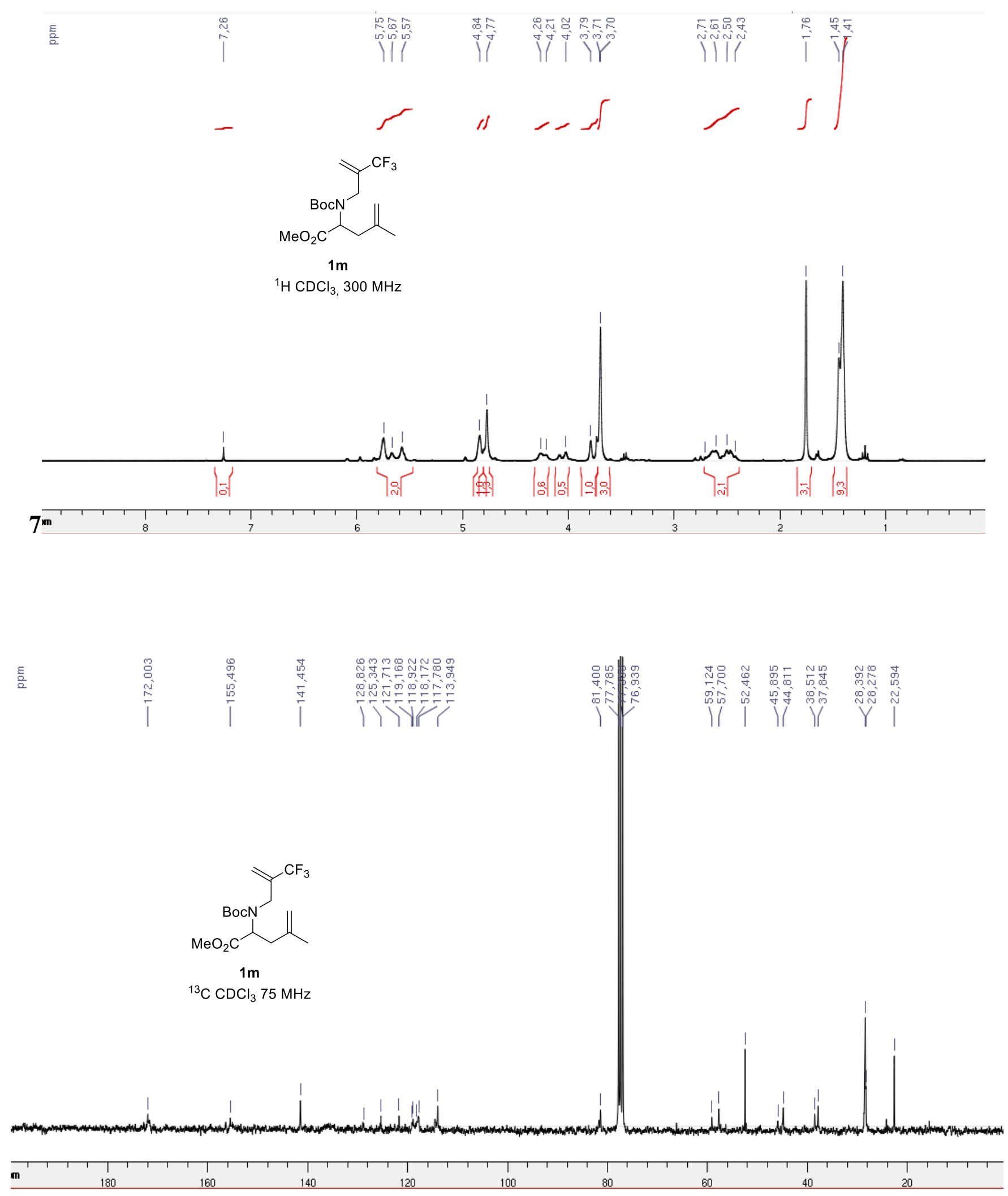


$$
{ }^{19} \mathrm{~F} \mathrm{CDCl}_{3} 282 \mathrm{MHz}
$$

m 


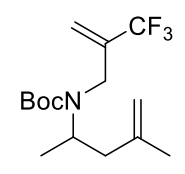

1n

${ }^{1} \mathrm{H} \mathrm{CDCl}_{3}, 300 \mathrm{MHz}$
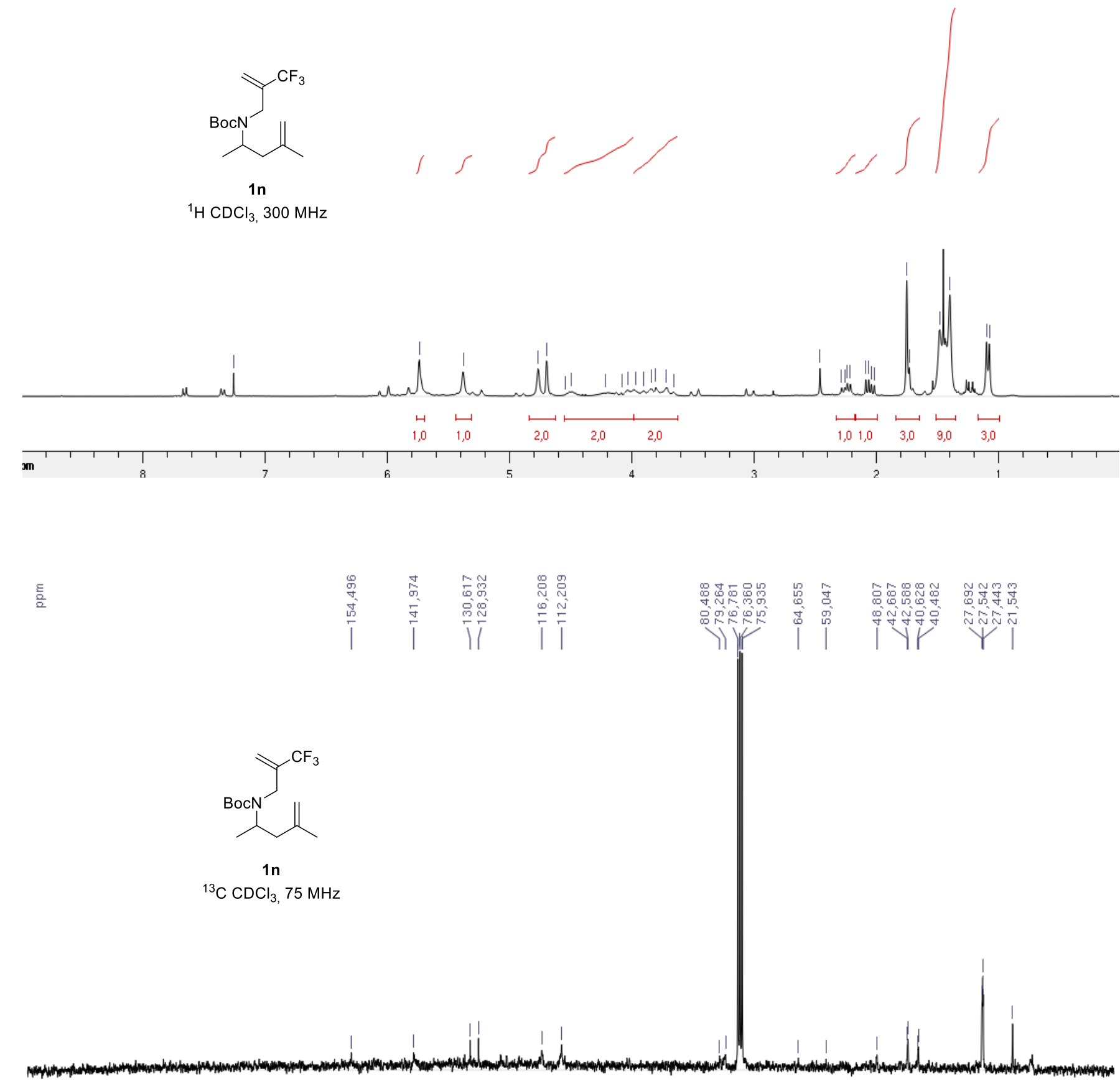

m 200 180 160 140 120 100 80 60 1
40 20 


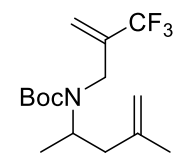

$1 \mathrm{n}$

${ }^{19} \mathrm{FCDCl}_{3}, 282 \mathrm{MHz}$

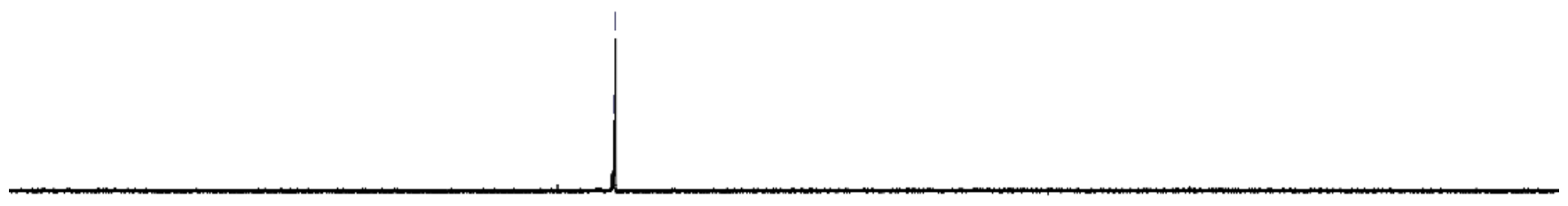

1 

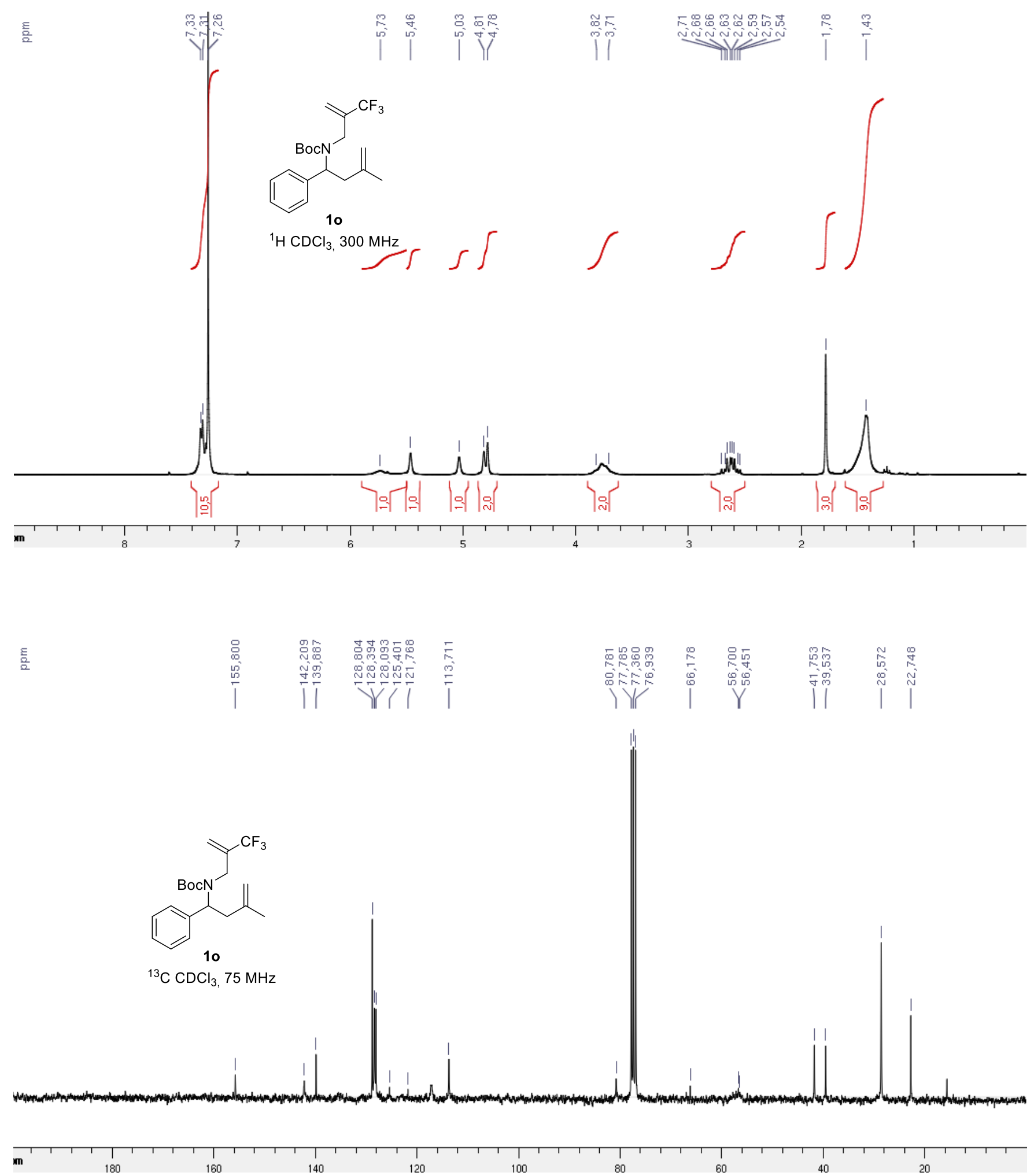
흠

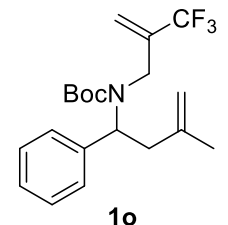

${ }^{19} \mathrm{FCDCl}_{3,}, 282 \mathrm{MHz}$

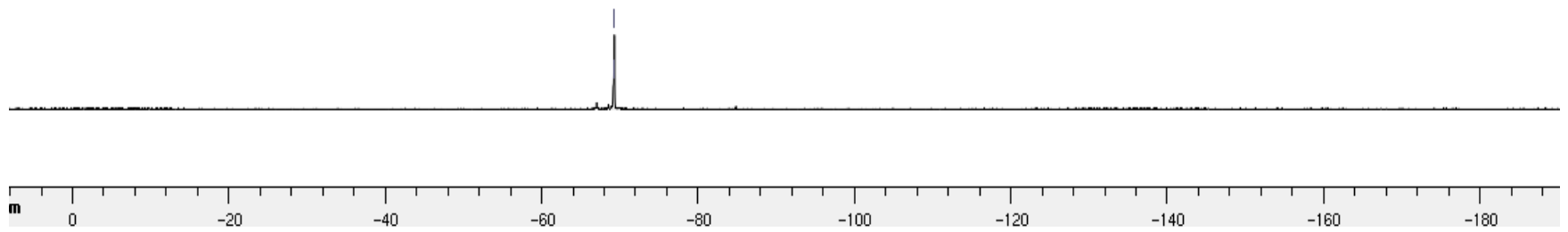




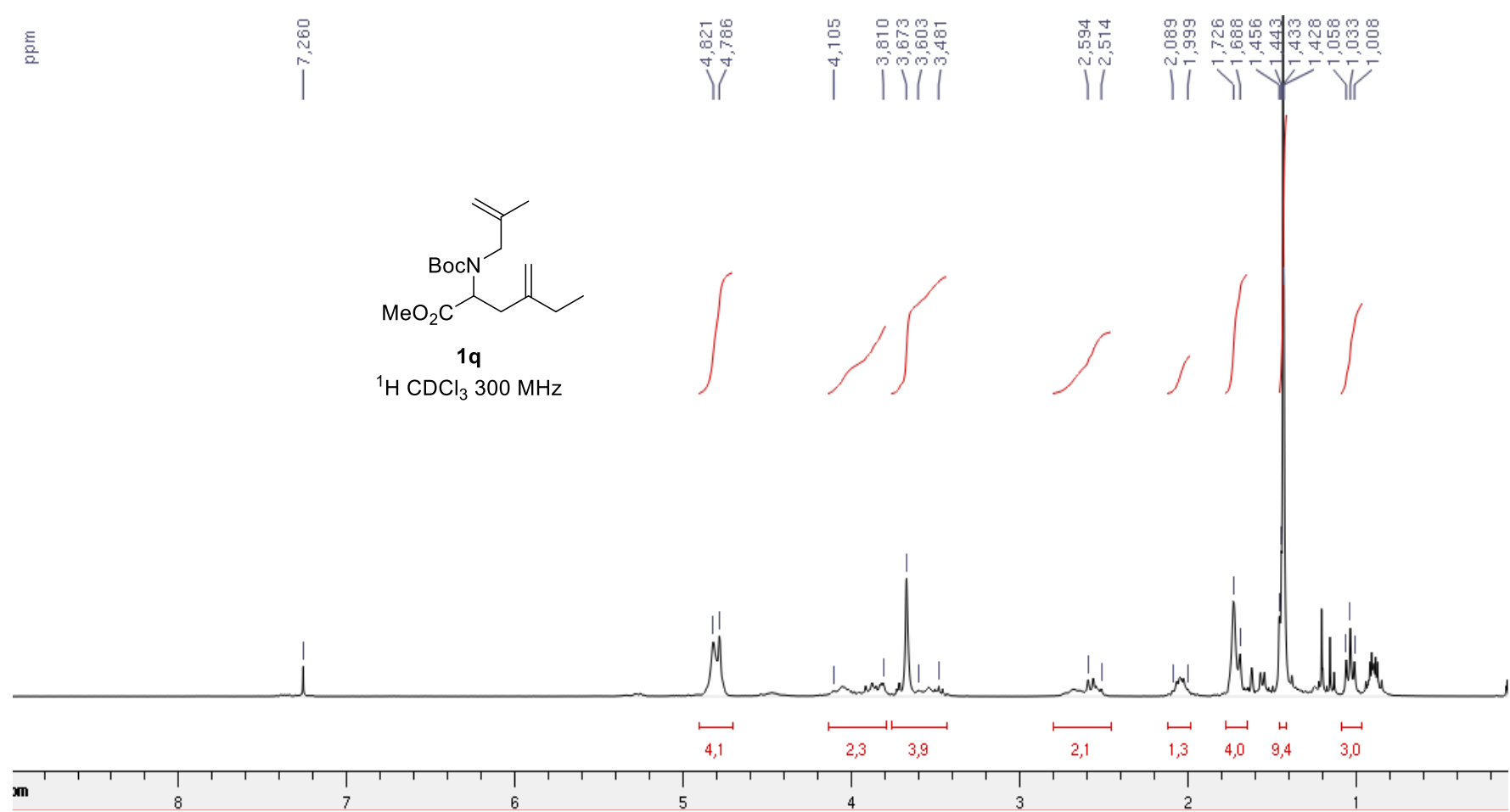

\begin{tabular}{|c|c|c|c|c|c|}
\hline 总 & 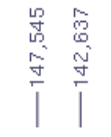 & 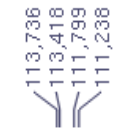 & 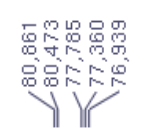 & 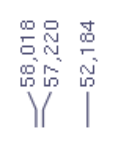 & 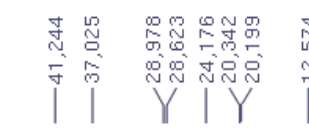 \\
\hline
\end{tabular}

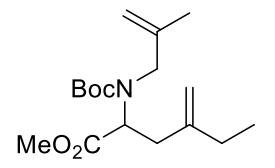

19

${ }^{13} \mathrm{C} \mathrm{CDCl}_{3} 75 \mathrm{MHz}$

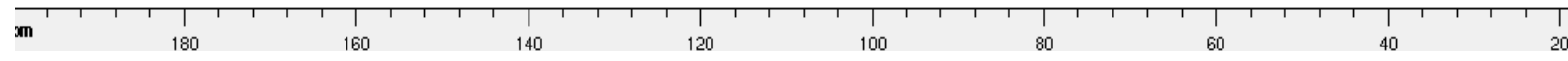



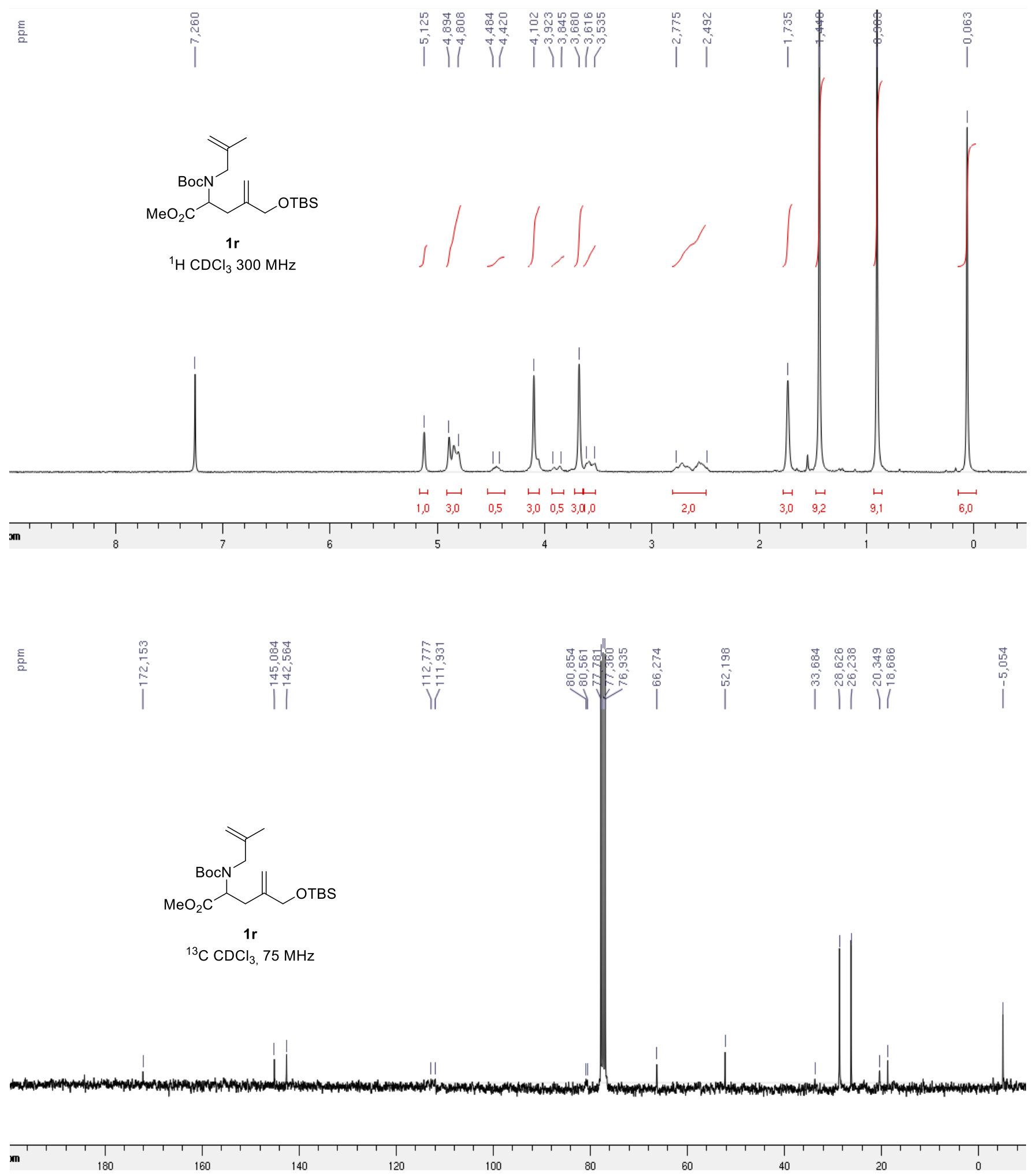


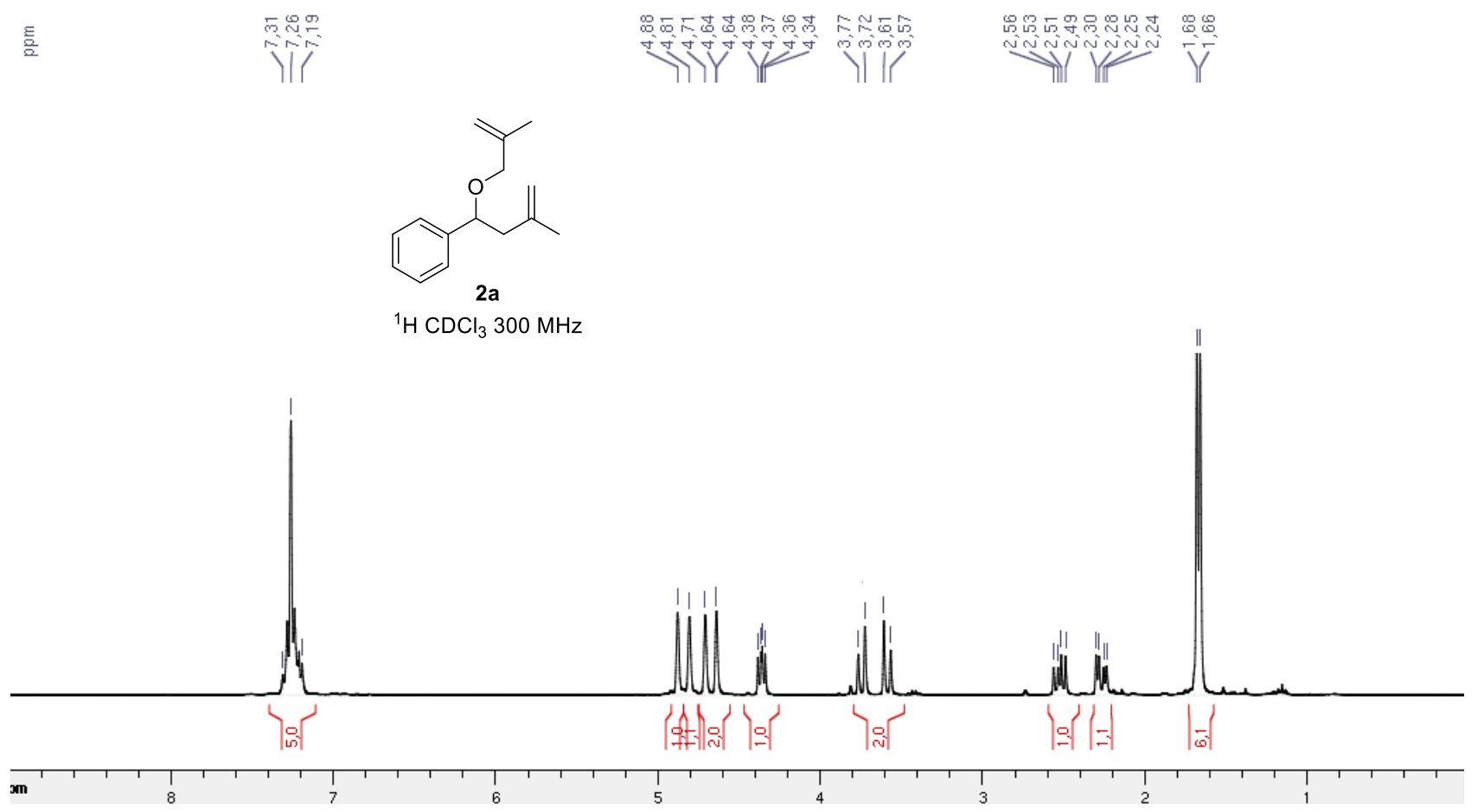

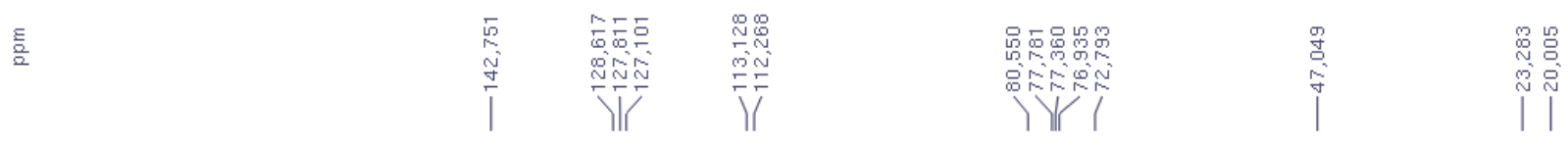
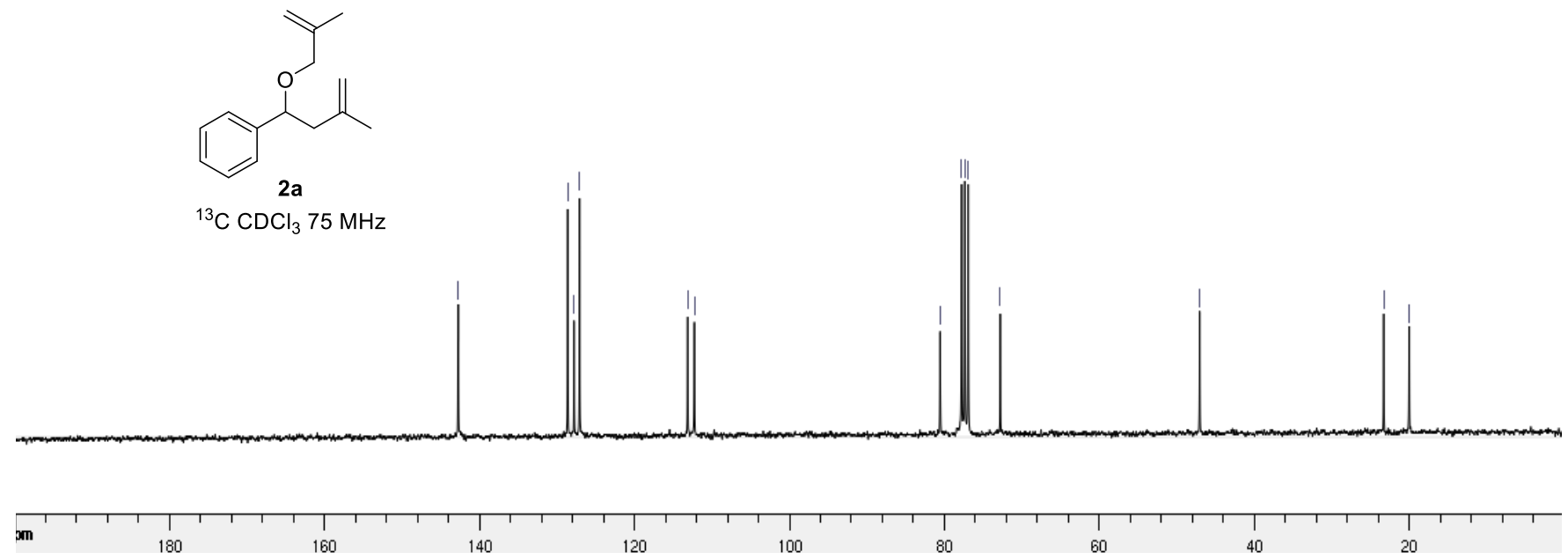

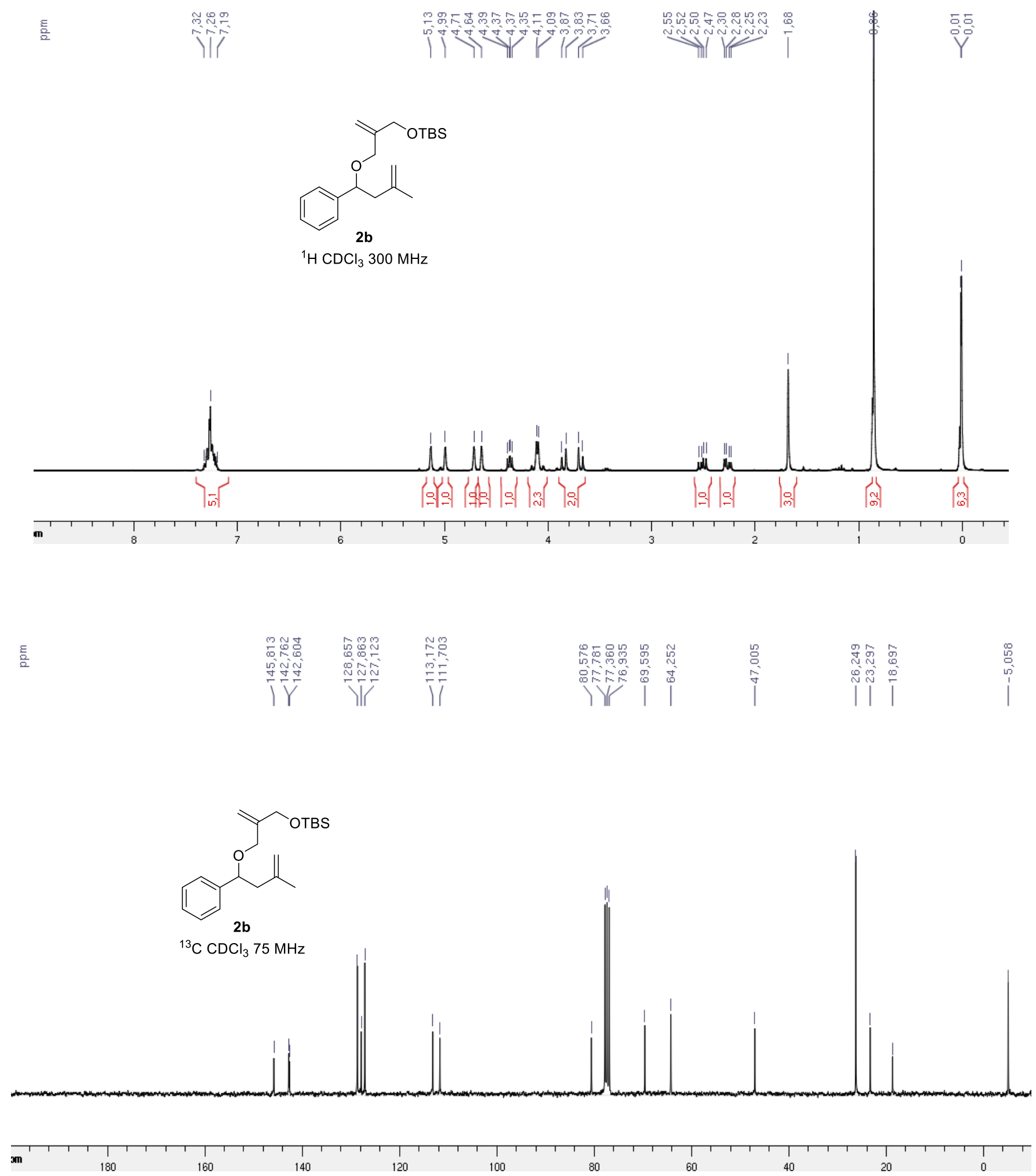

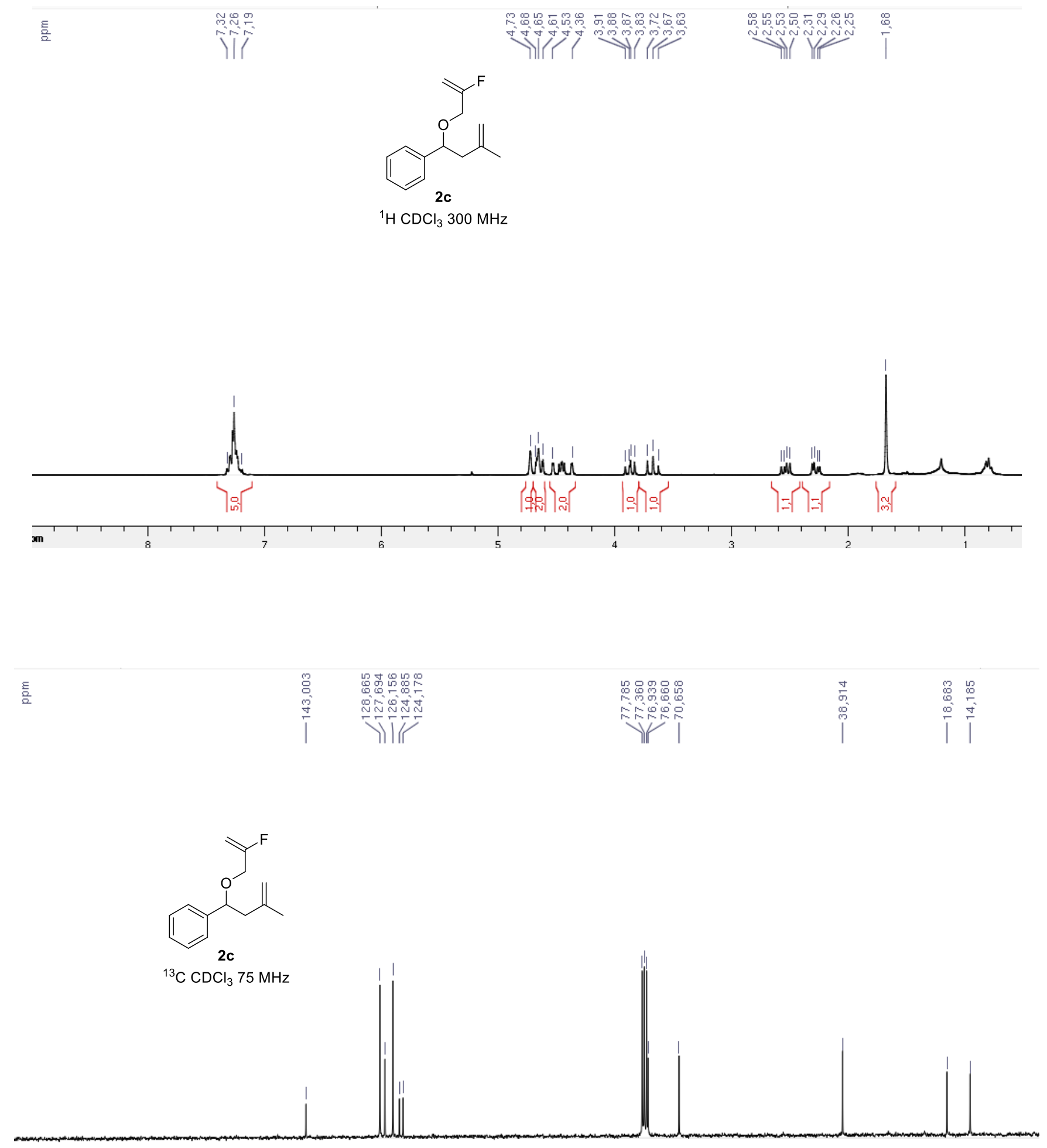

$$
\text { m }
$$



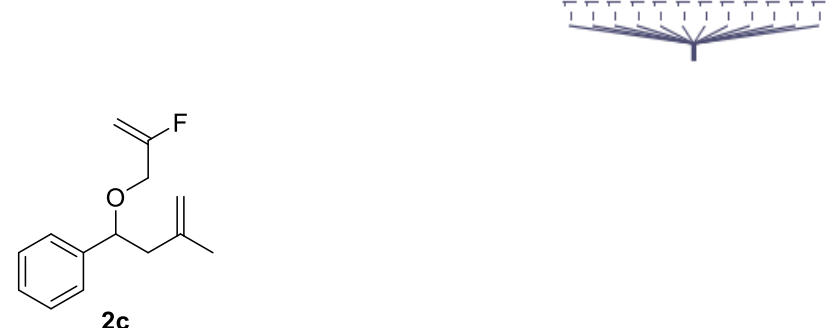

${ }^{19} \mathrm{FCDCl}_{3} 282 \mathrm{MHz}$

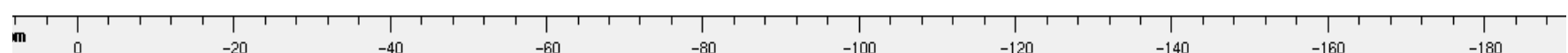



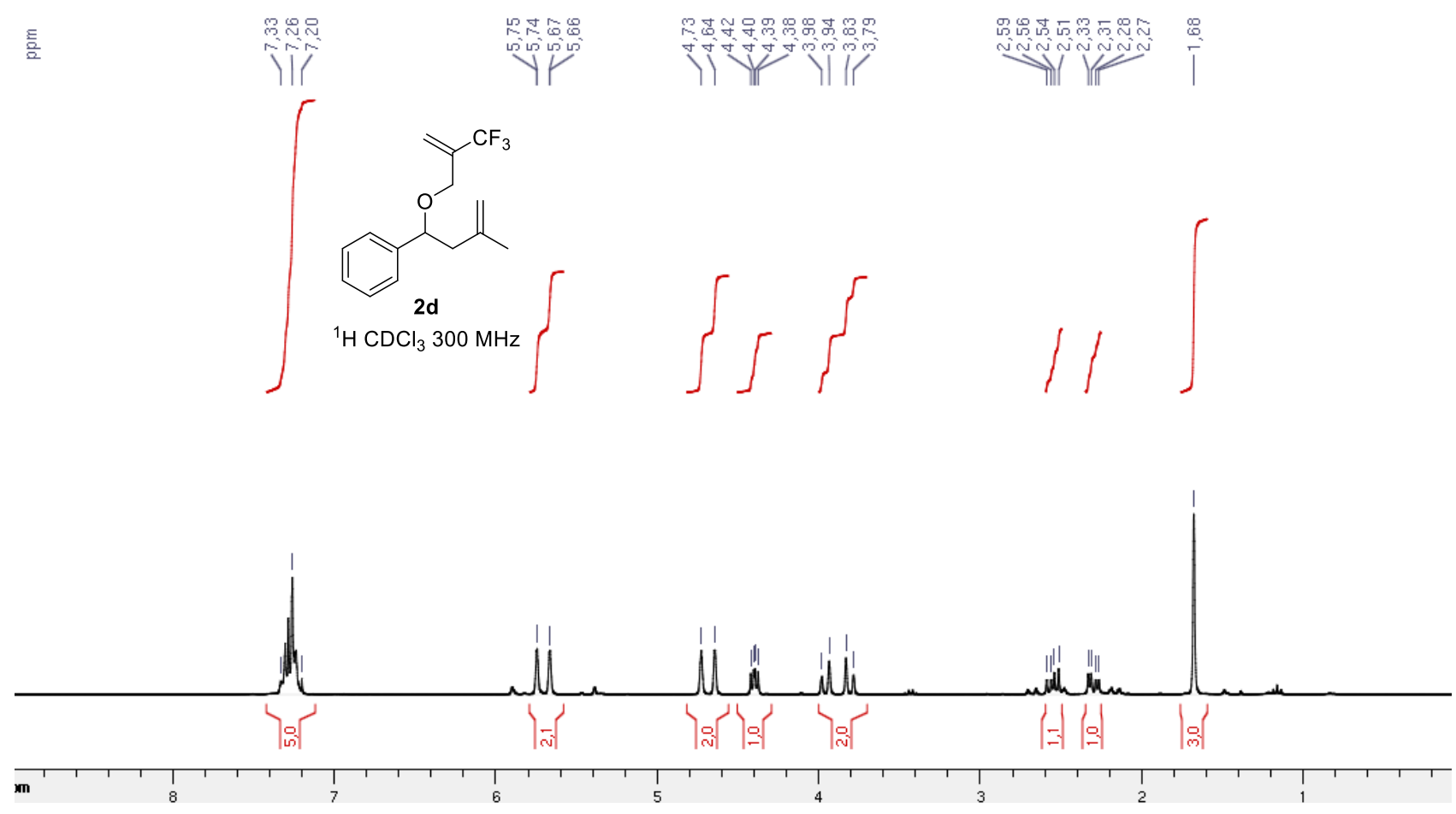

흘

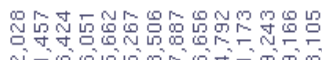

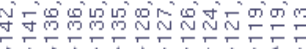

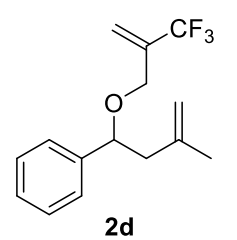

${ }^{13} \mathrm{C} \mathrm{CDCl}_{3} 75 \mathrm{MHz}$

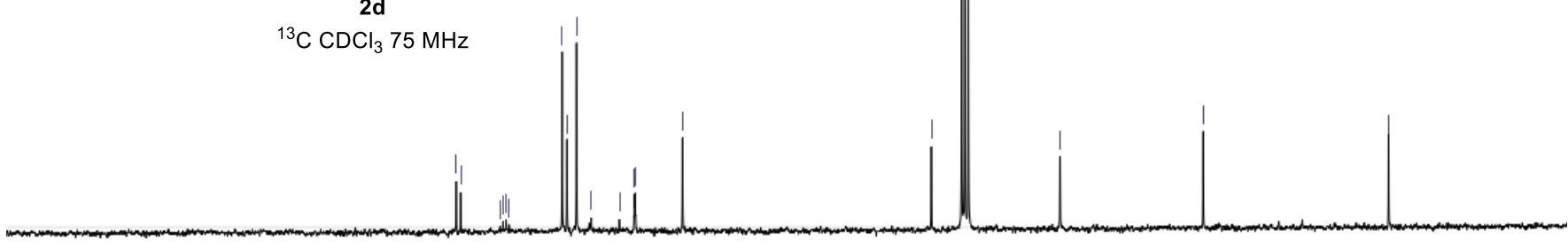

m

160

120

80

60

40

20 


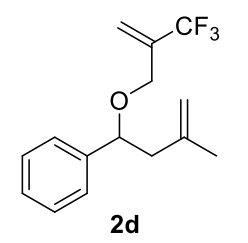

${ }^{19} \mathrm{~F} \mathrm{CDCl}_{3} 282 \mathrm{MHz}$

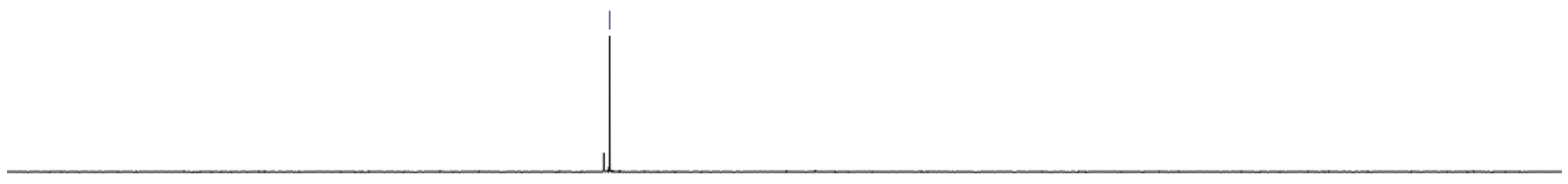




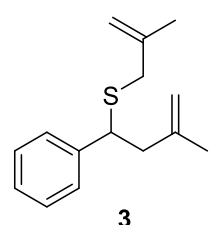

${ }^{1} \mathrm{H} \mathrm{CDCl}_{3} 300 \mathrm{MHz}$

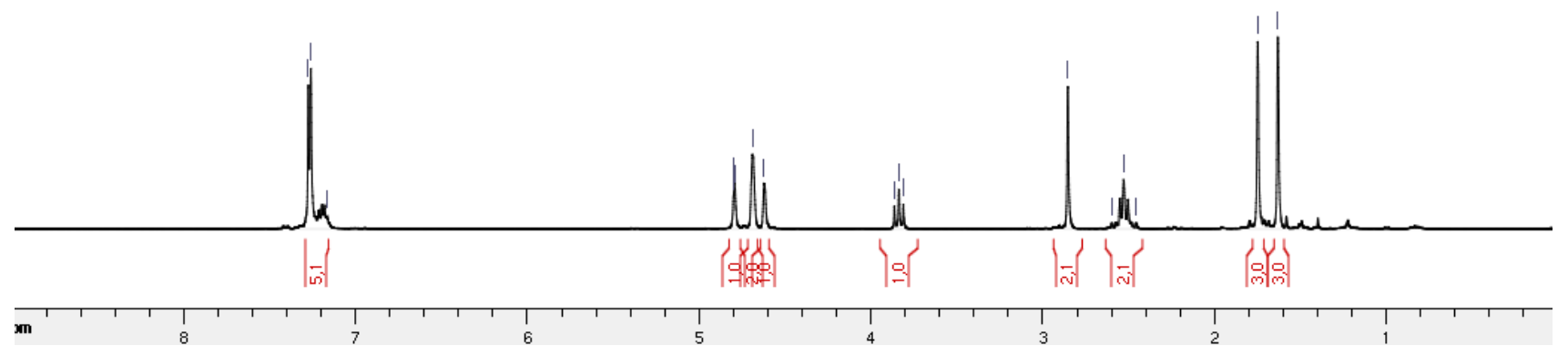

言
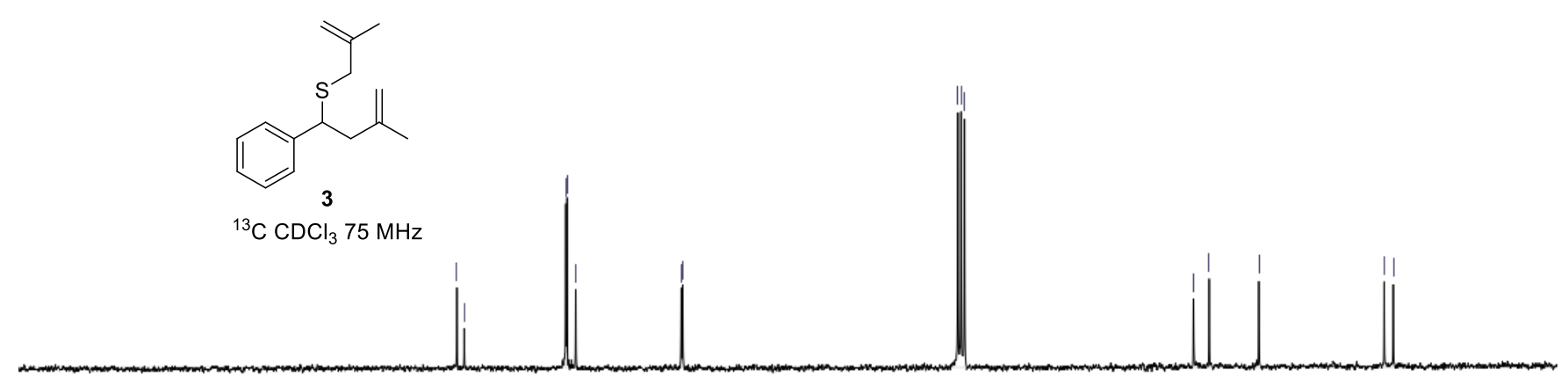

m

180

$\underbrace{1}_{160}$

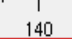

120

100

80

60

40 

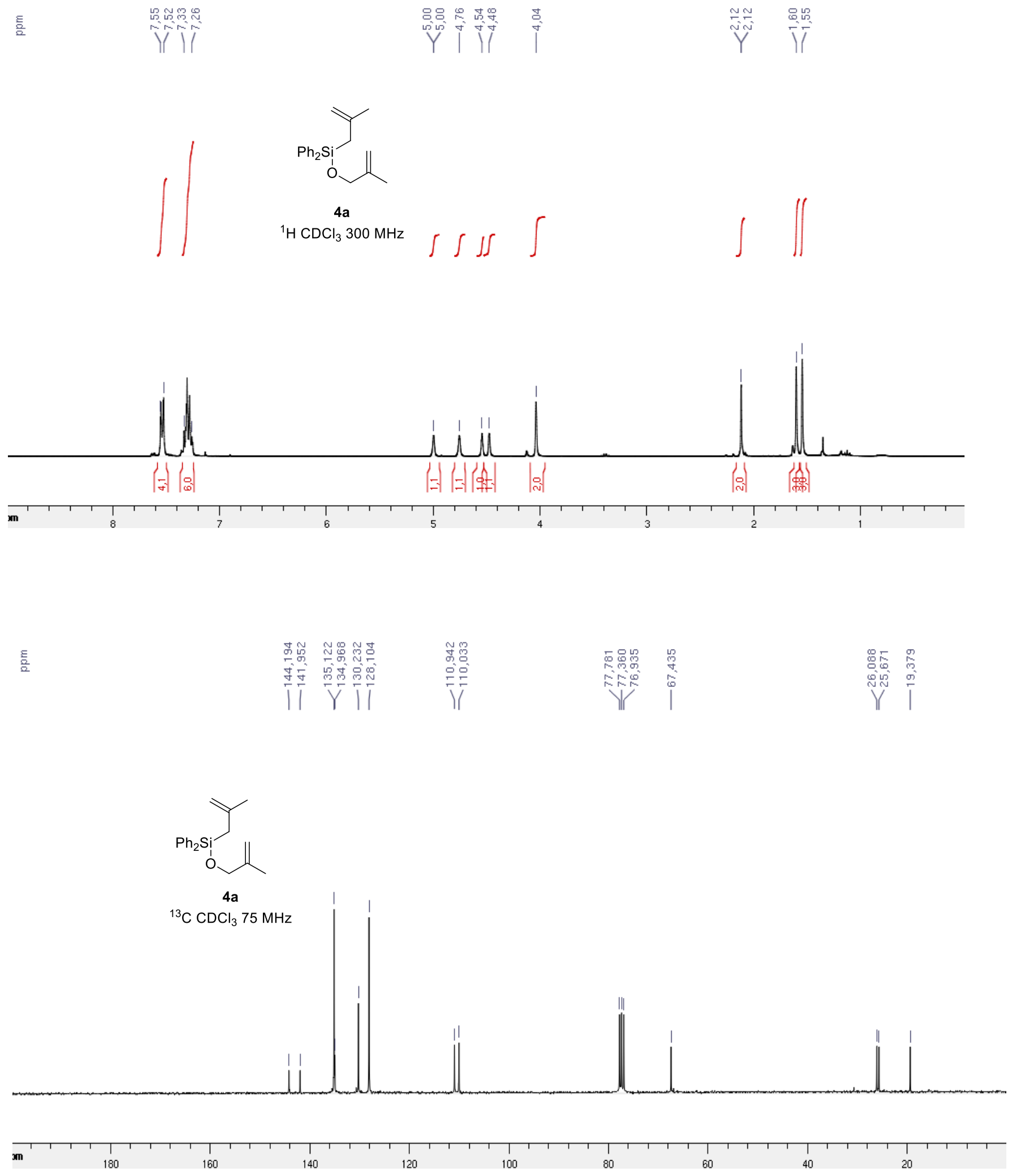

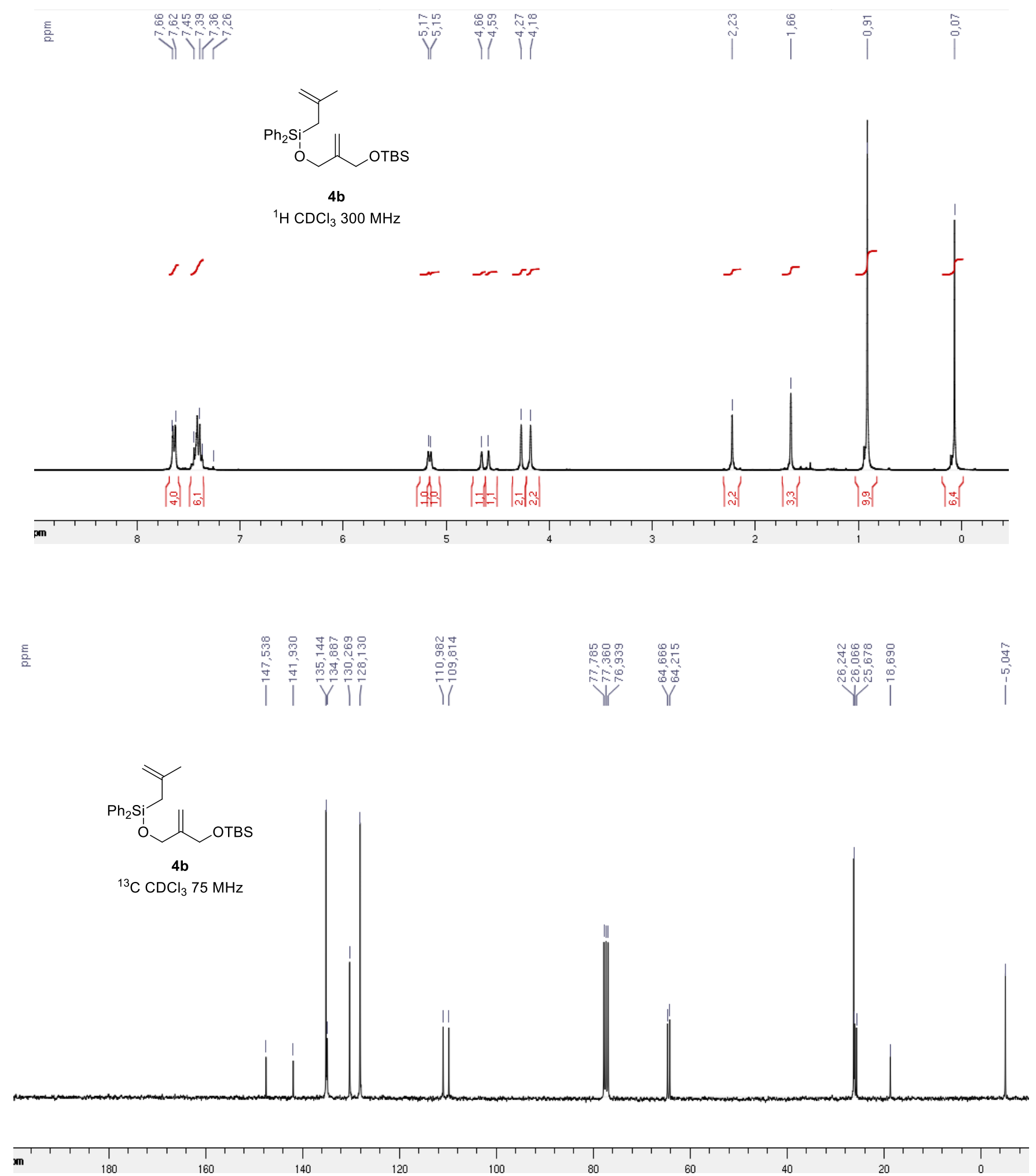

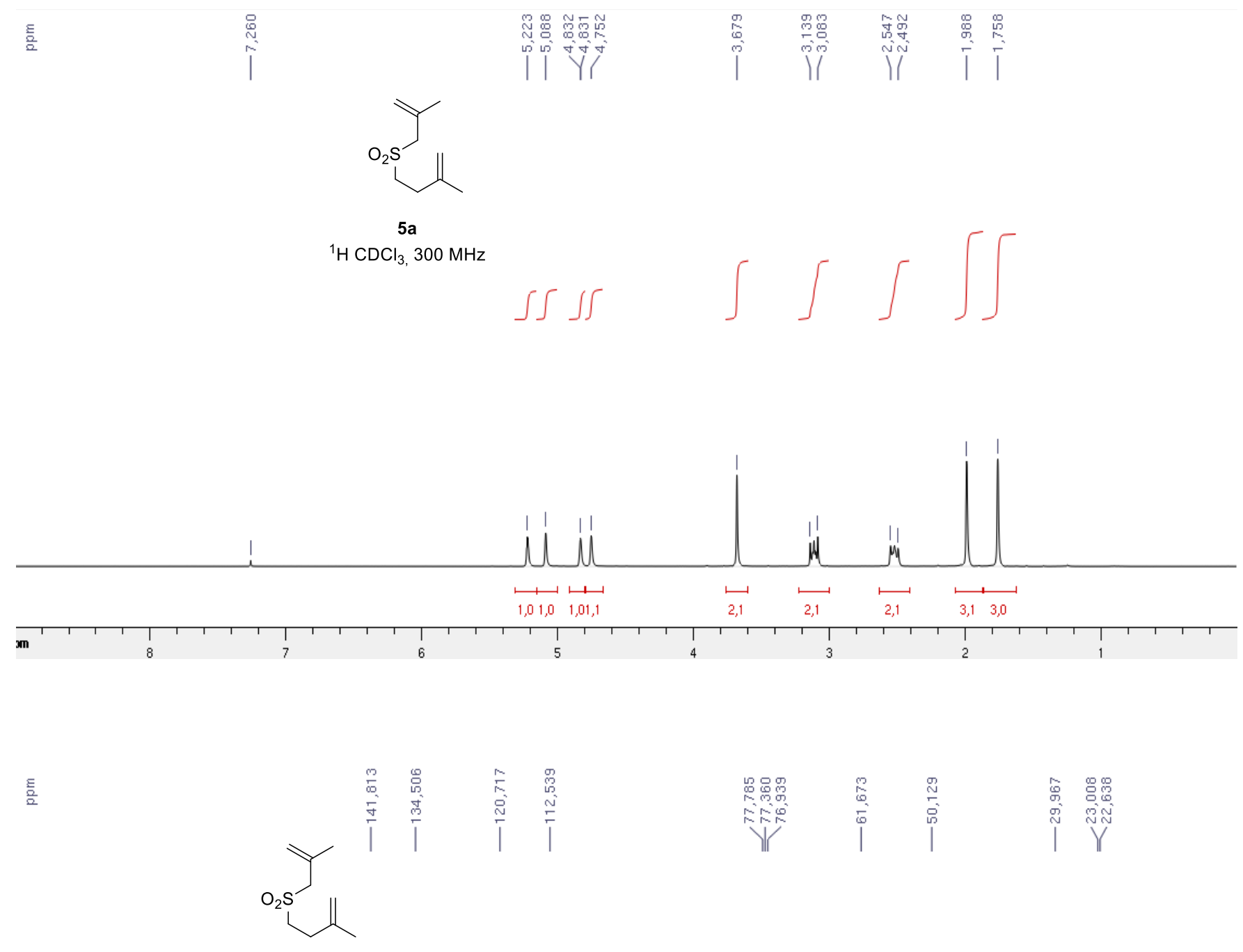

${ }^{13} \mathrm{C} \mathrm{CDCl}_{3}, 75 \mathrm{MHz}$
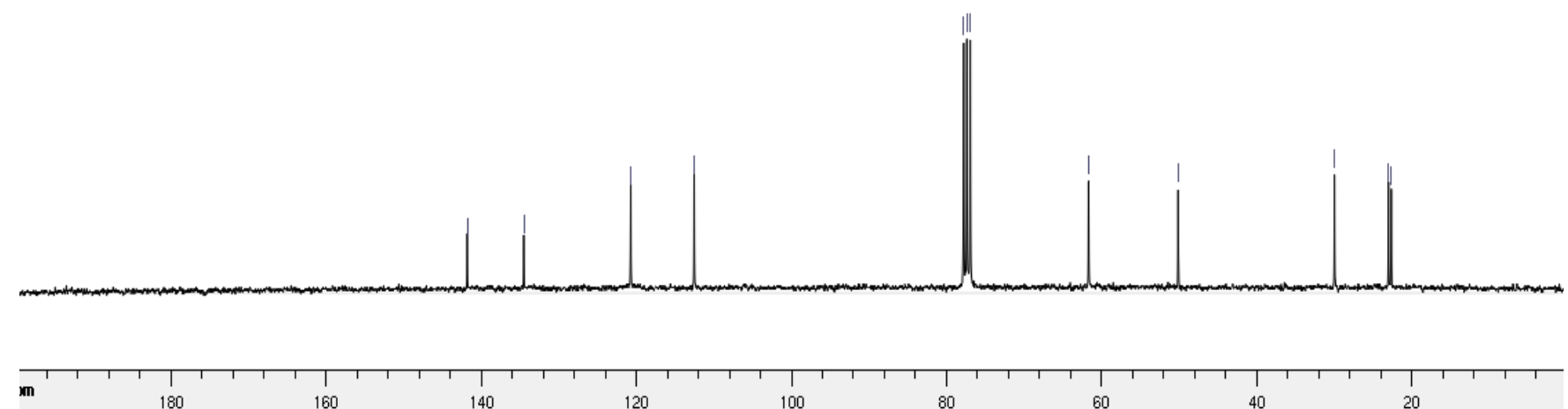


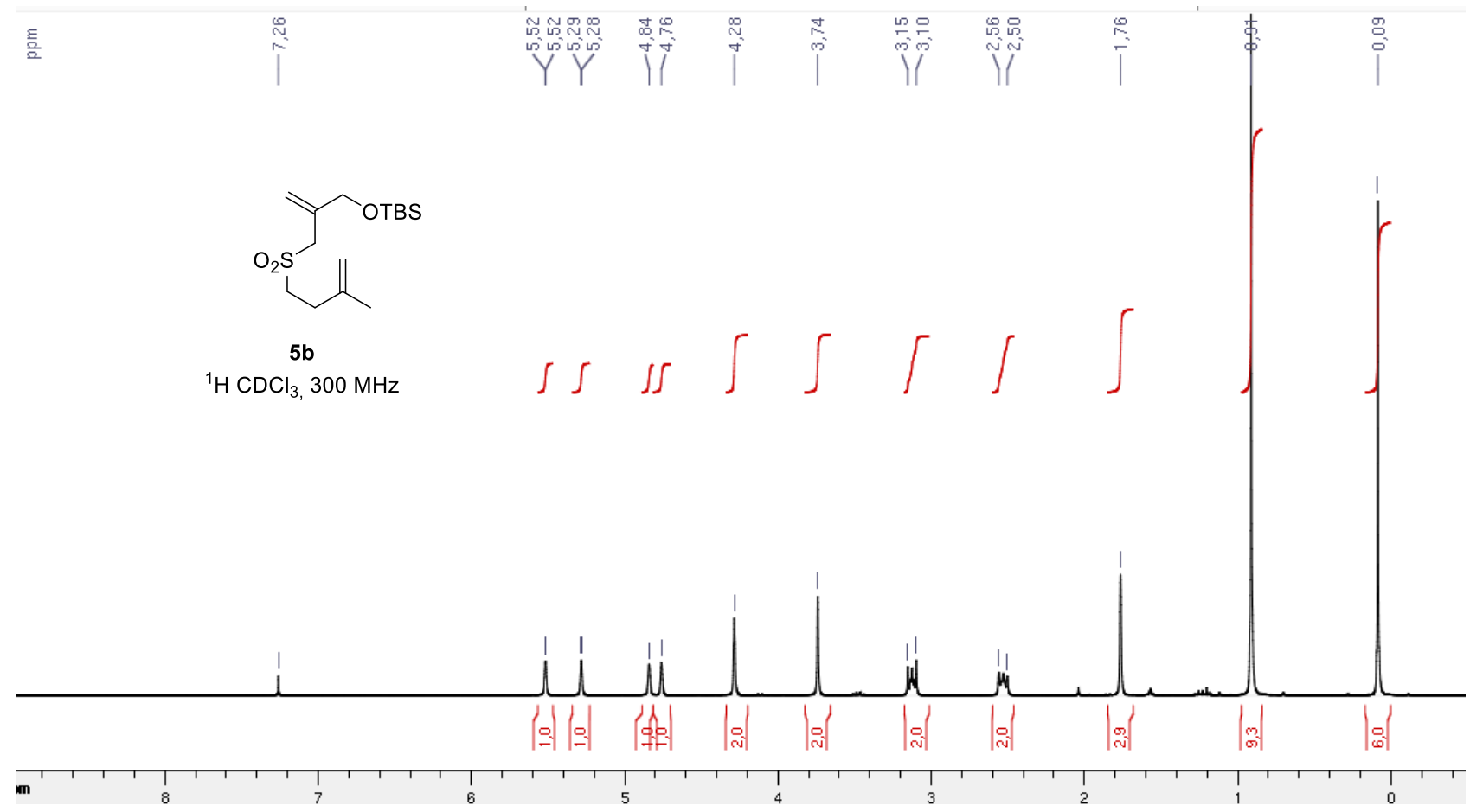

言
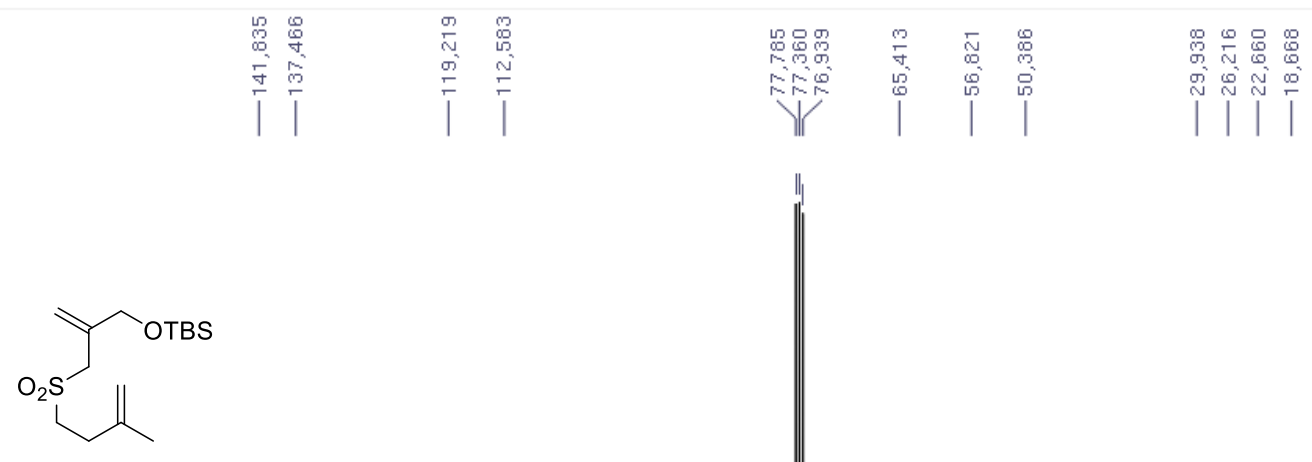

5b

${ }^{13} \mathrm{C} \mathrm{CDCl}_{3}, 75 \mathrm{MHz}$ 


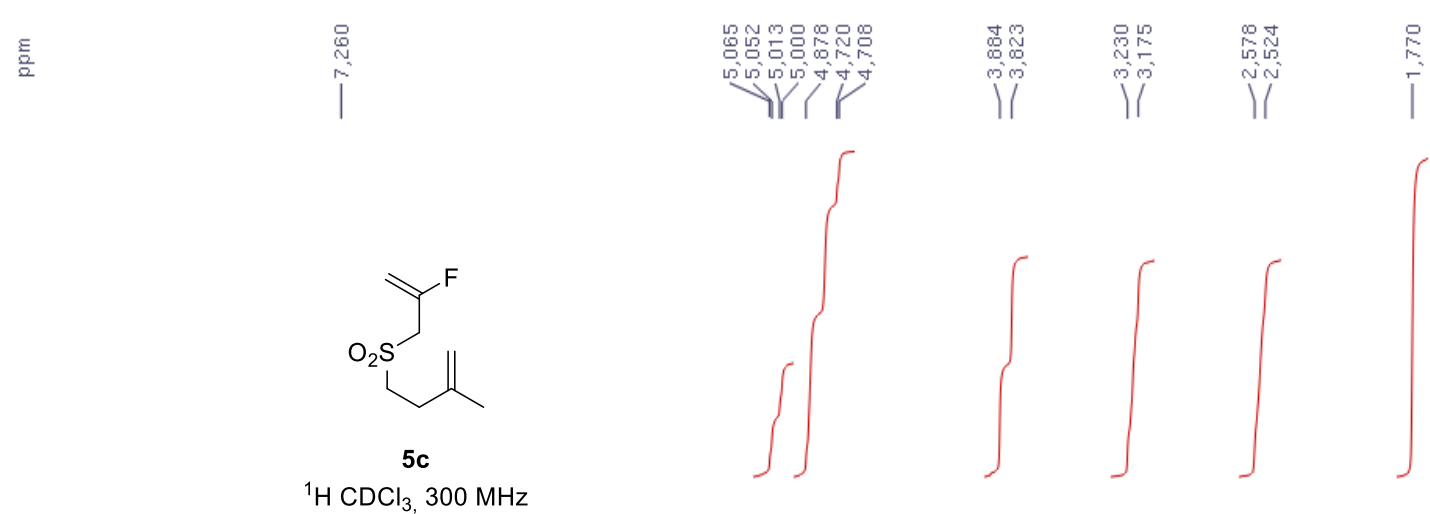

${ }^{1} \mathrm{H} \mathrm{CDCl}_{3}, 300 \mathrm{MHz}$
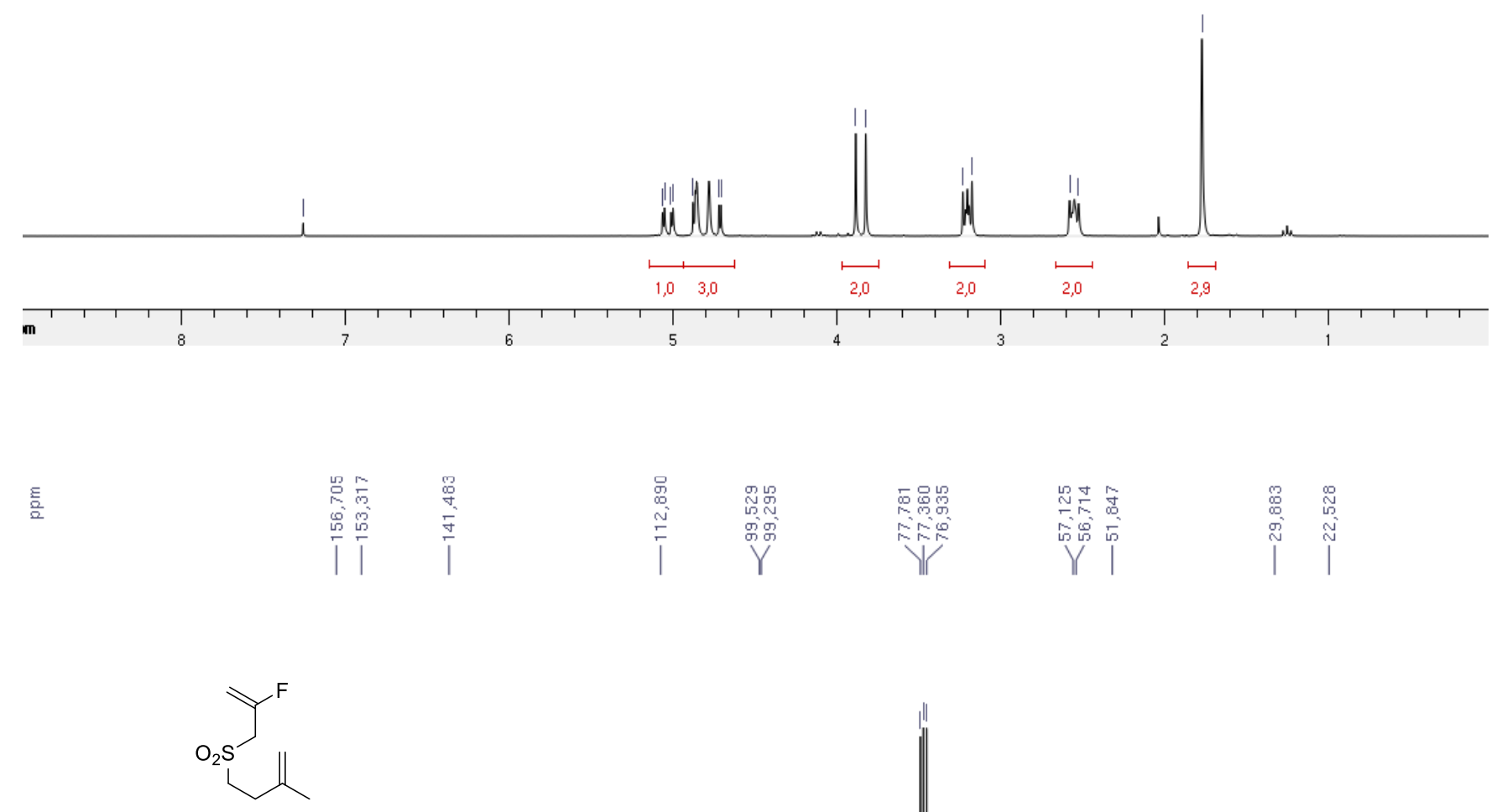

5c

${ }^{13} \mathrm{C} \mathrm{CDCl}_{3}, 75 \mathrm{MHz}$

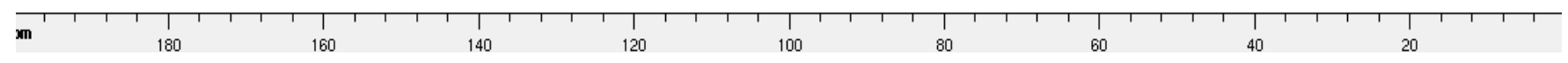




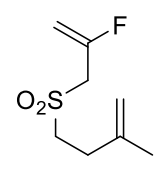

$5 c$

${ }^{19} \mathrm{~F} \mathrm{CDCl}_{3}, 282 \mathrm{MHz}$

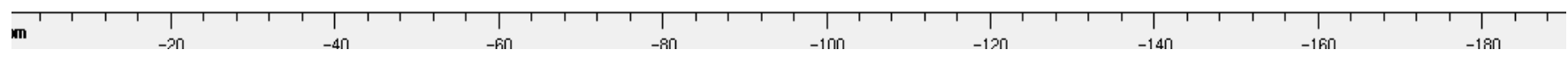



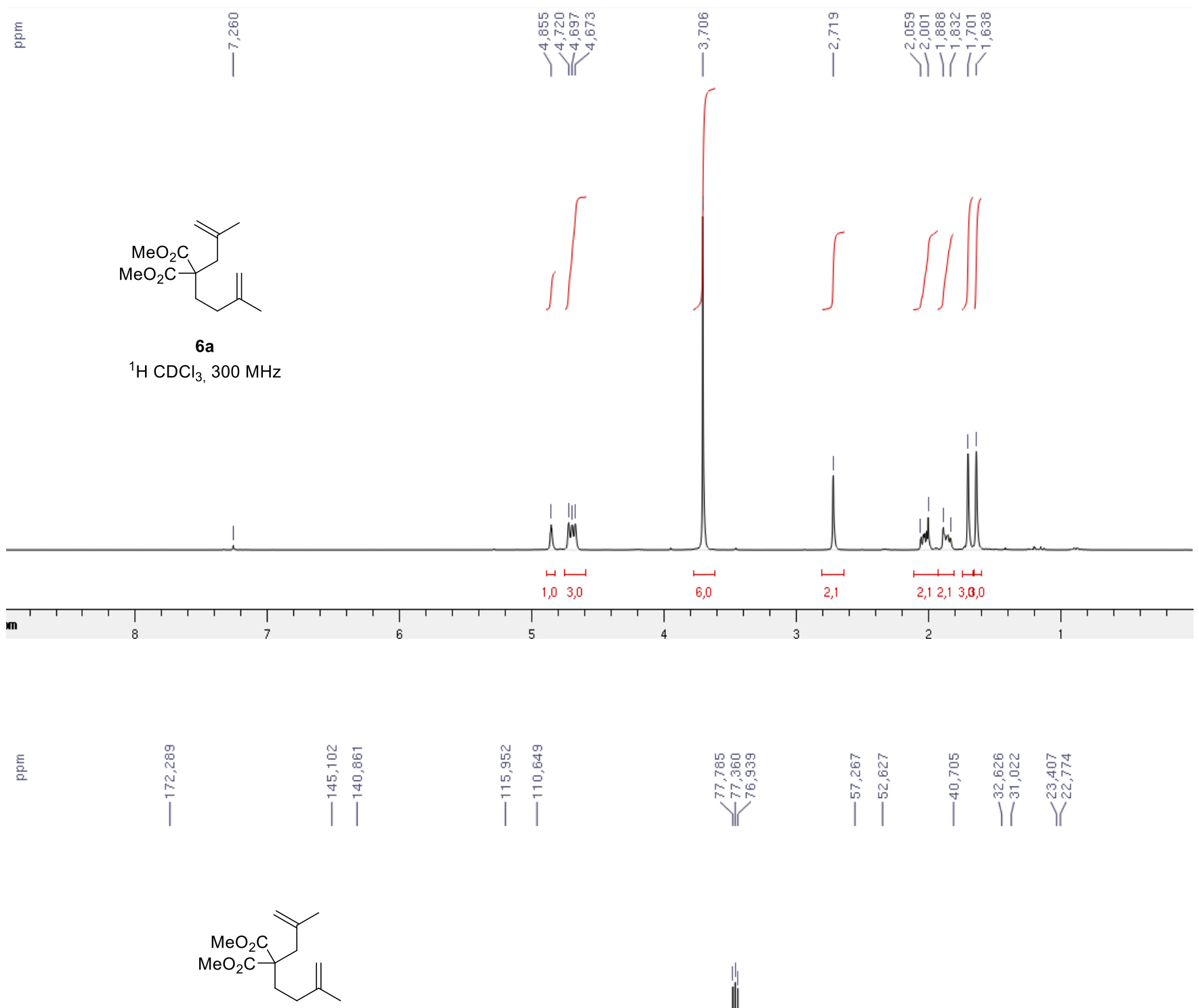

${ }^{13} \mathrm{C} \mathrm{CDCl}_{3}, 75 \mathrm{MHz}$

m

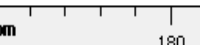

180
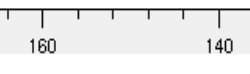

120
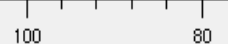

60

40 20 

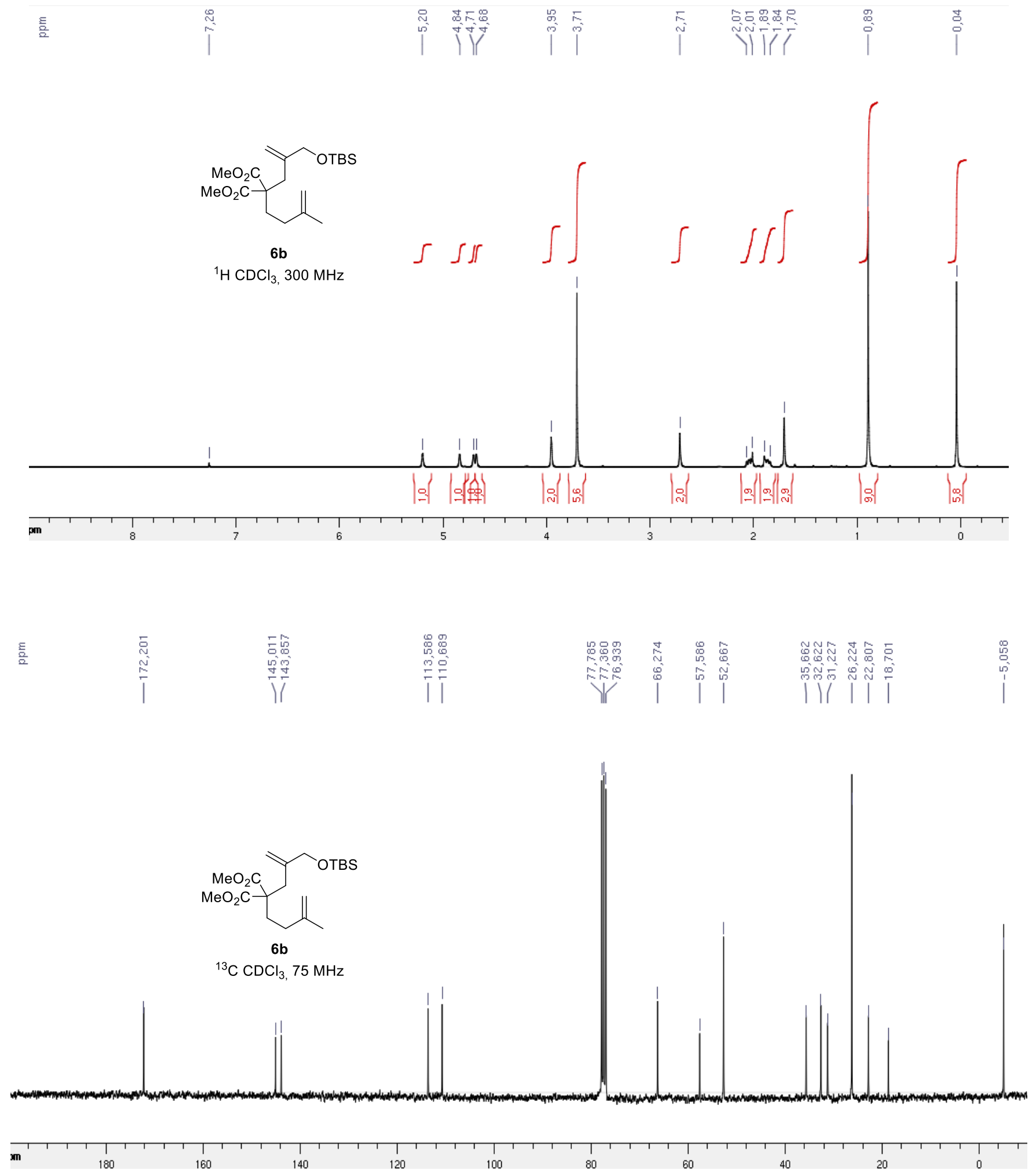


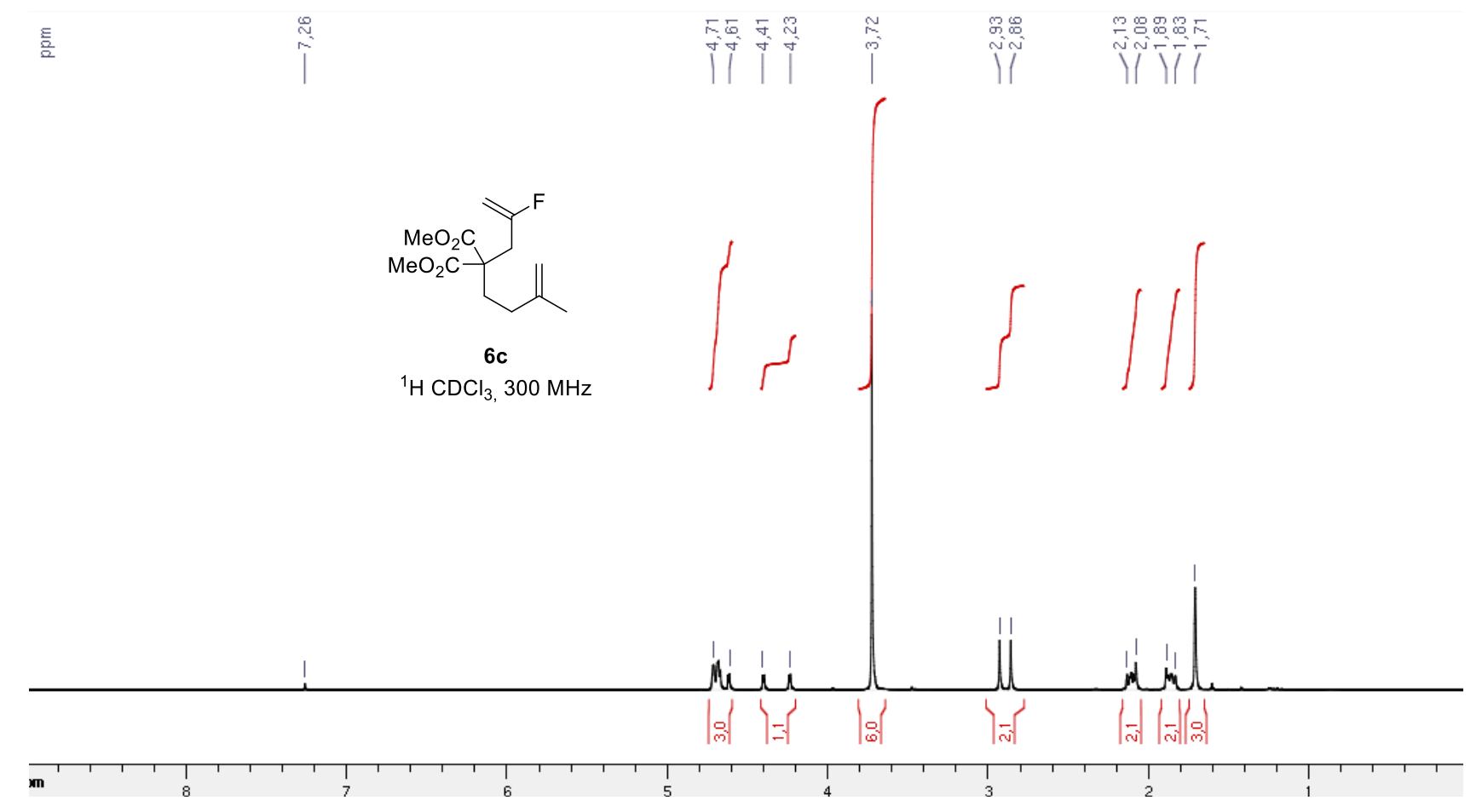

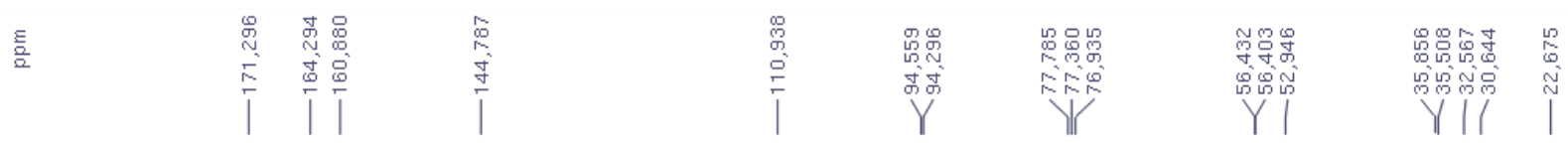

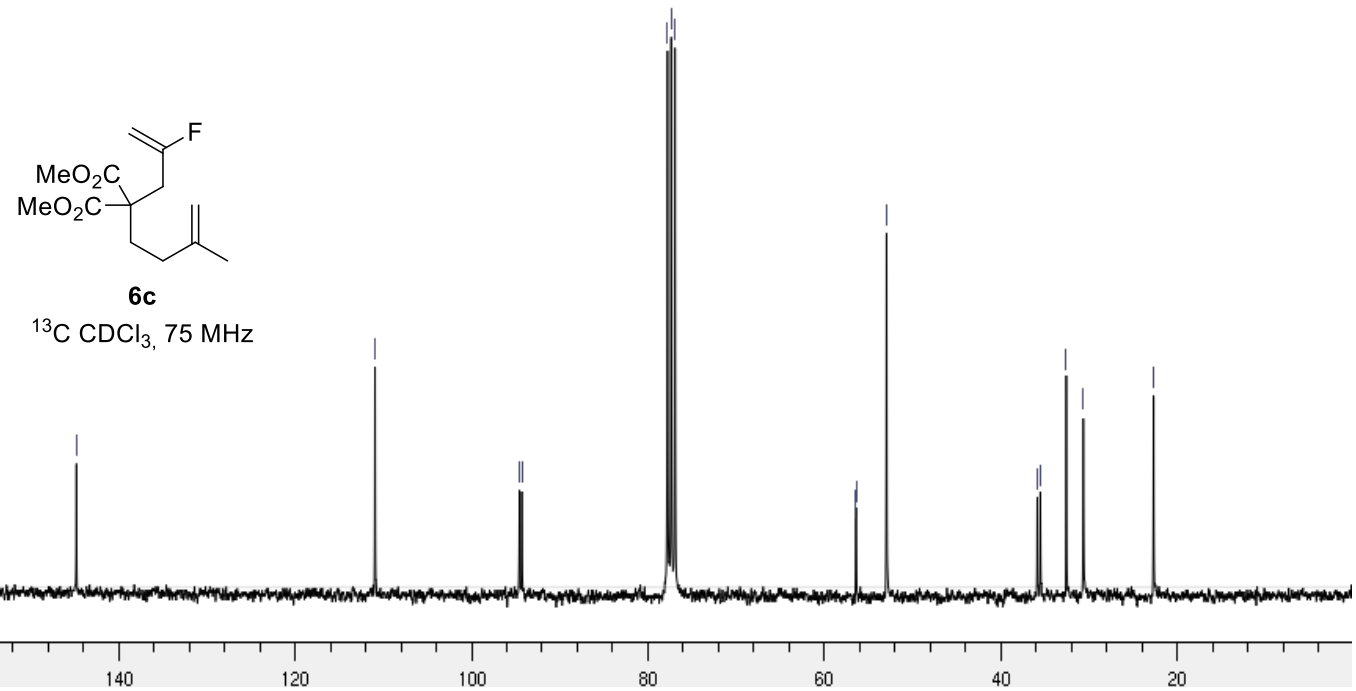




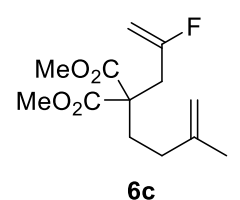

${ }^{19} \mathrm{FCDCl}_{3}, 282 \mathrm{MHz}$

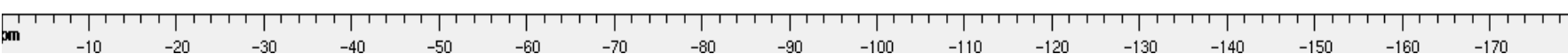



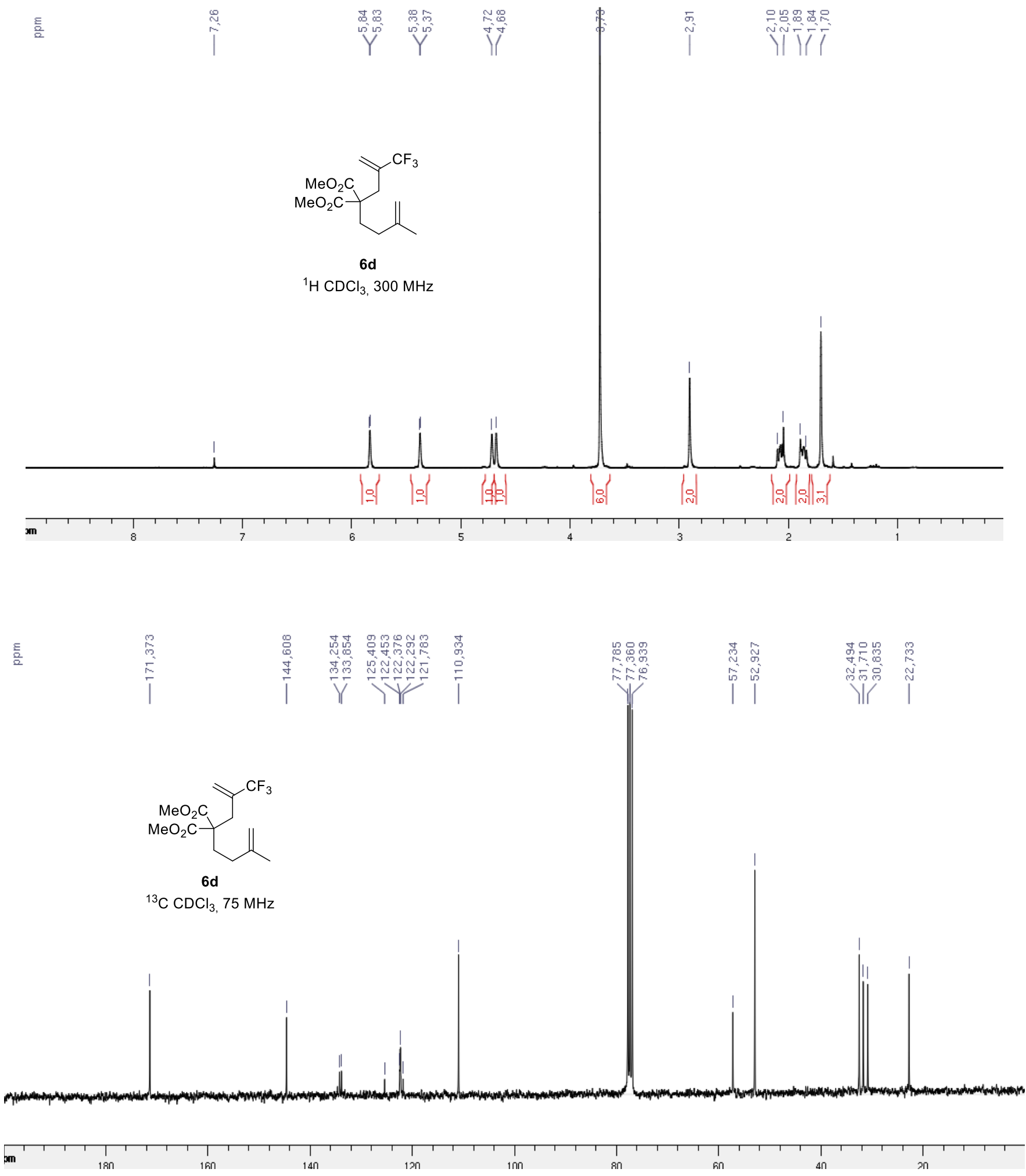


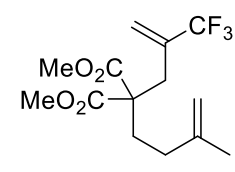

6d

${ }^{19} \mathrm{~F} \mathrm{CDCl}_{3}, 282 \mathrm{MHz}$

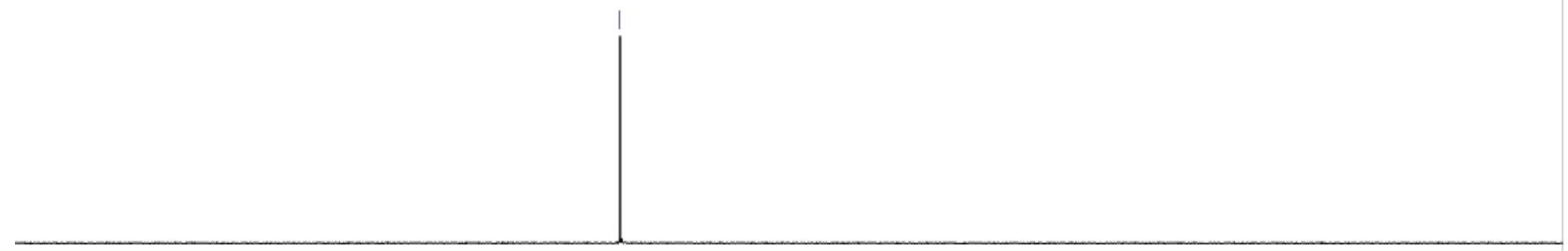




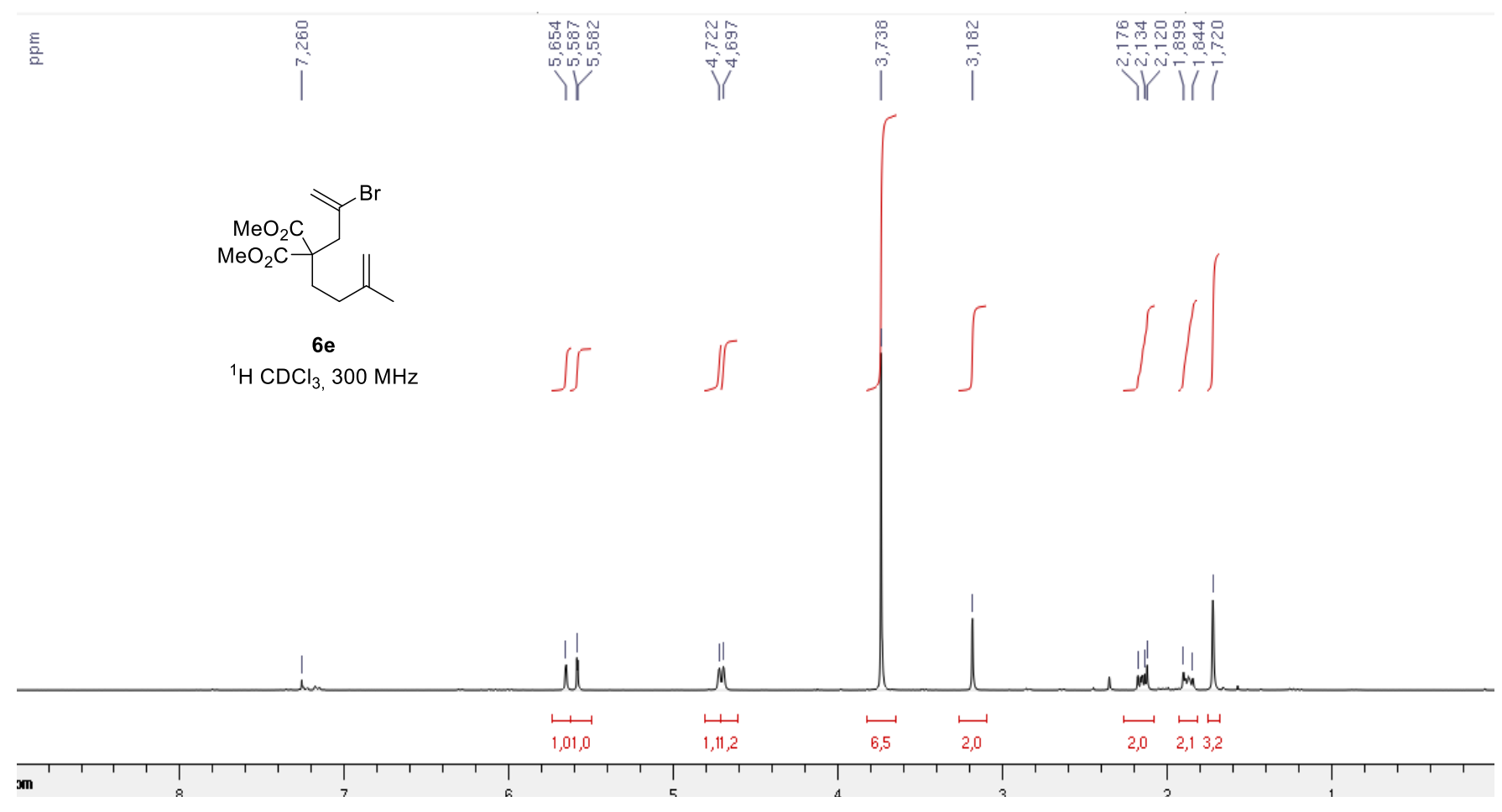

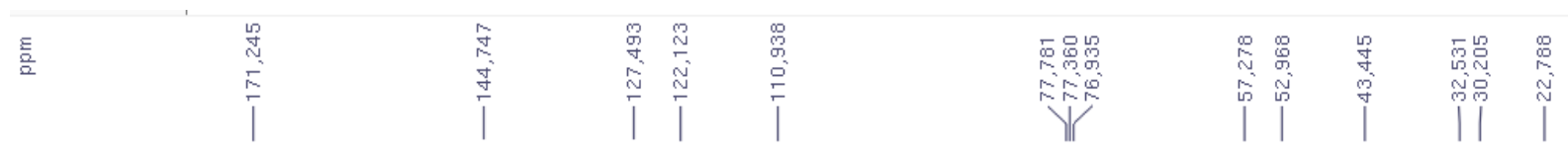

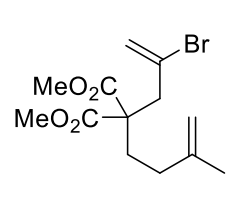

${ }^{13} \mathrm{C} \mathrm{CDCl}_{3}, 75 \mathrm{MHz}$

m

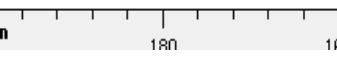

160

140

120

100

10

60

$\left.\right|_{40}$

$1_{20}^{1}$ 
言
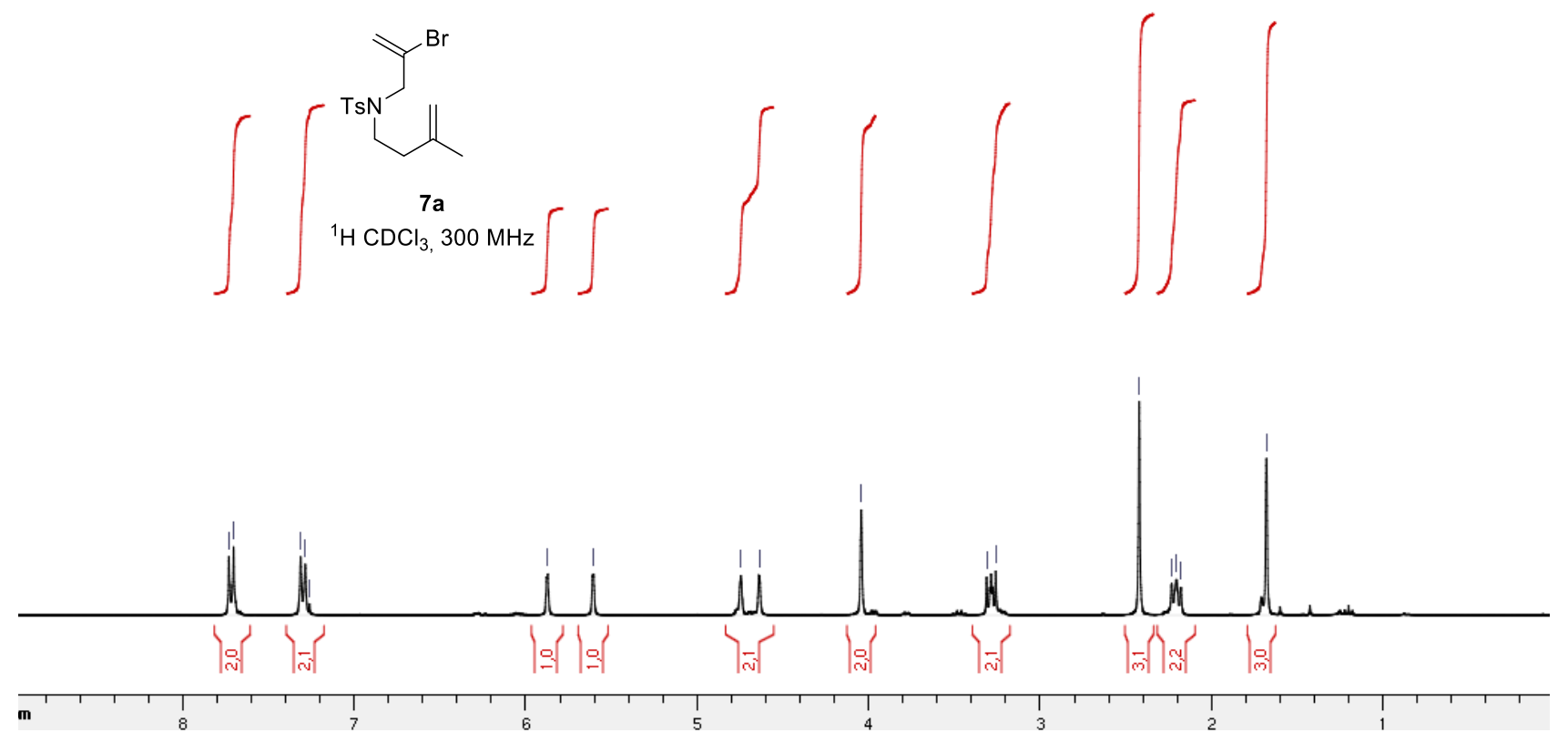

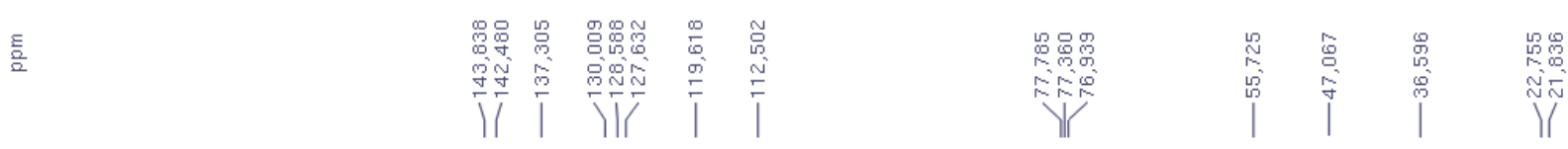
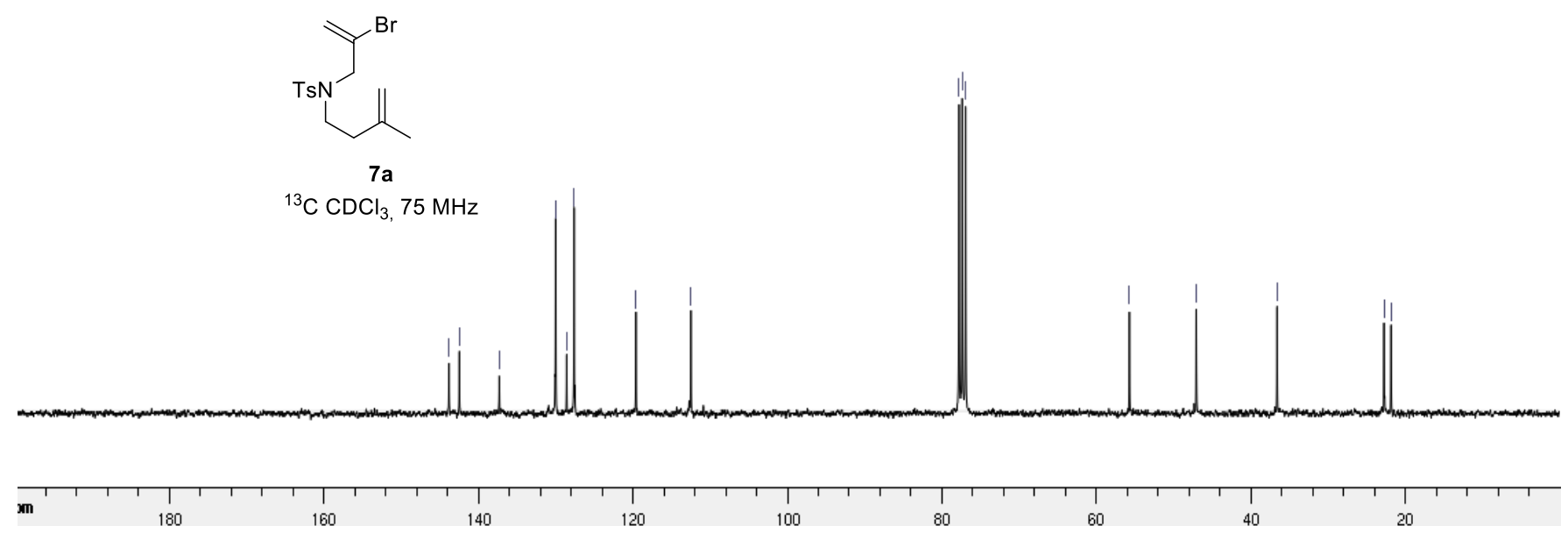


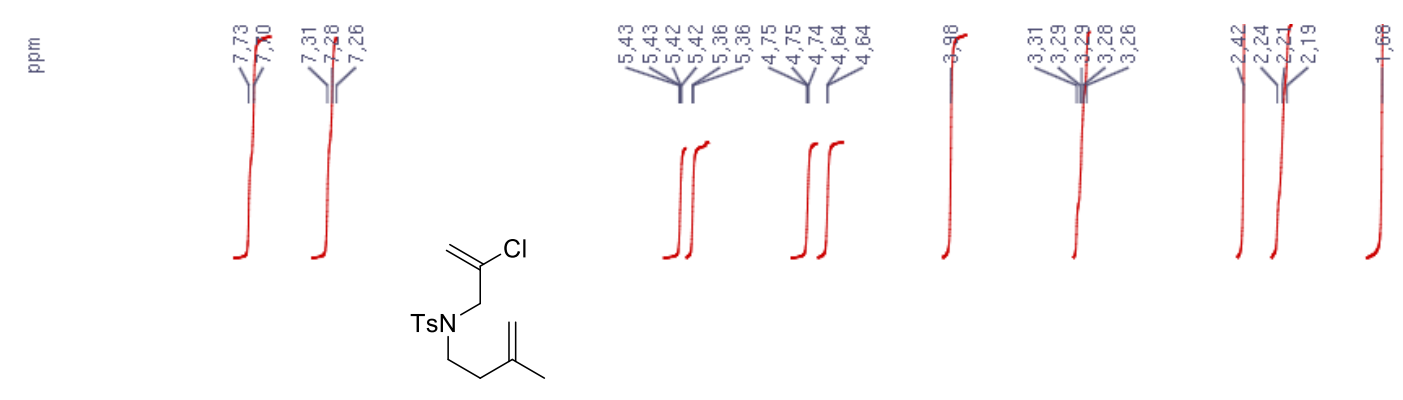

7b

${ }^{1} \mathrm{H} \mathrm{CDCl}_{3}, 300 \mathrm{MHz}$

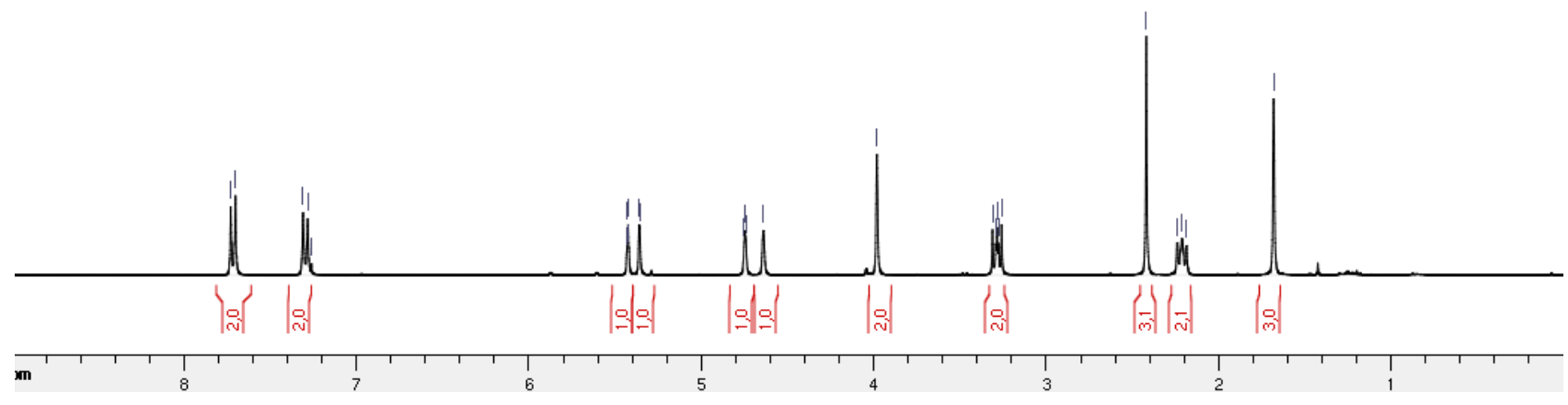

흘
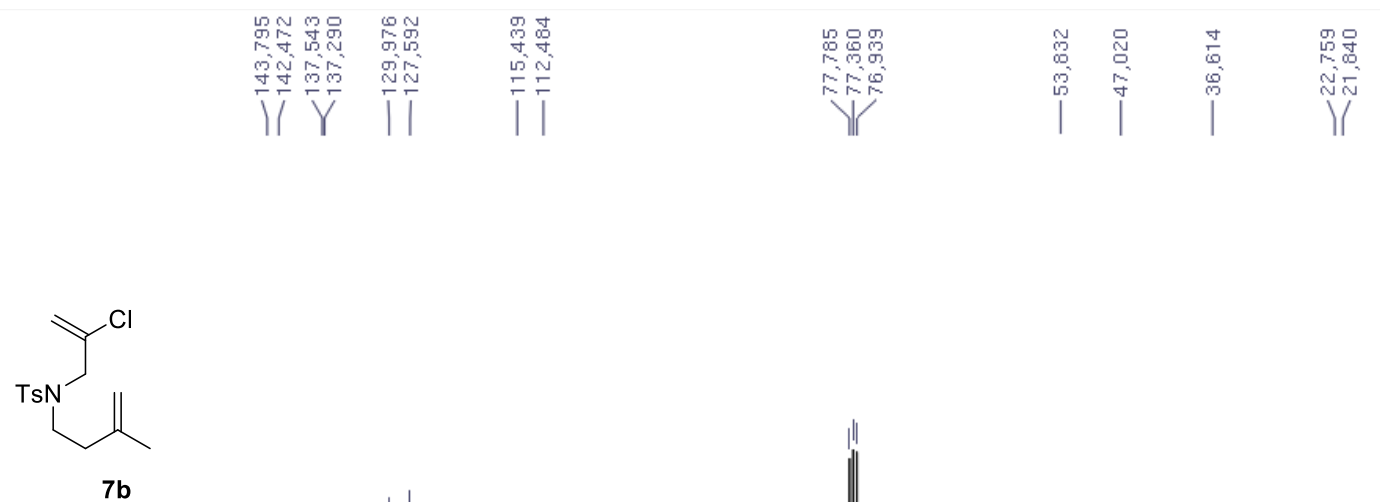

${ }^{13} \mathrm{C} \mathrm{CDCl}_{3}, 75 \mathrm{MHz}$

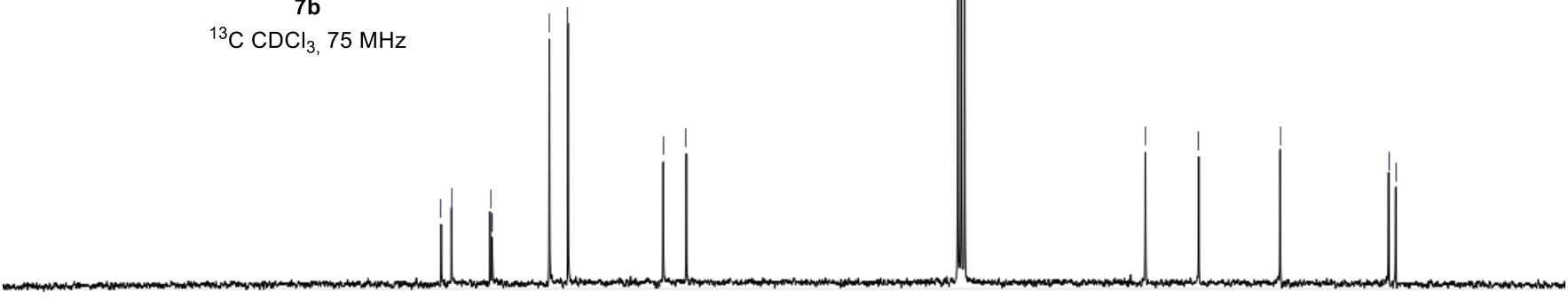

m
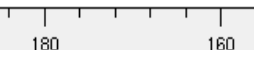

140

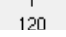

100

80

40

20 

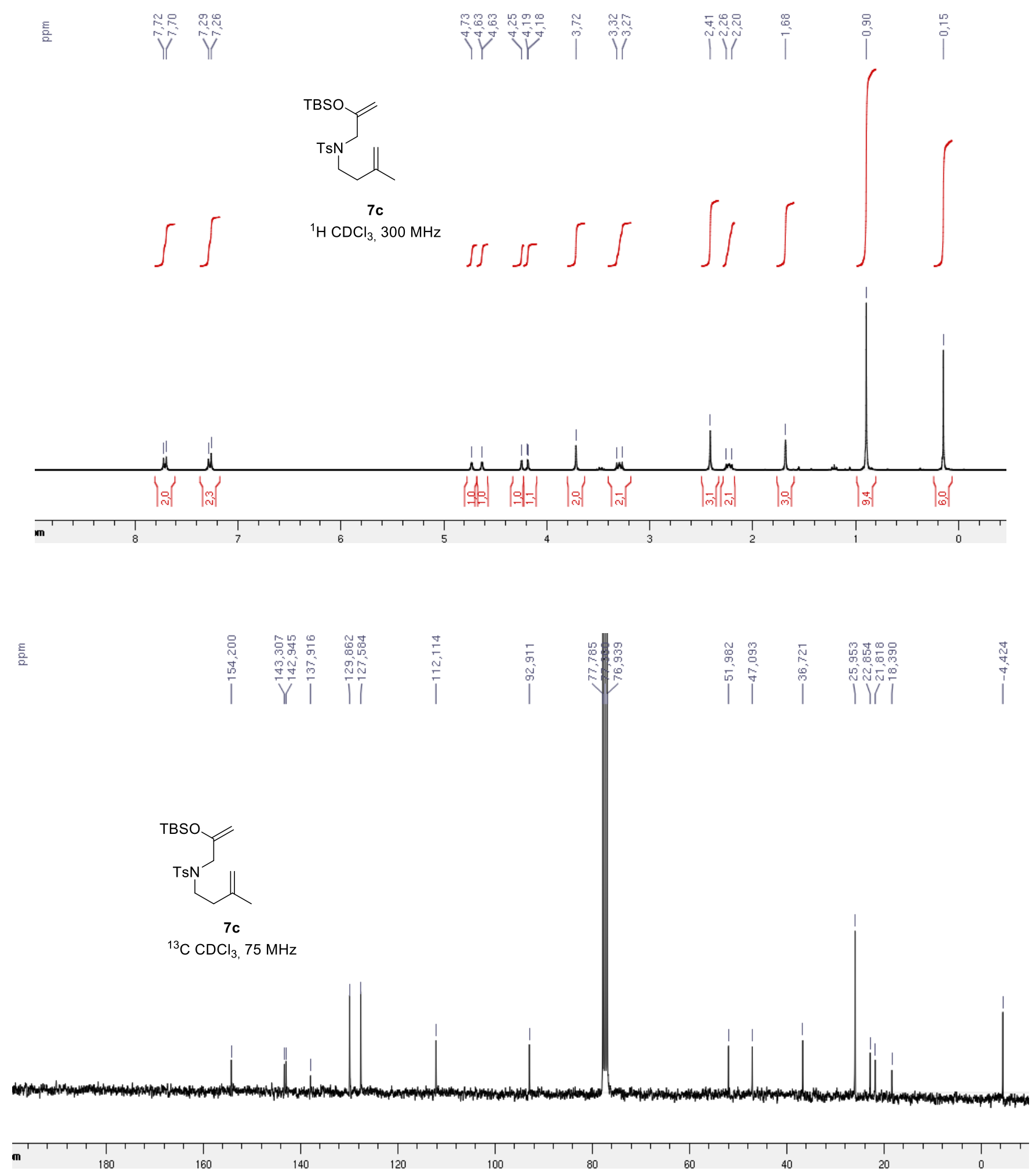
${ }^{1} \mathrm{H}$ and ${ }^{13} \mathrm{C}$ spectra for compounds 8a-h, 8j-q, 9a-b, 11a-b, 12a-b, 13a-d, 14b-c, 15a-b

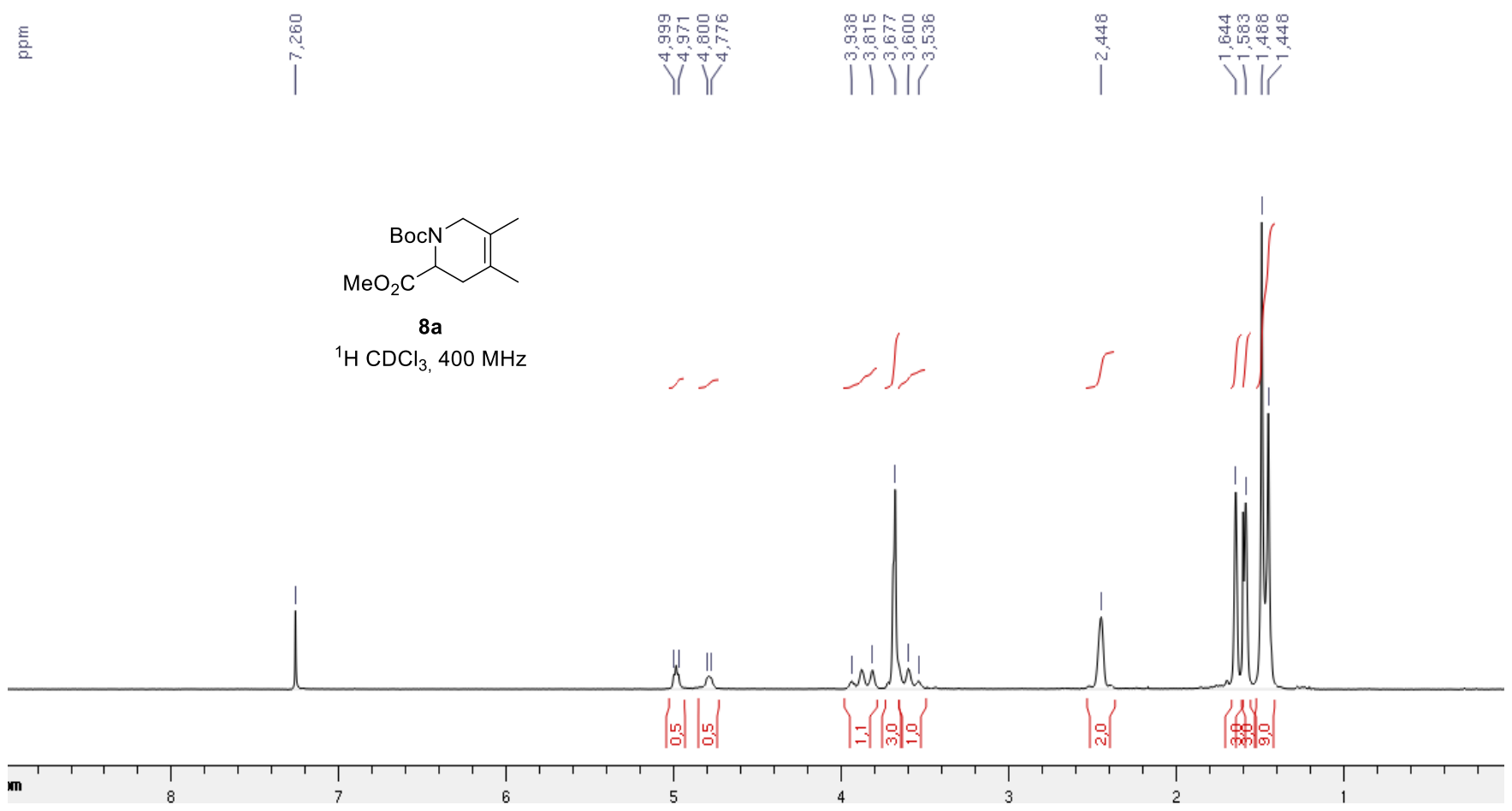

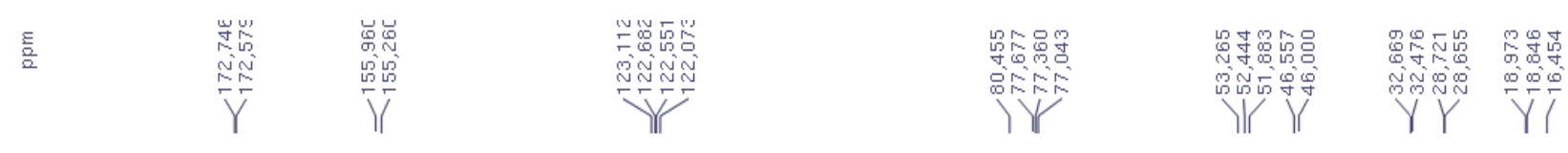

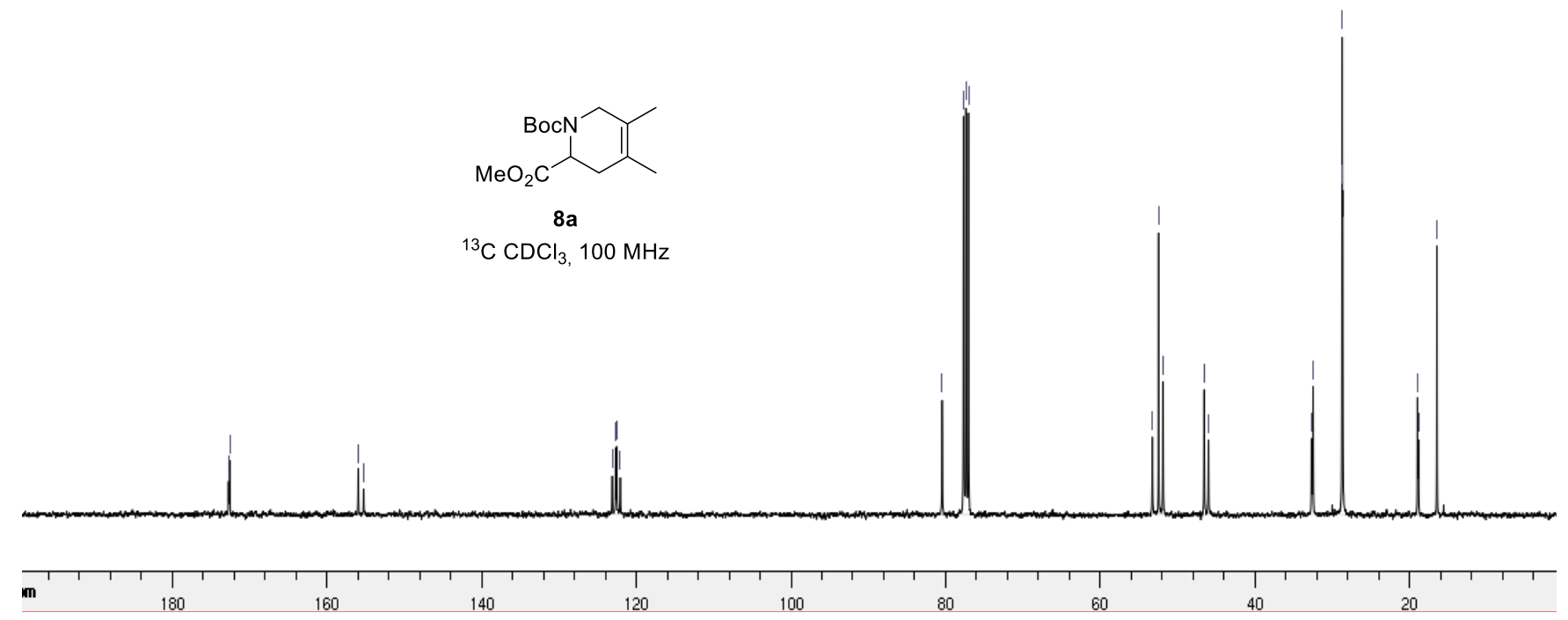




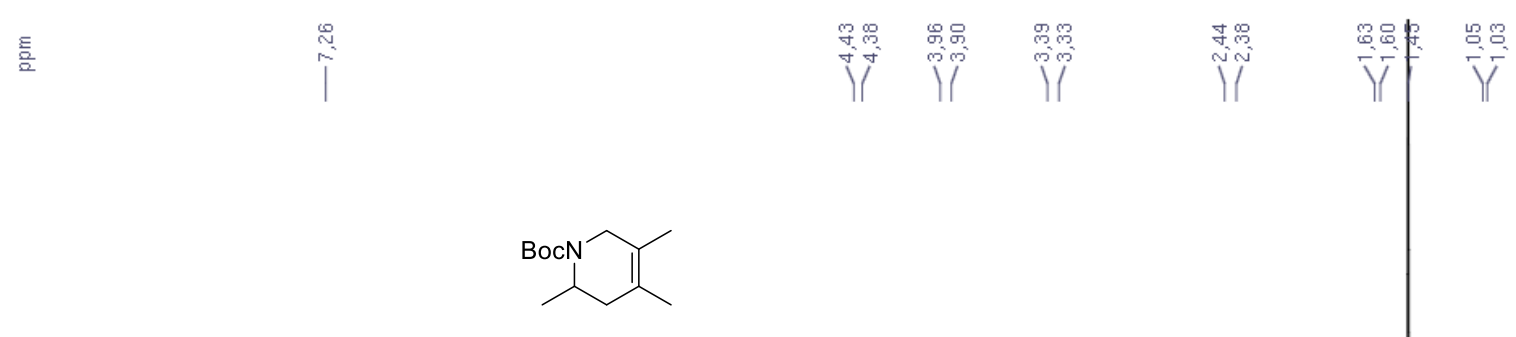

$8 b$

${ }^{1} \mathrm{H} \mathrm{CDCl}_{3}, 300 \mathrm{MHz}$

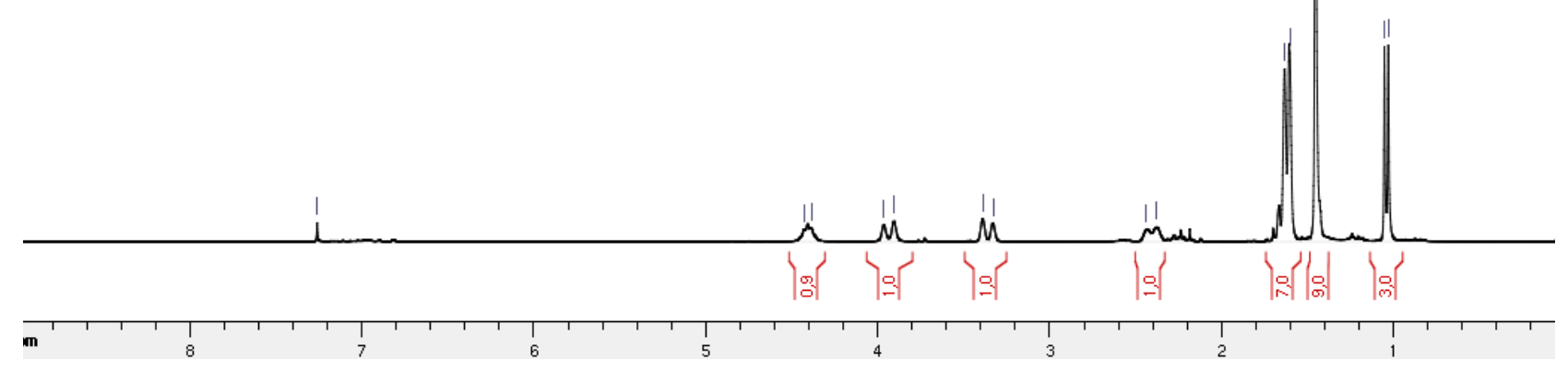

흘

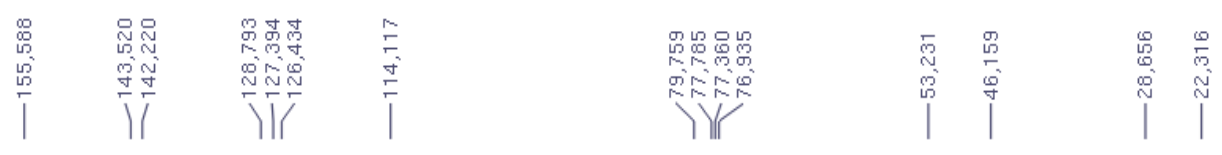

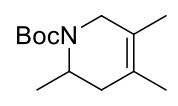

8b

${ }^{13} \mathrm{C} \mathrm{CDCl}_{3}, 75 \mathrm{MHz}$ 

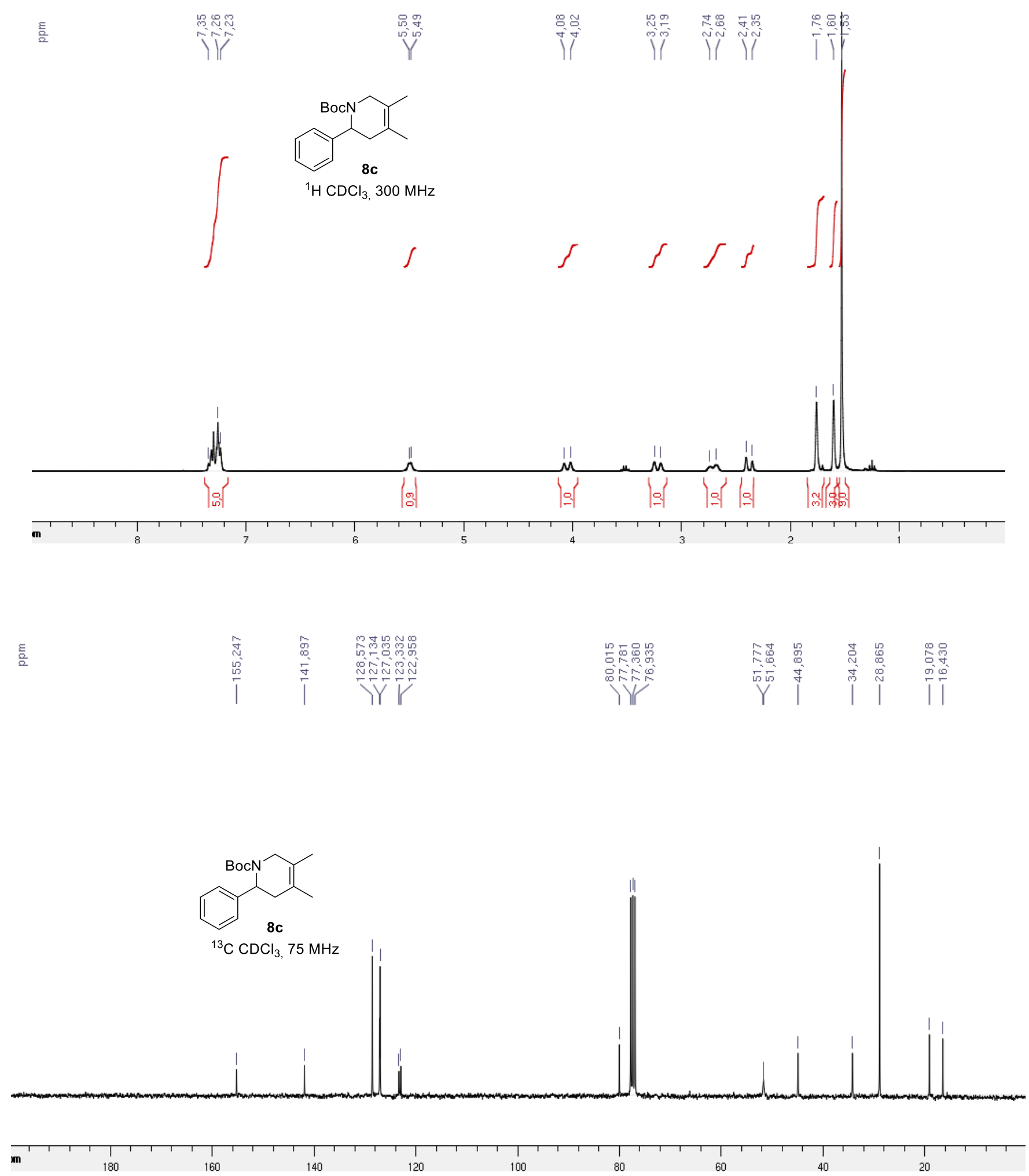


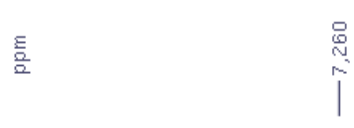

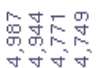

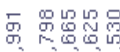 \\ în.

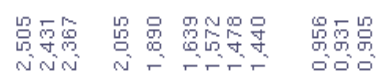

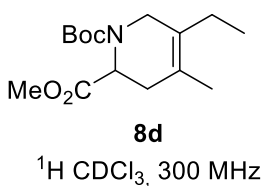

$$
{ }^{1} \mathrm{H} \mathrm{CDCl}_{3}, 300 \mathrm{MHz}
$$

\section{hi} Inl

$0,5 \quad 0,5$ $1,0 \quad 4,0$<smiles>C=CC#CCCCCCC</smiles>

$$
\text { m }
$$
I I 1
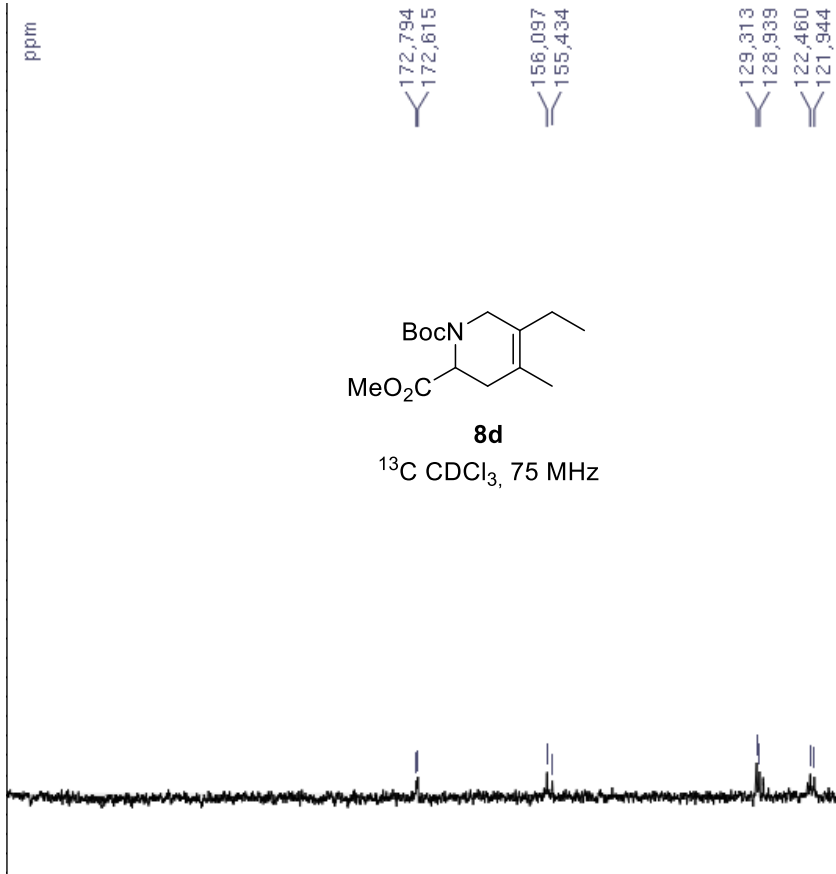

pm 

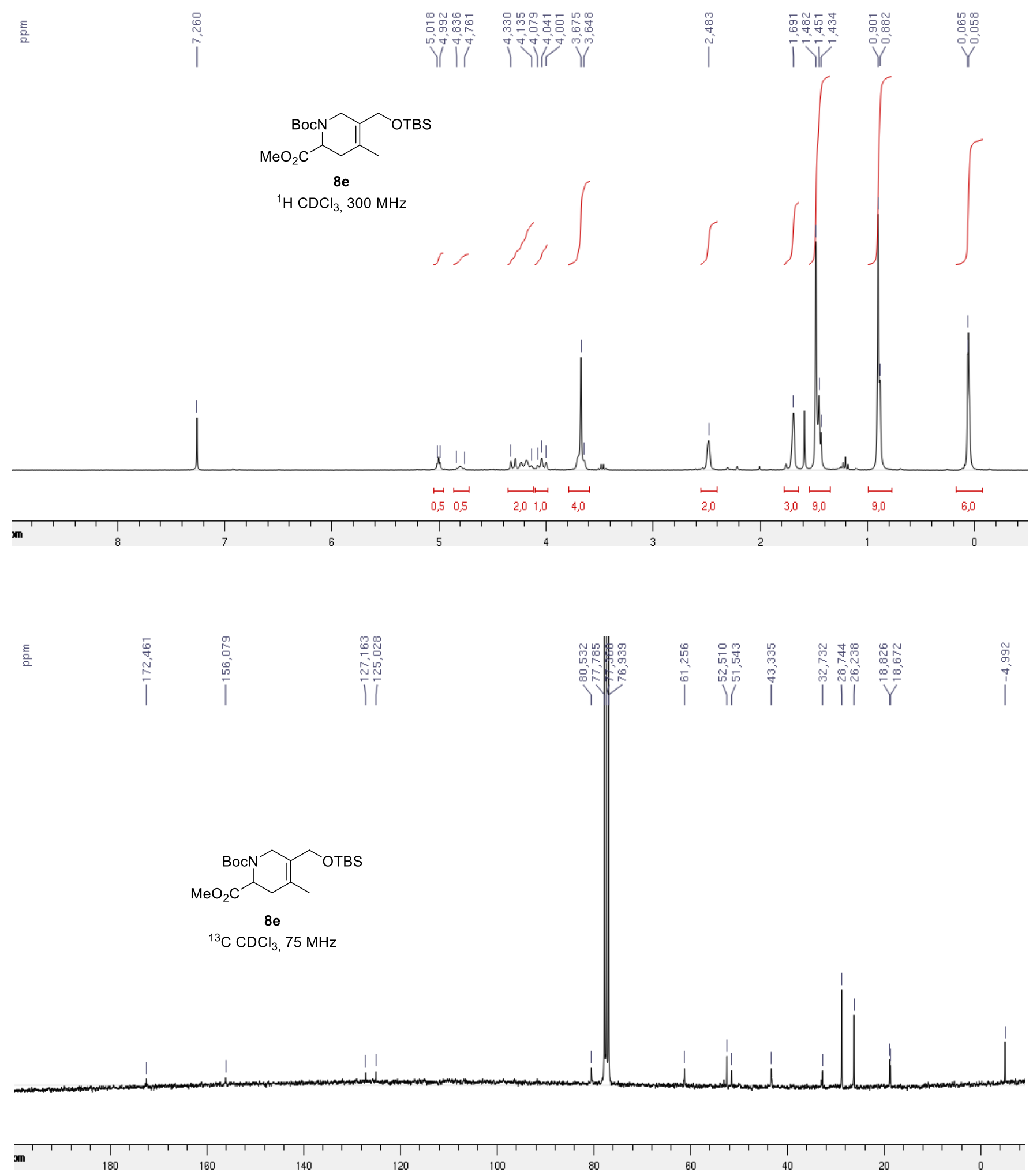

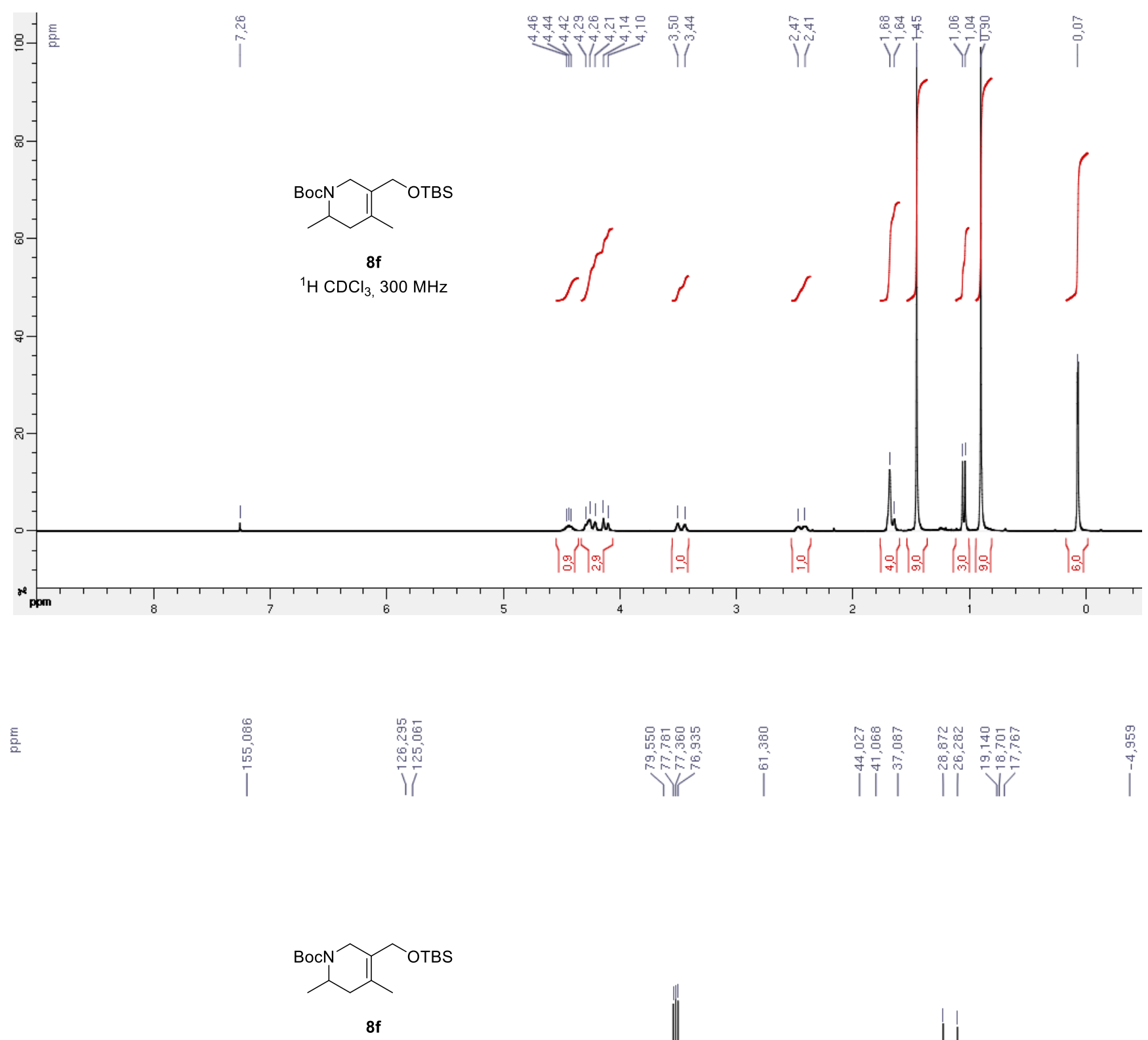

${ }^{13} \mathrm{C} \mathrm{CDCl}_{3}, 75 \mathrm{MHz}$

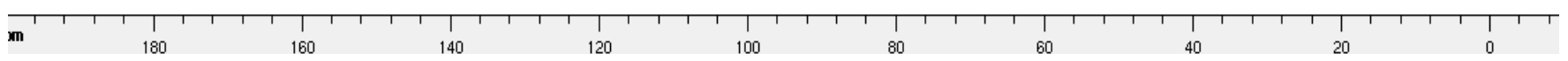




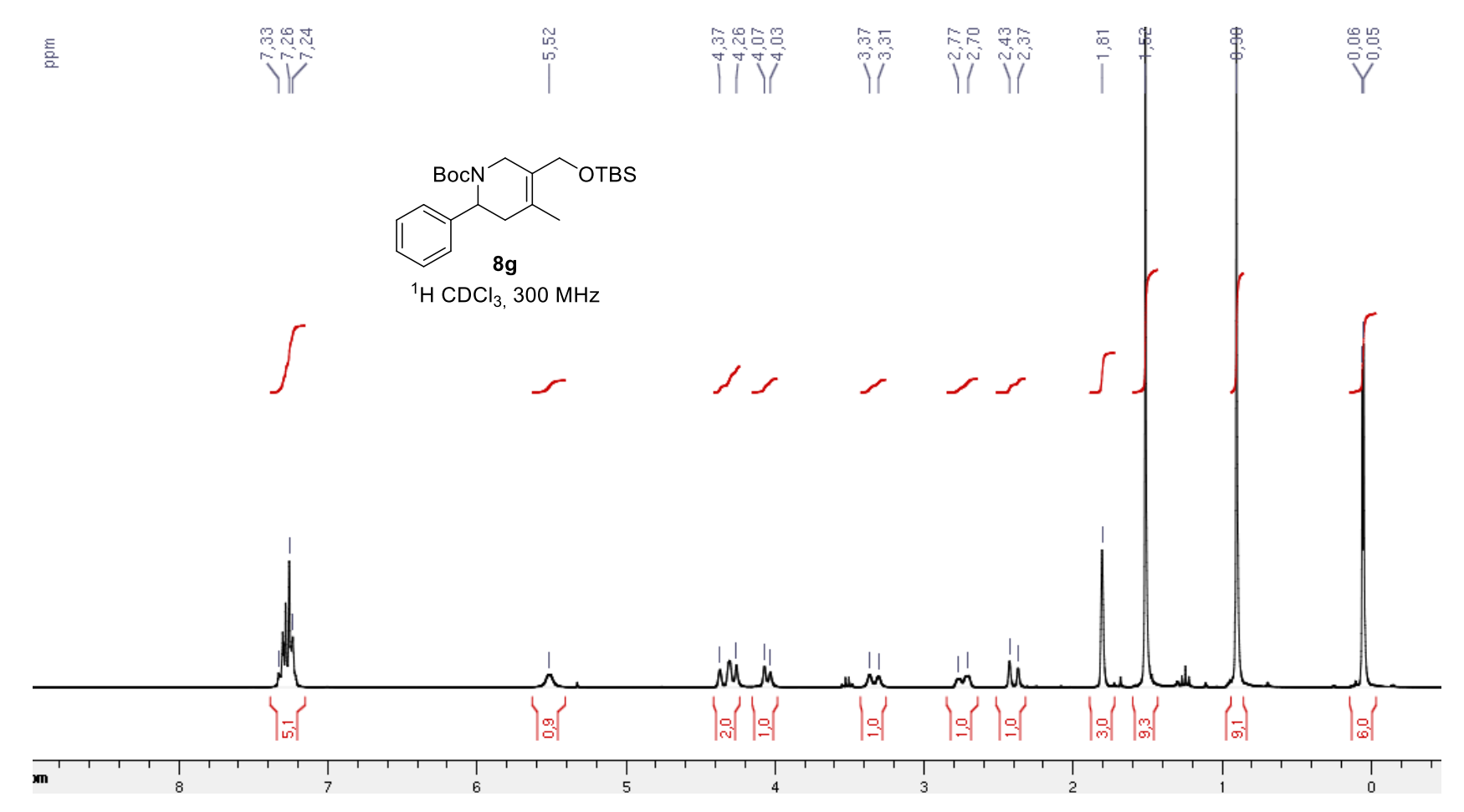

1 $\quad$\begin{tabular}{l}
$n$ \\
\hline
\end{tabular}
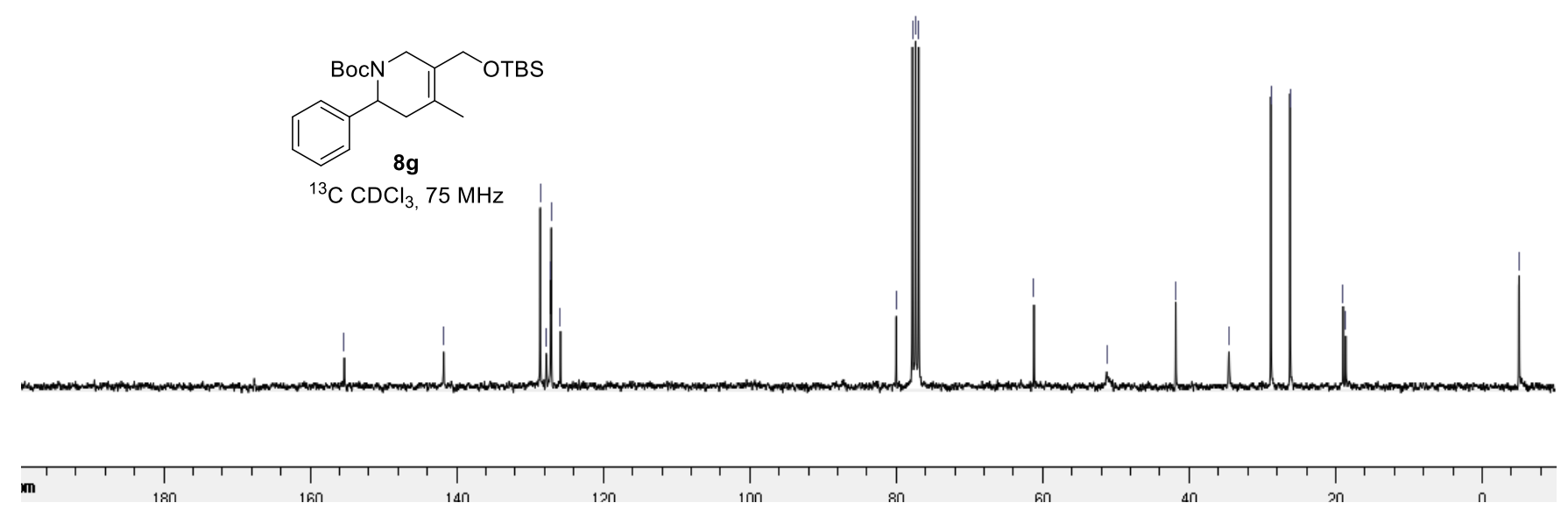


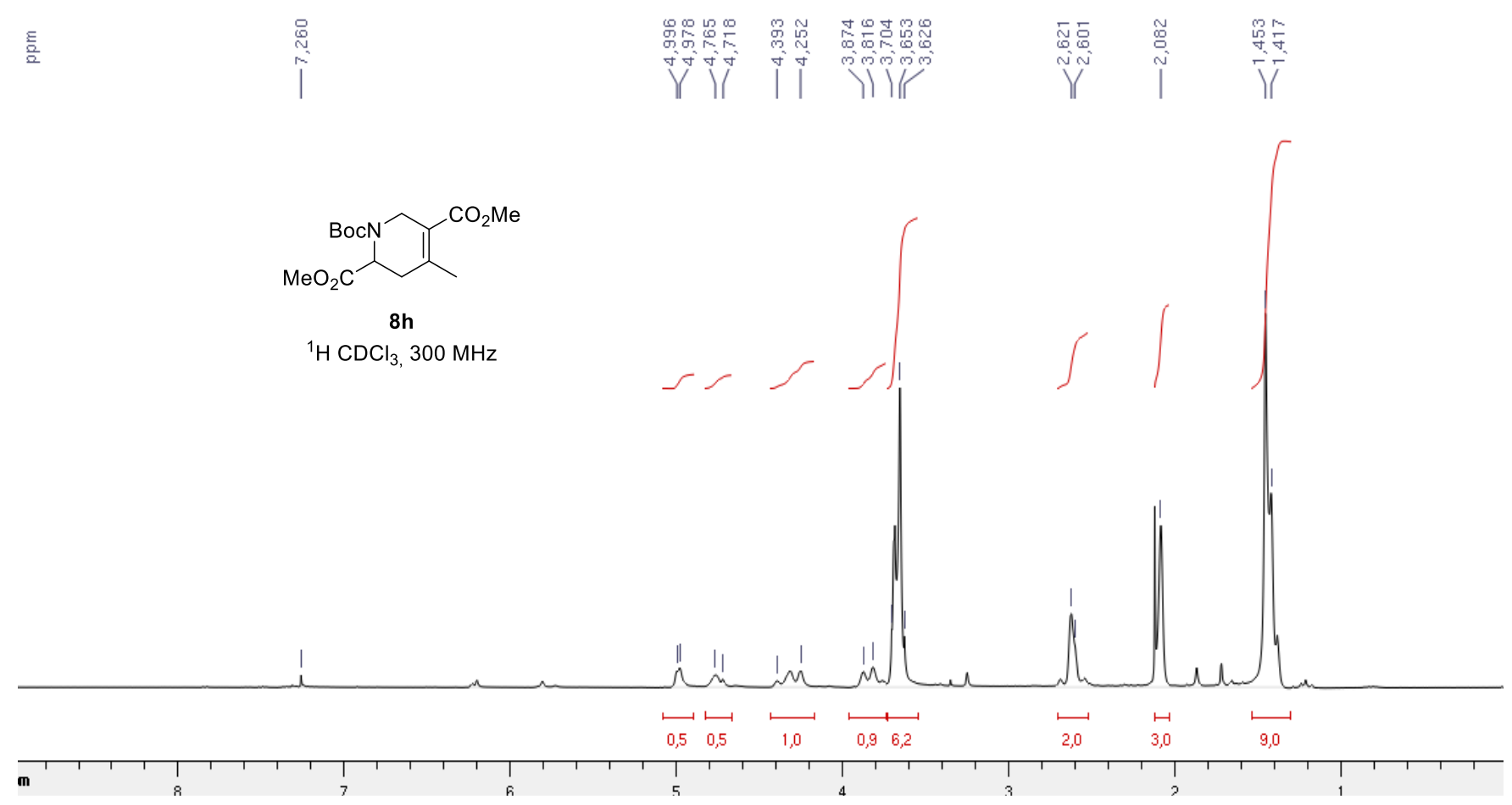

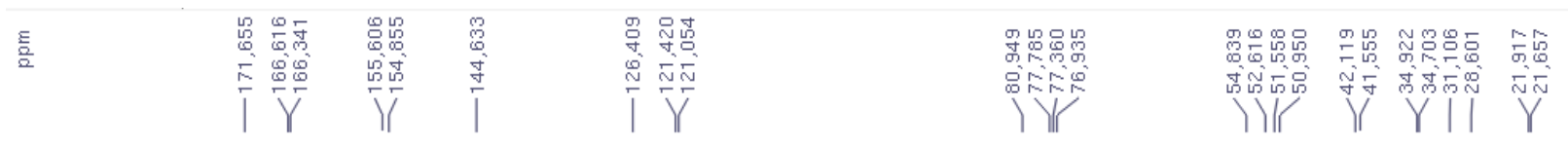

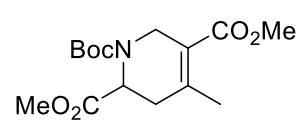

$8 h$

${ }^{13} \mathrm{C} \mathrm{CDCl}_{3}, 75 \mathrm{MHz}$

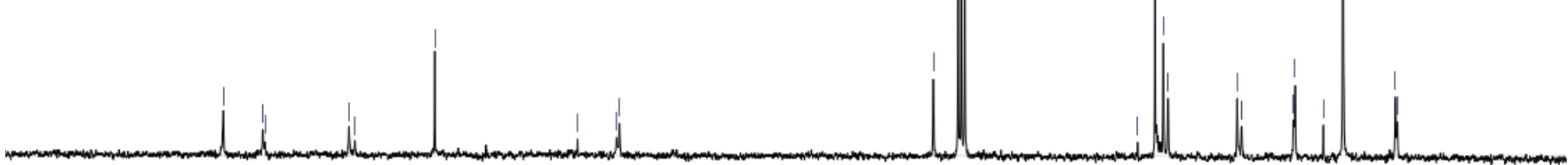

m

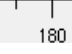

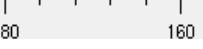

140

120

100

60

20 


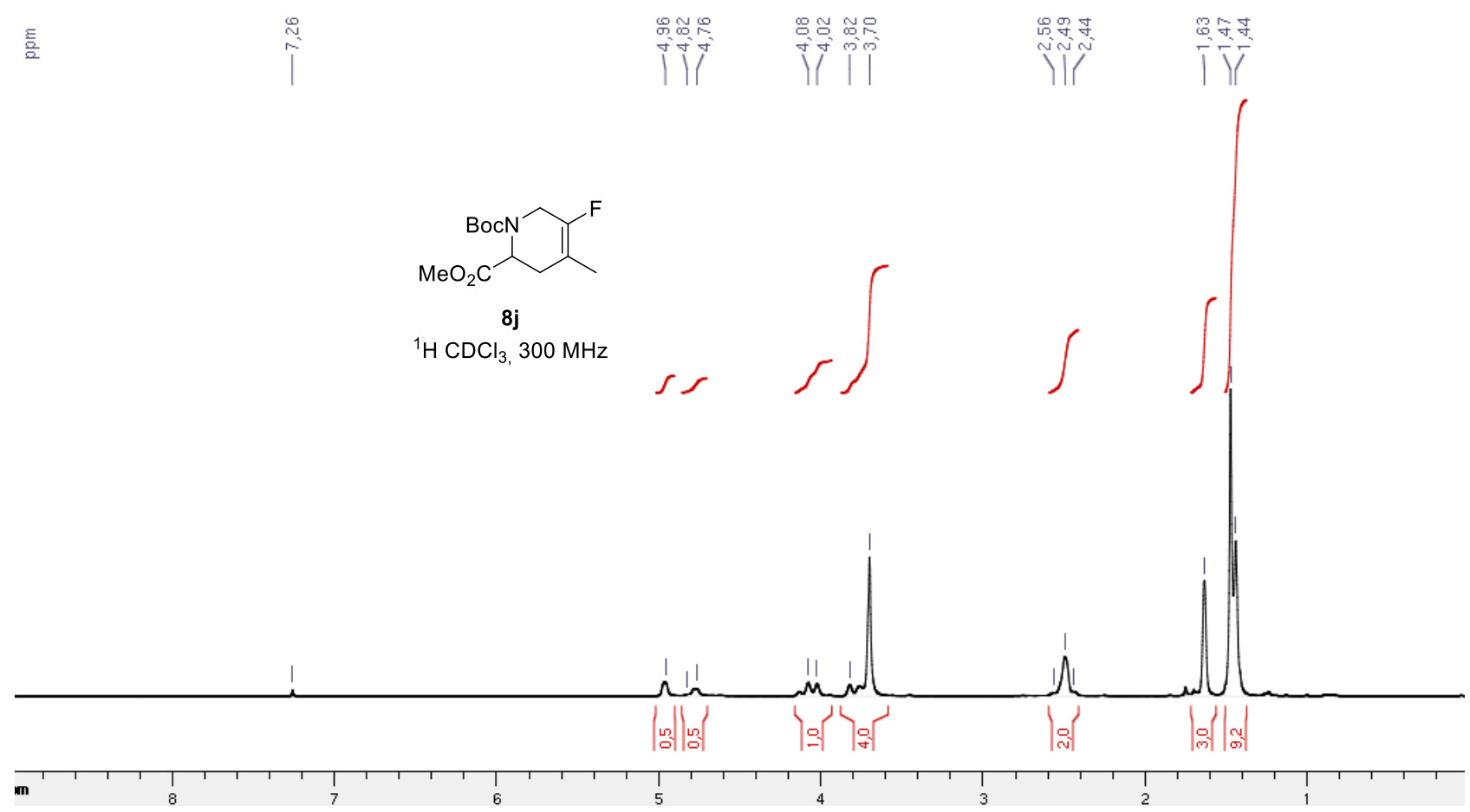

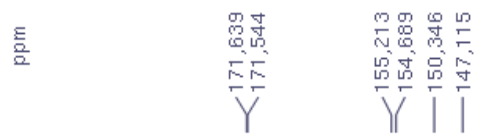

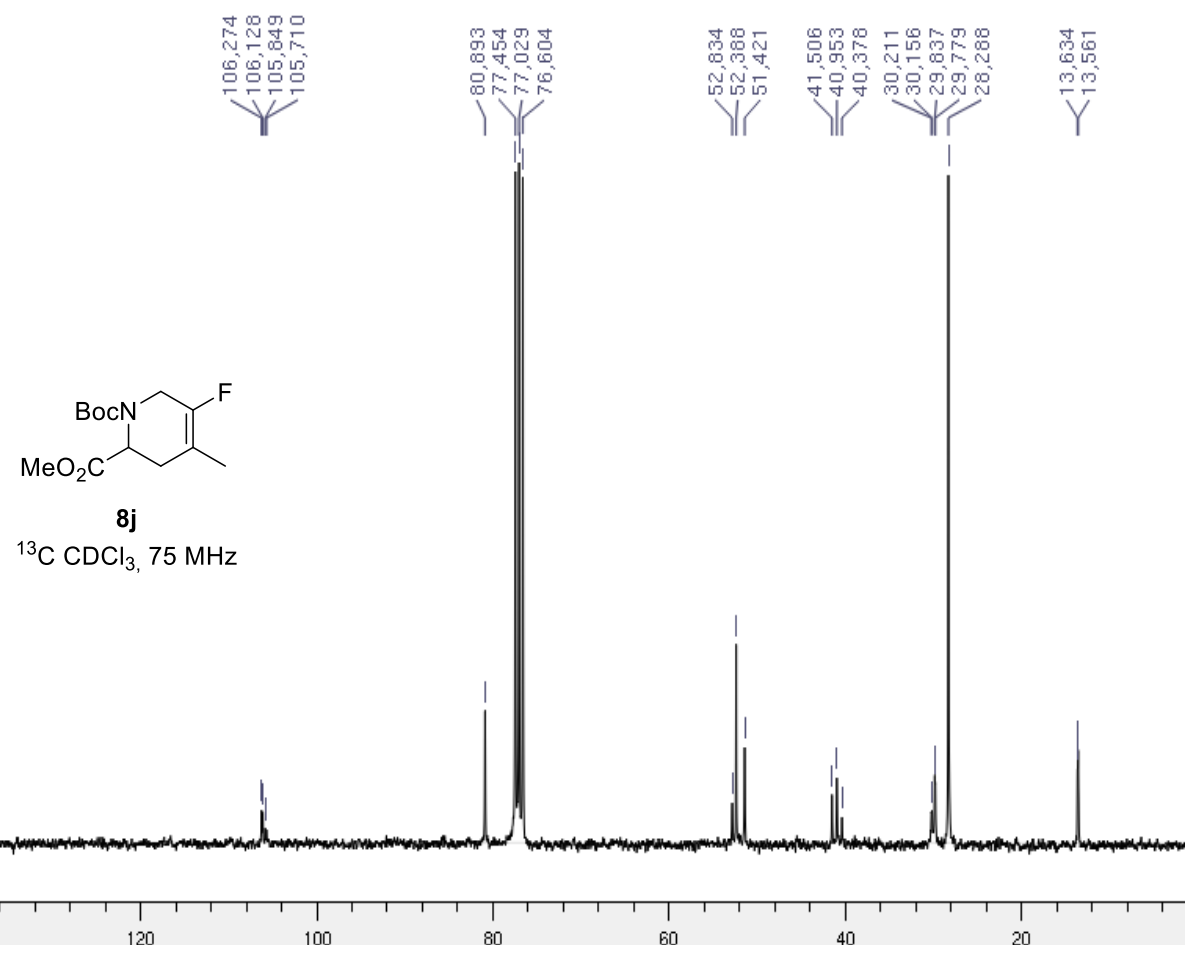




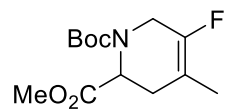

8j

${ }^{19} \mathrm{~F} \mathrm{CDCl}_{3}, 282 \mathrm{MHz}$

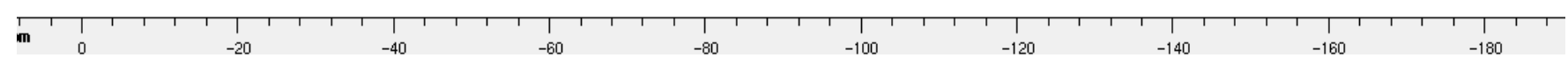




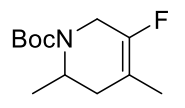

$8 \mathbf{k}$

${ }^{1} \mathrm{H} \mathrm{CDCl}_{3}, 300 \mathrm{MHz}$

흠

|

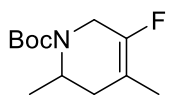

8 k

${ }^{13} \mathrm{C} \mathrm{CDCl}_{3}, 75 \mathrm{MHz}$

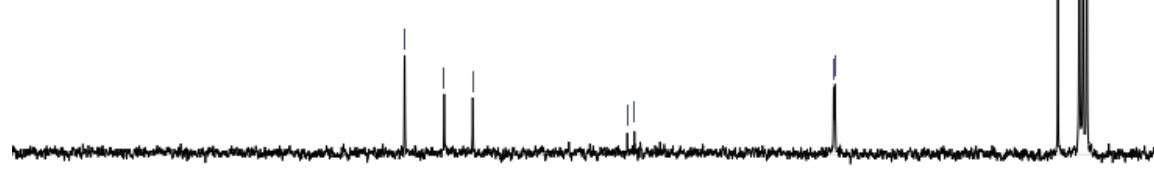

Me Nhal 


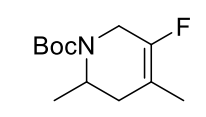

$8 k$

${ }^{13} \mathrm{~F} \mathrm{CDCl}_{3}, 282 \mathrm{MHz}$

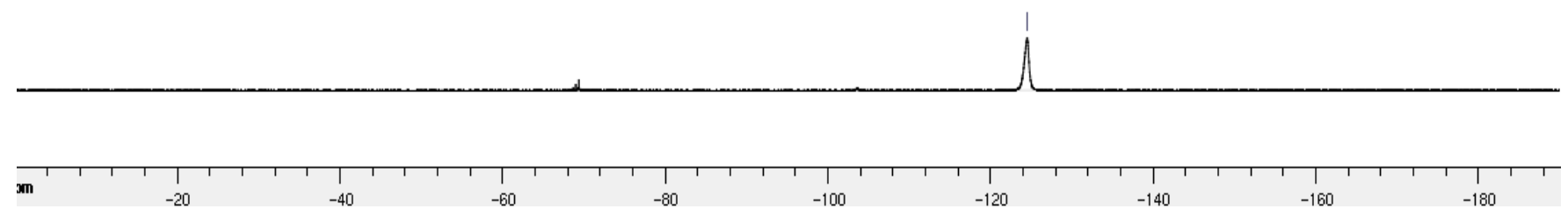



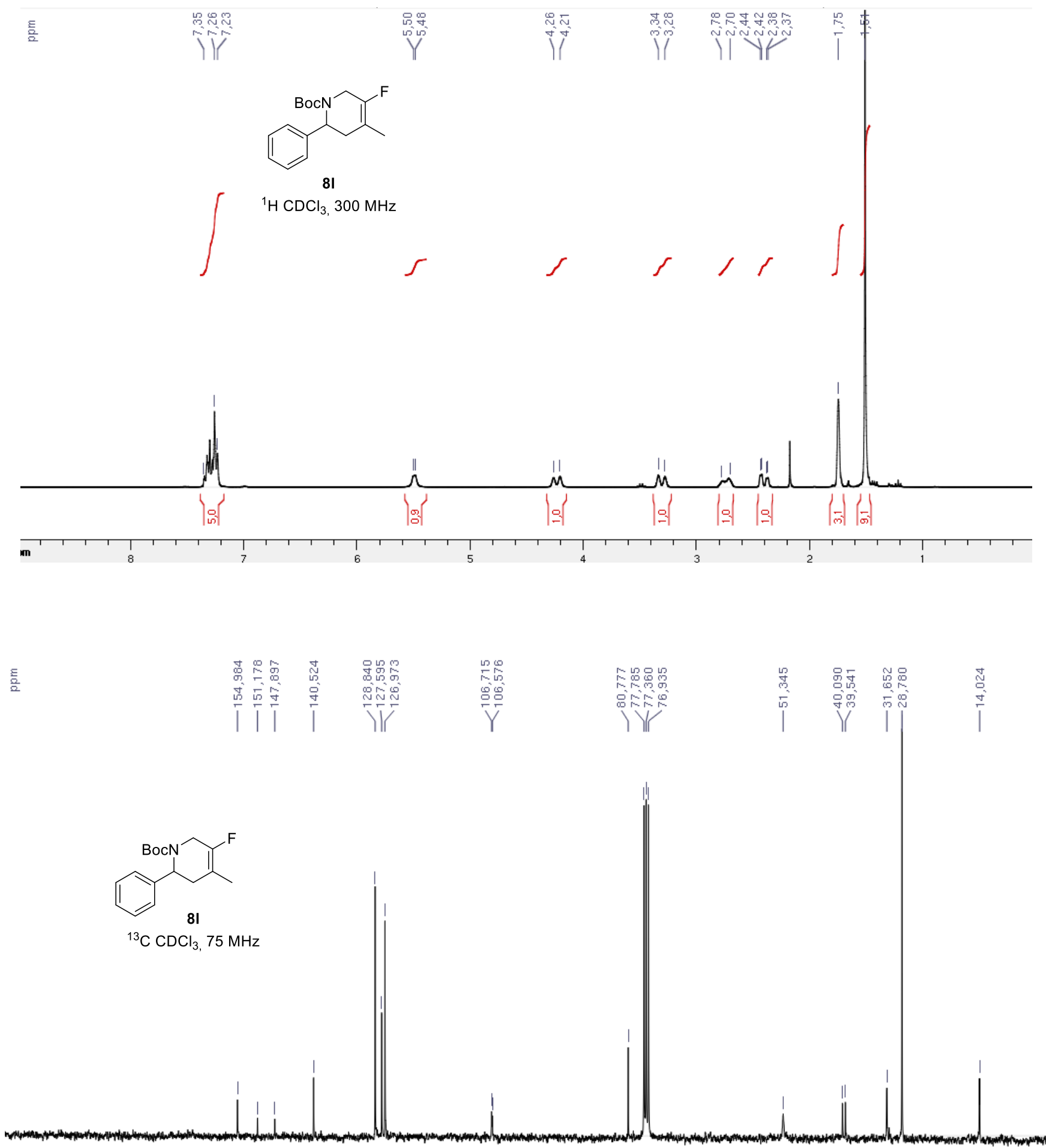

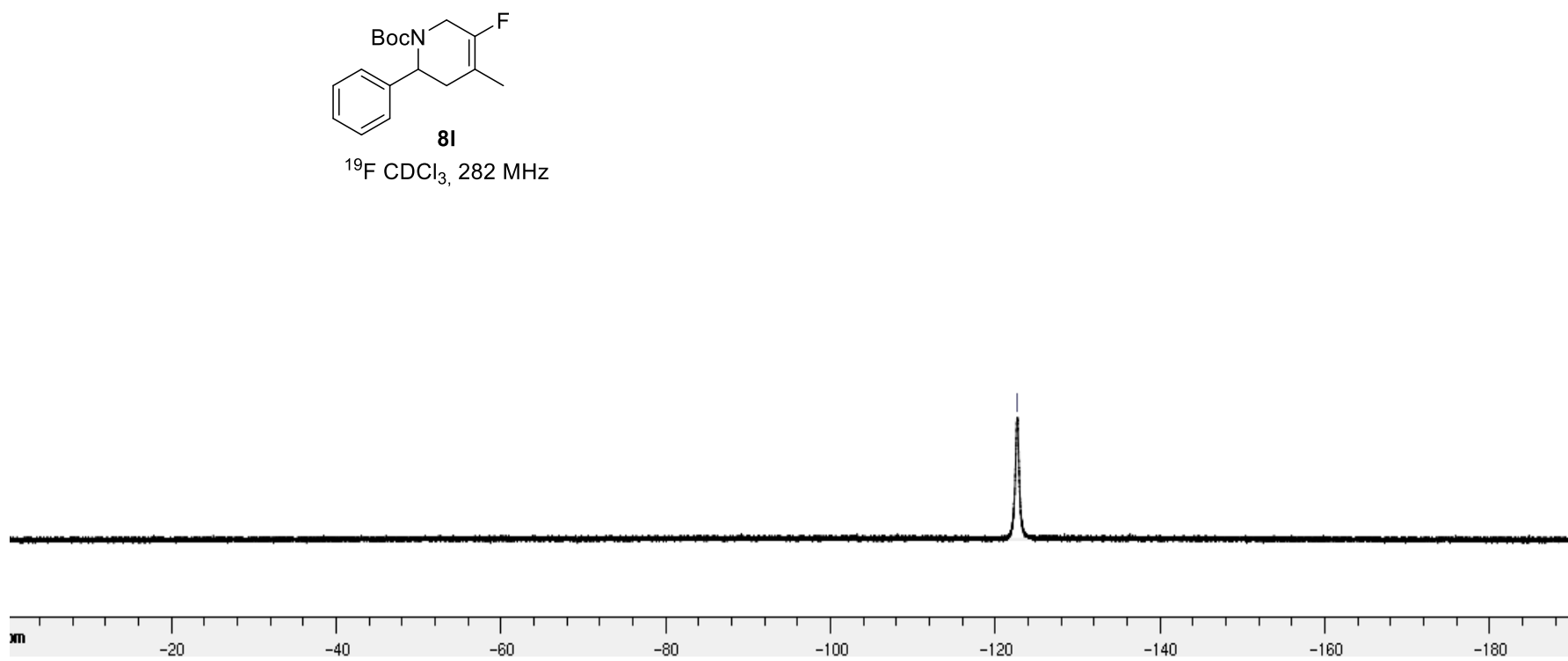

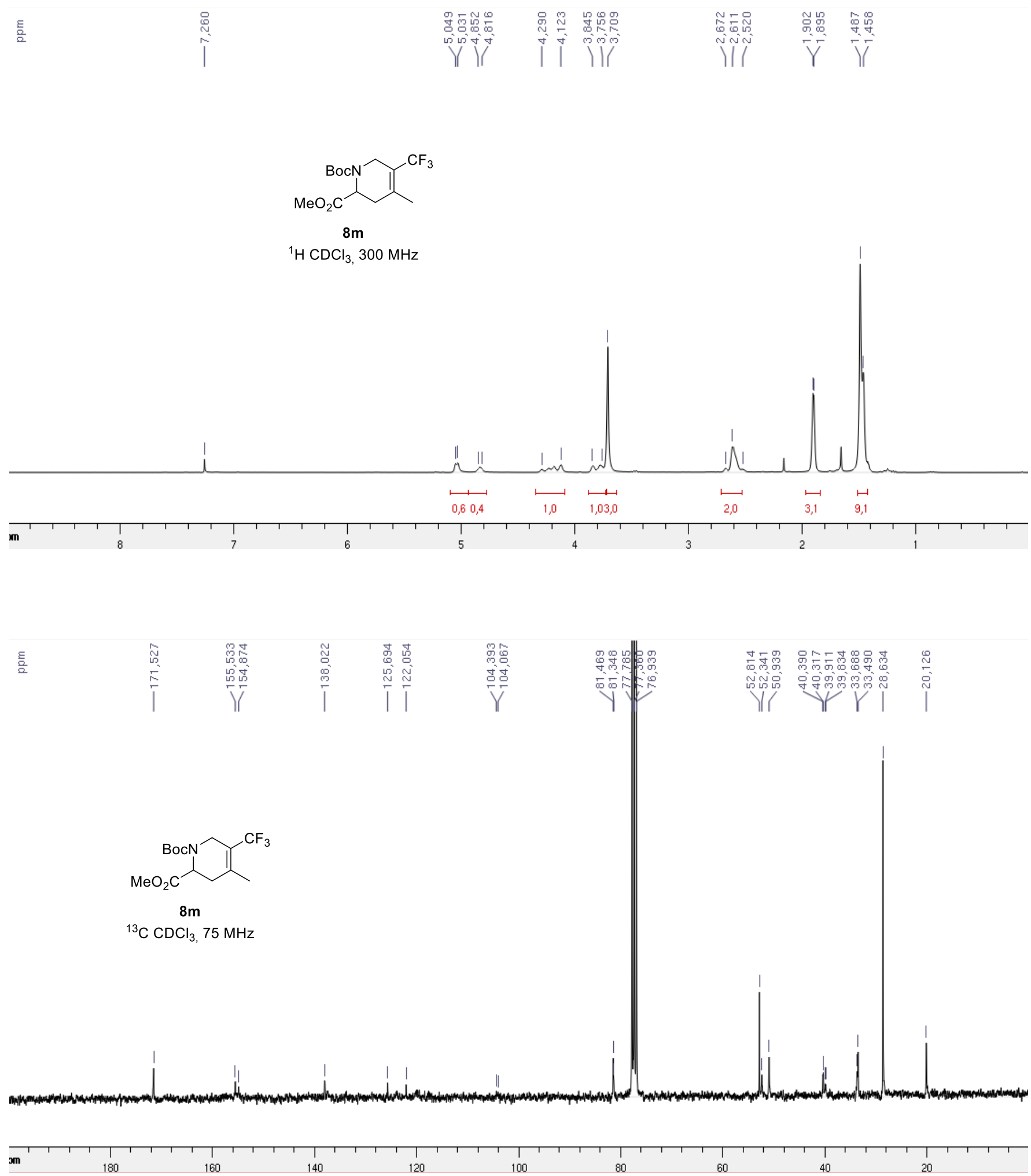


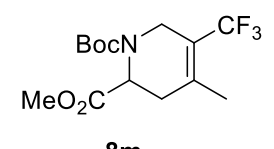

${ }^{19} \mathrm{~F} \mathrm{CDCl}_{3}, 282 \mathrm{MHz}$

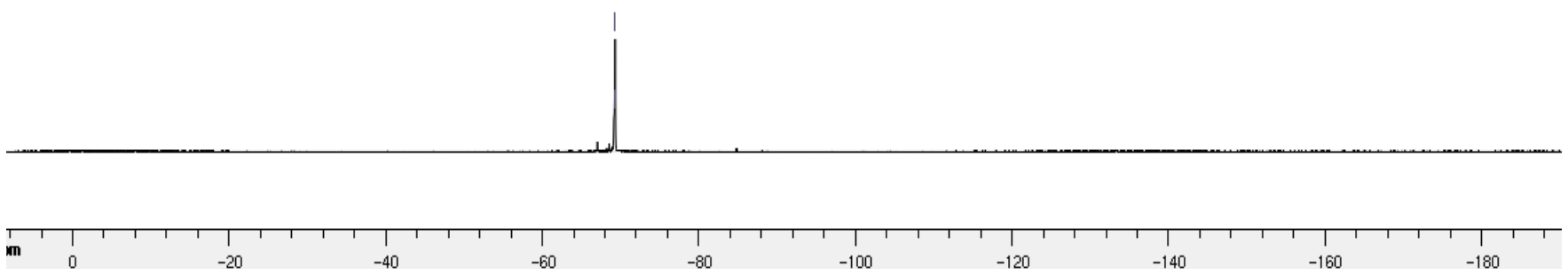




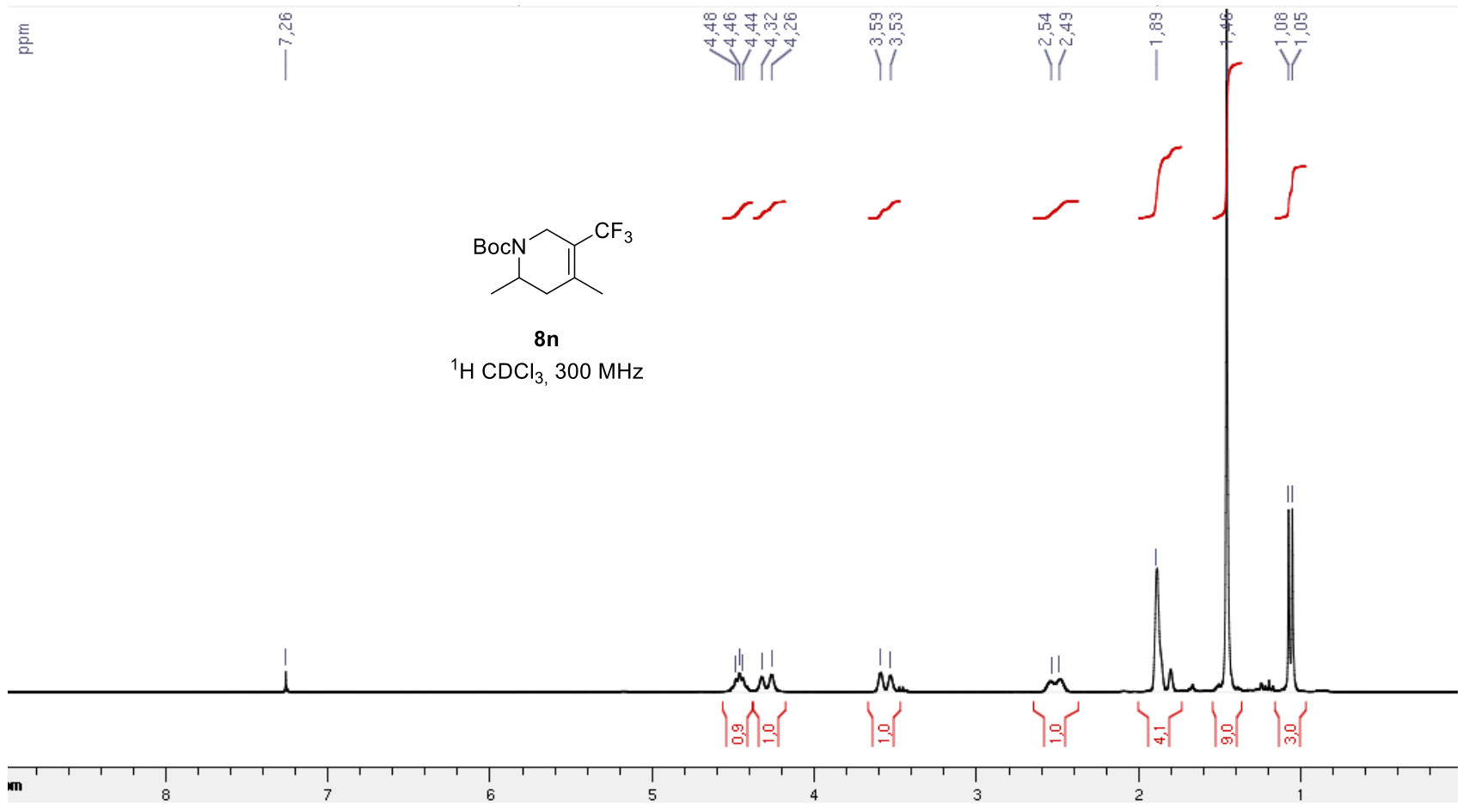

흘

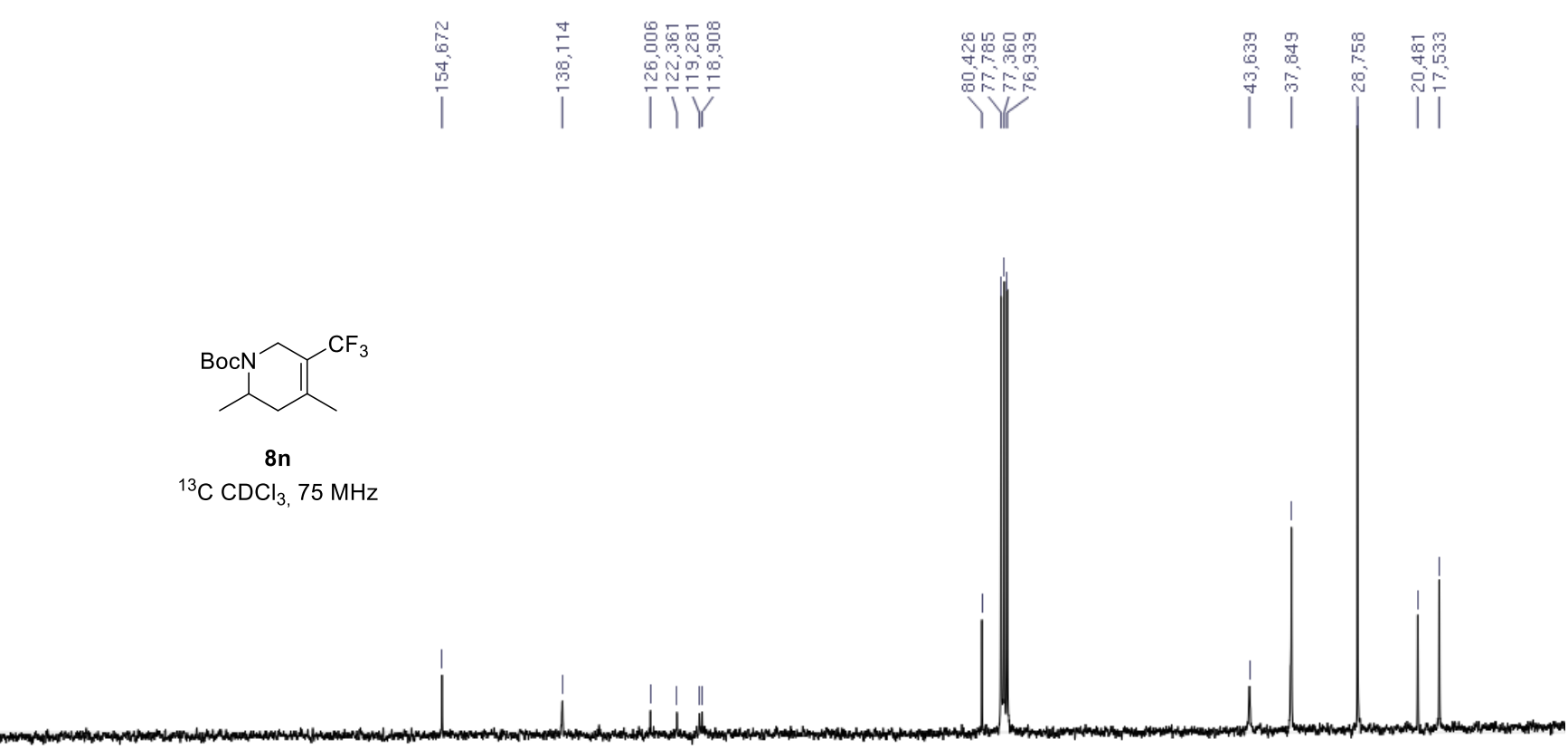

m 200

180

160

$\frac{1}{140}$

120

100

80

60

40 
흠

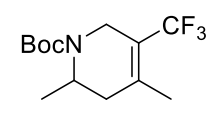

$8 n$

${ }^{19} \mathrm{FCDCl}_{3}, 282 \mathrm{MHz}$

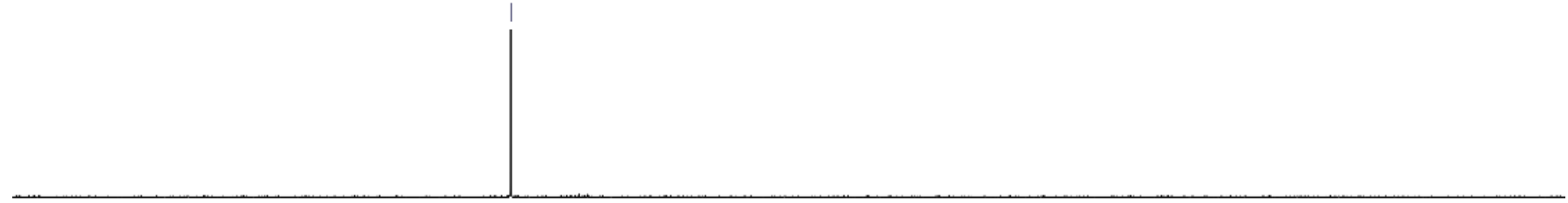

m

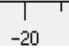

$-40$

$-60$

$-80$

$-100$

$-120$

$-140$

$-160$

$-180$ 

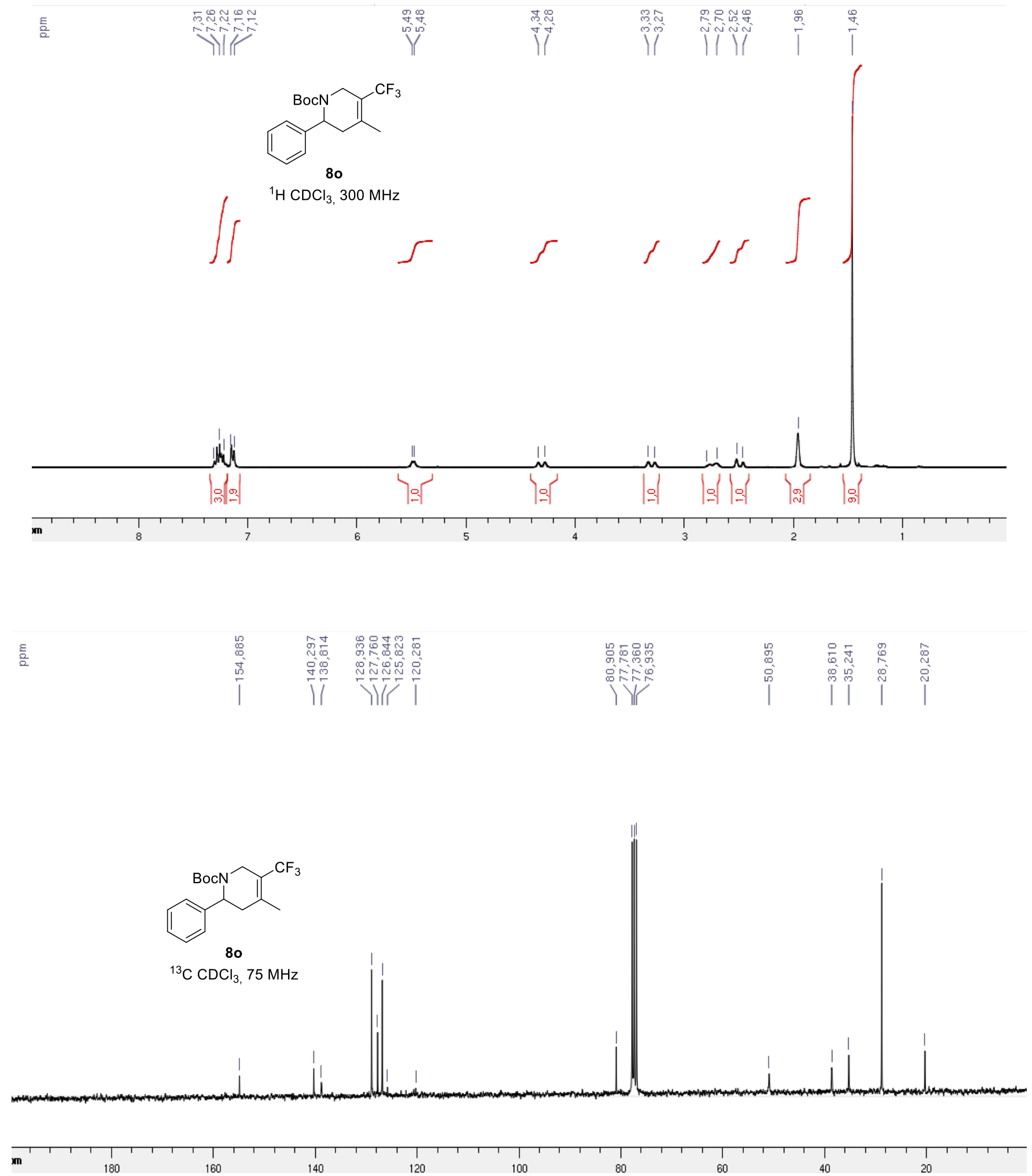
言

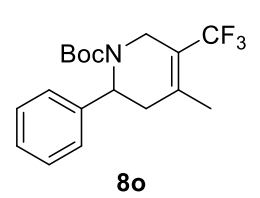

${ }^{19} \mathrm{~F} \mathrm{CDCl}_{3}, 282 \mathrm{MHz}$

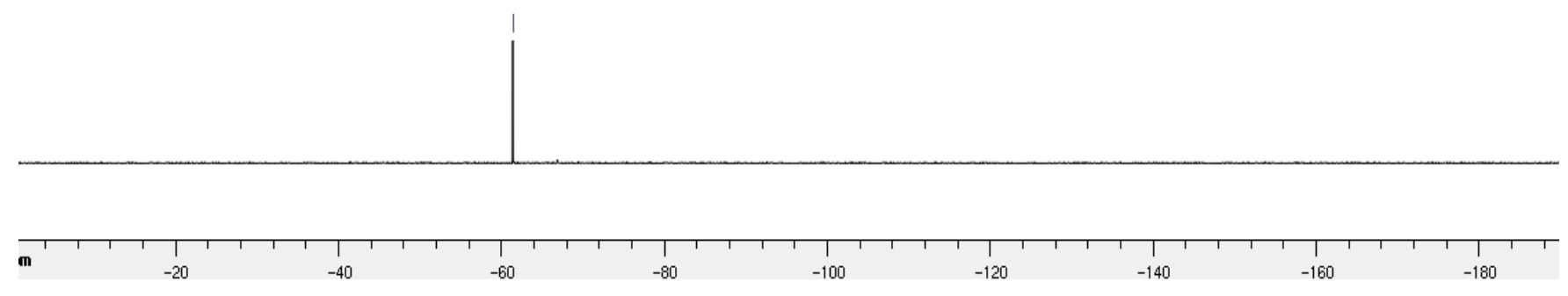



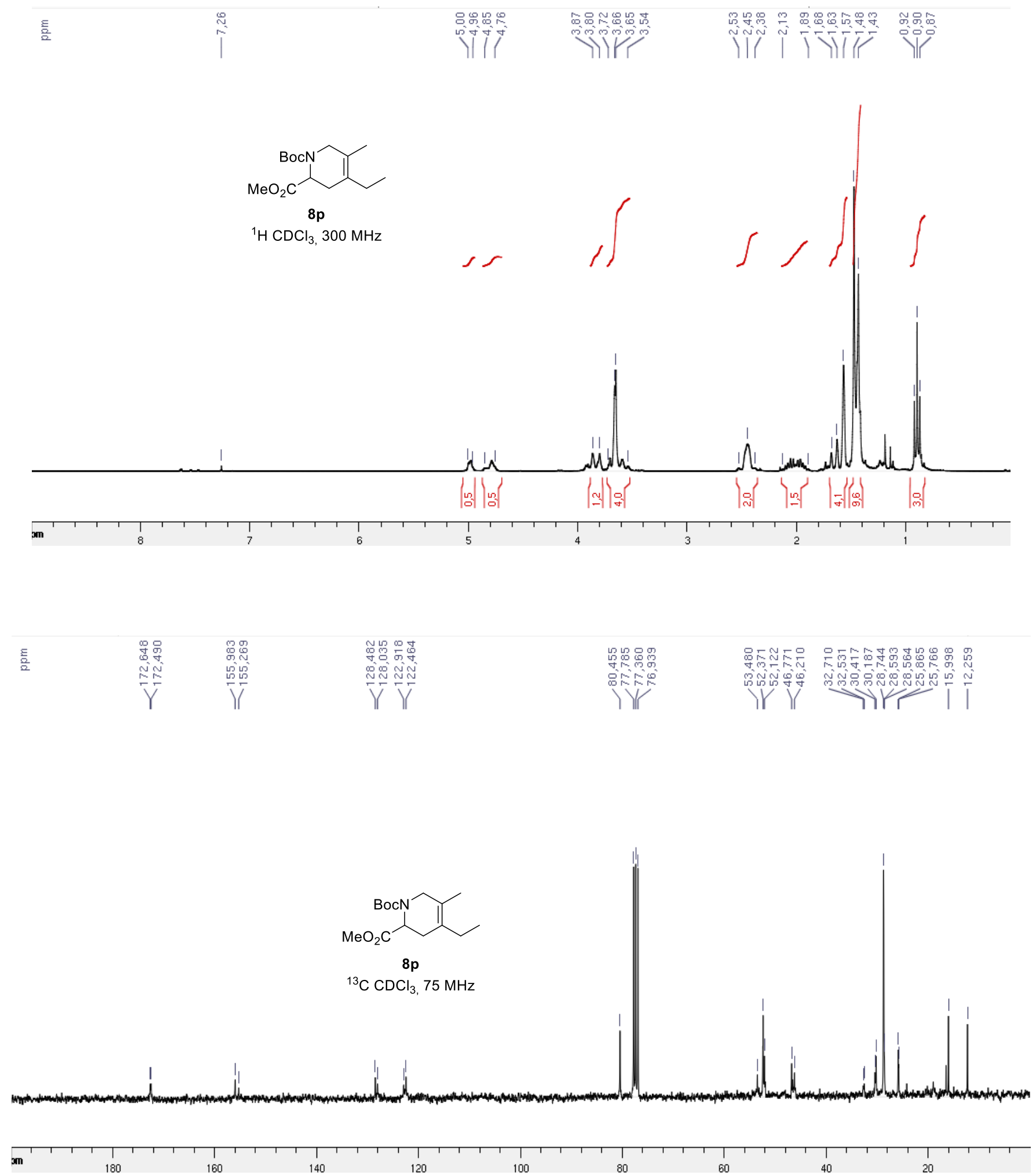

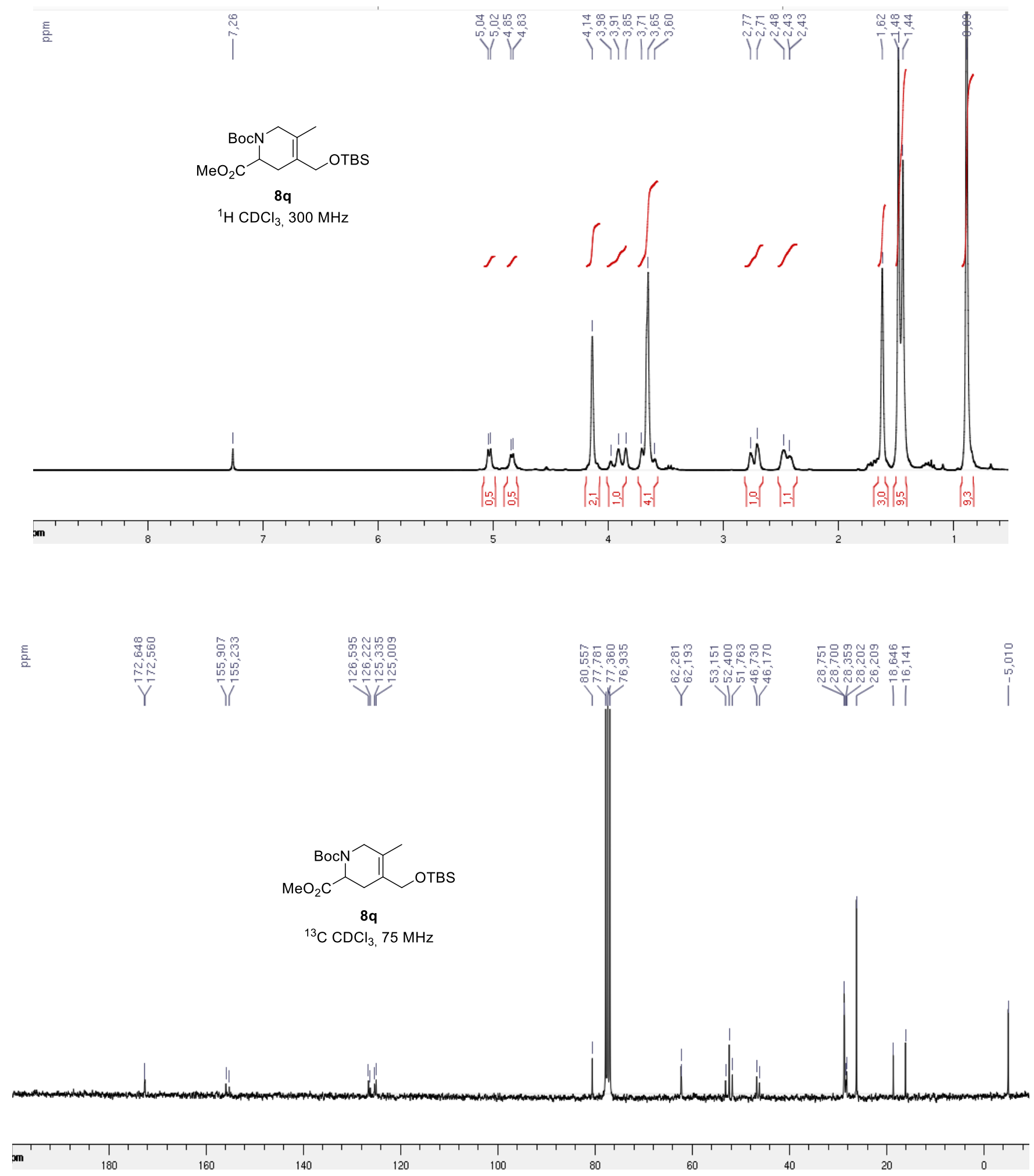


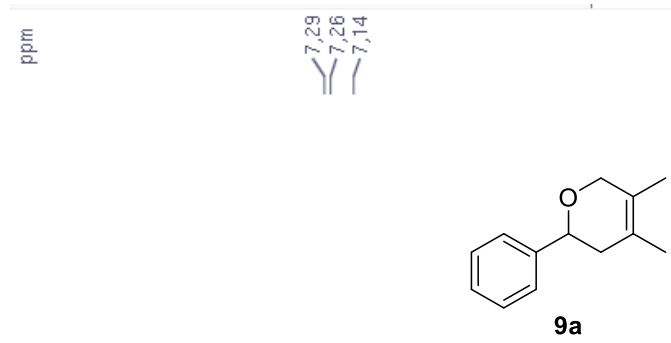

${ }^{1} \mathrm{H} \mathrm{CDCl}_{3}, 300 \mathrm{MHz}$

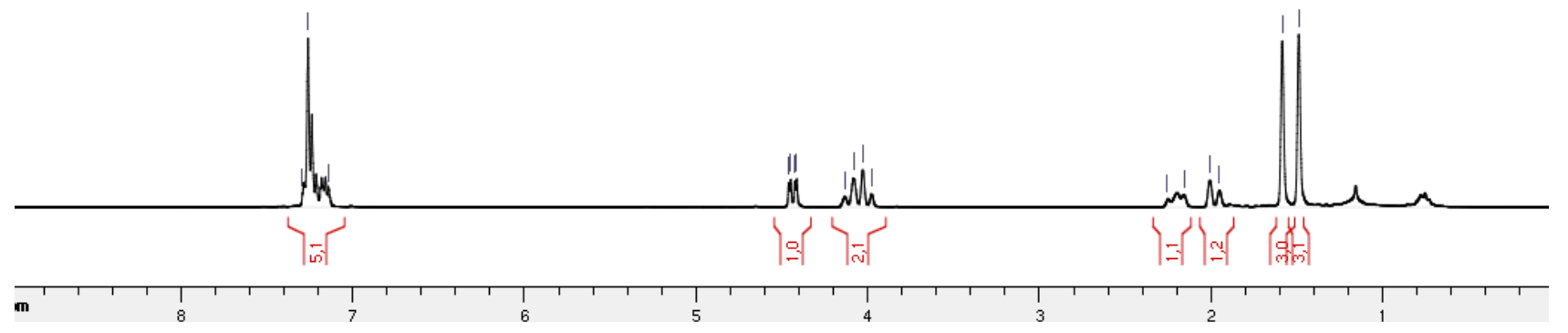

흘

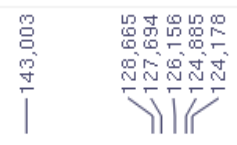

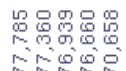

舟

$\mid$
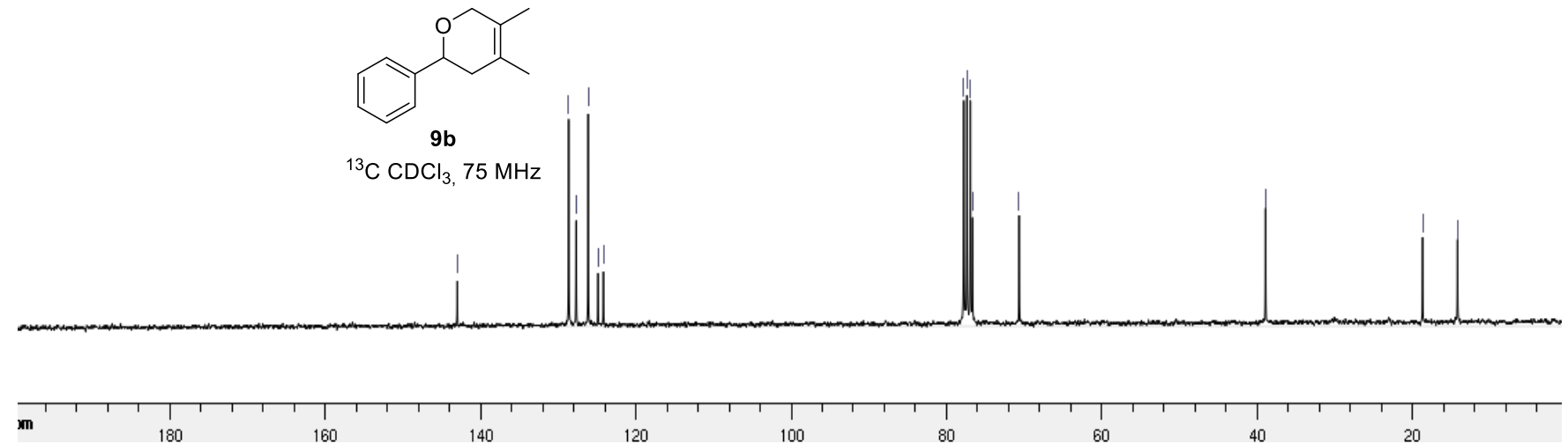

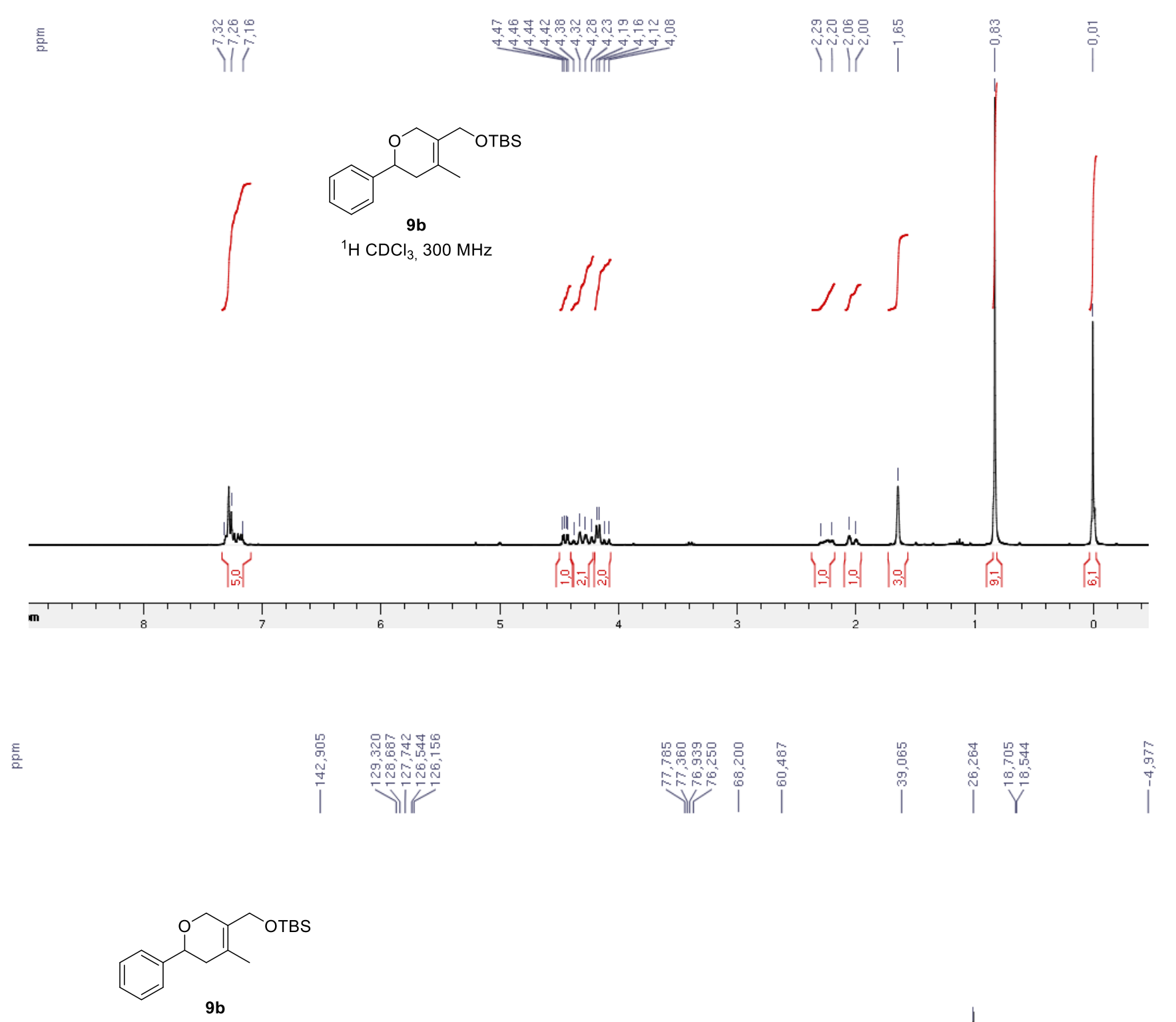

${ }^{13} \mathrm{C} \mathrm{CDCl}_{3}, 75 \mathrm{MHz}$
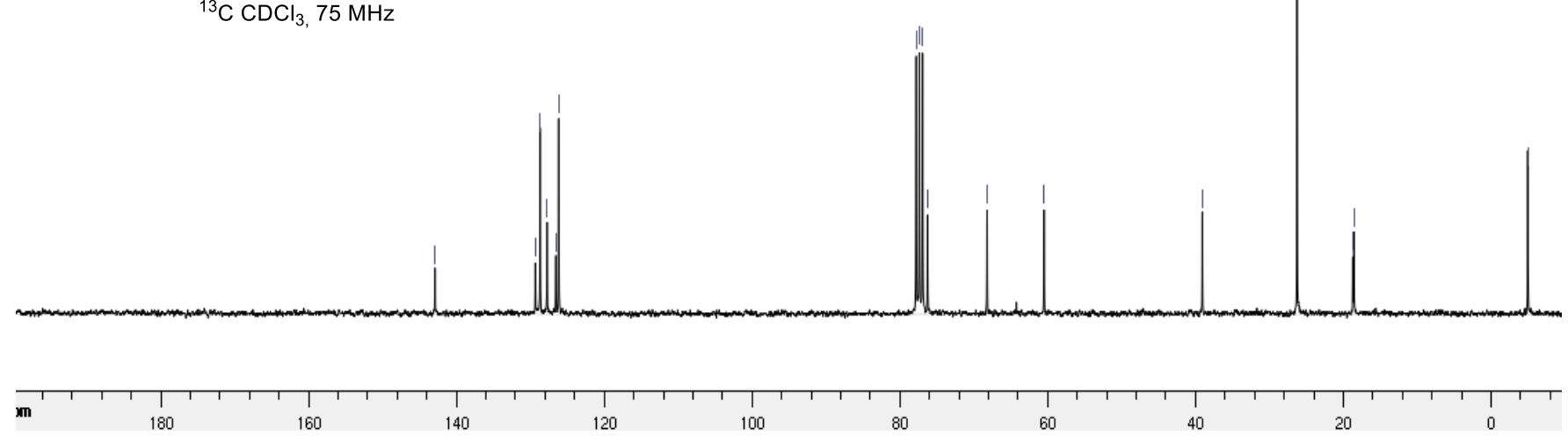

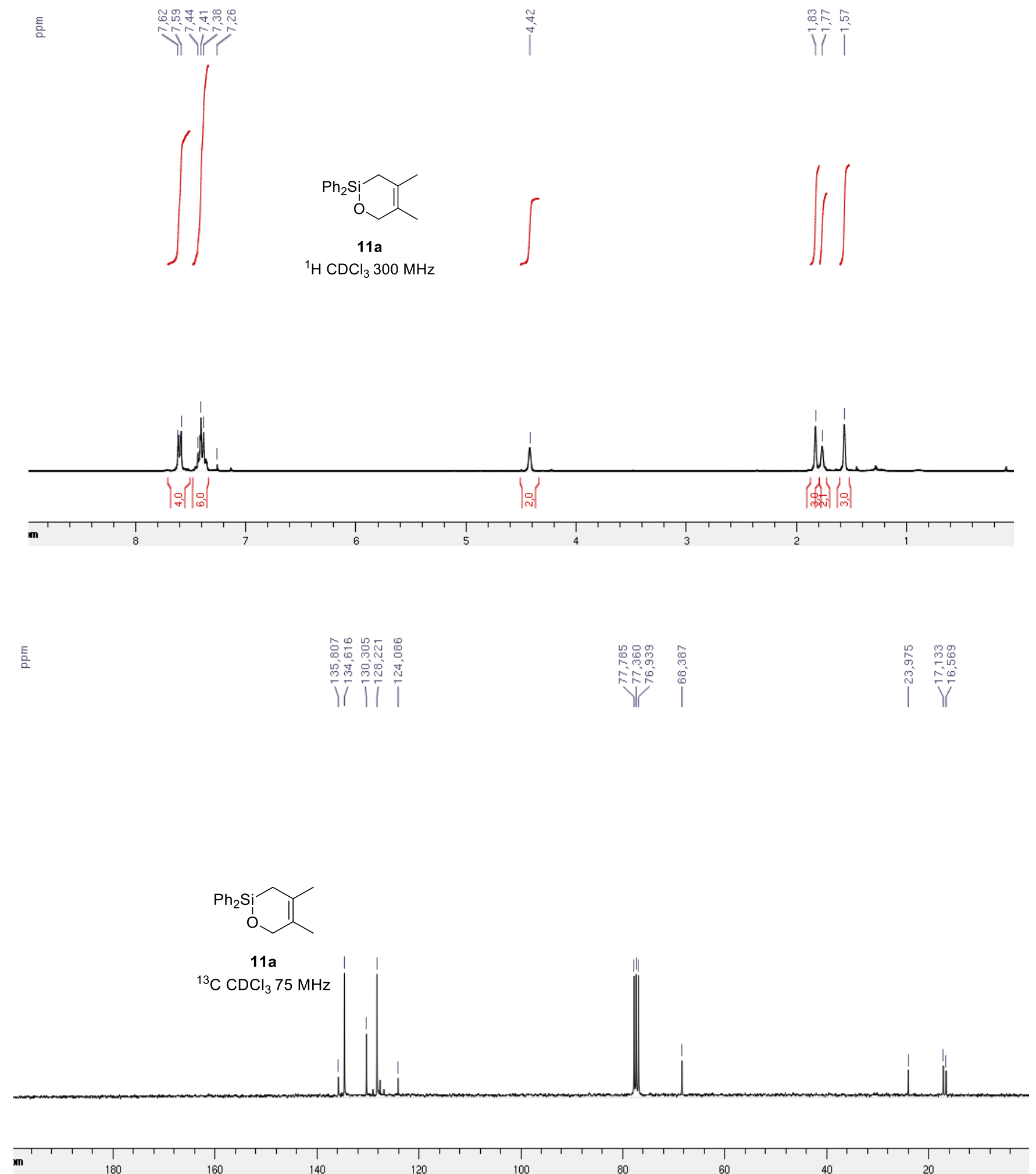


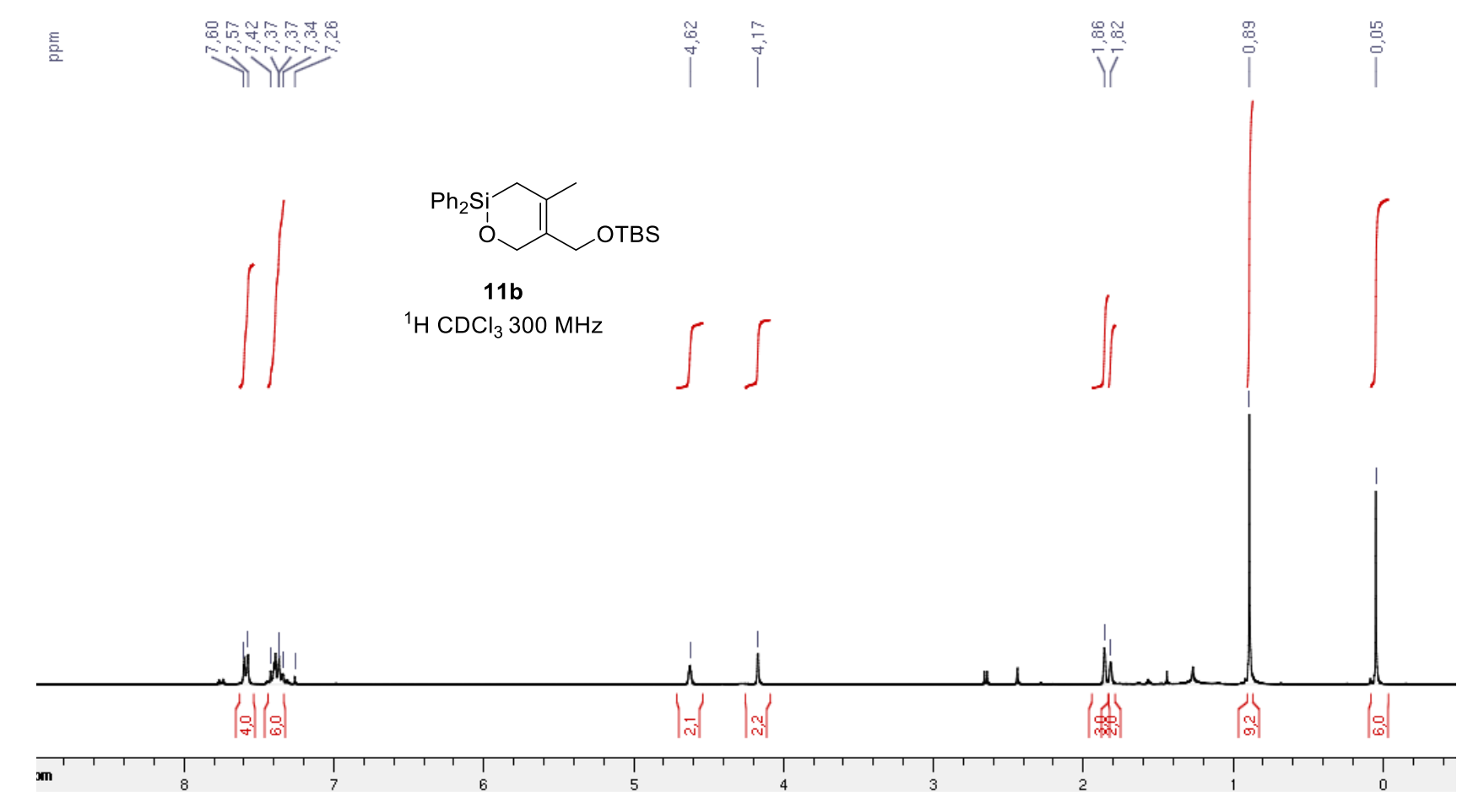

흘

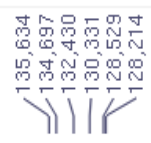

|

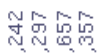

空 N

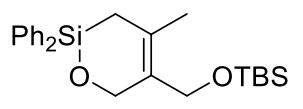

11b

${ }^{13} \mathrm{C} \mathrm{CDCl}_{3} 75 \mathrm{MHz}$
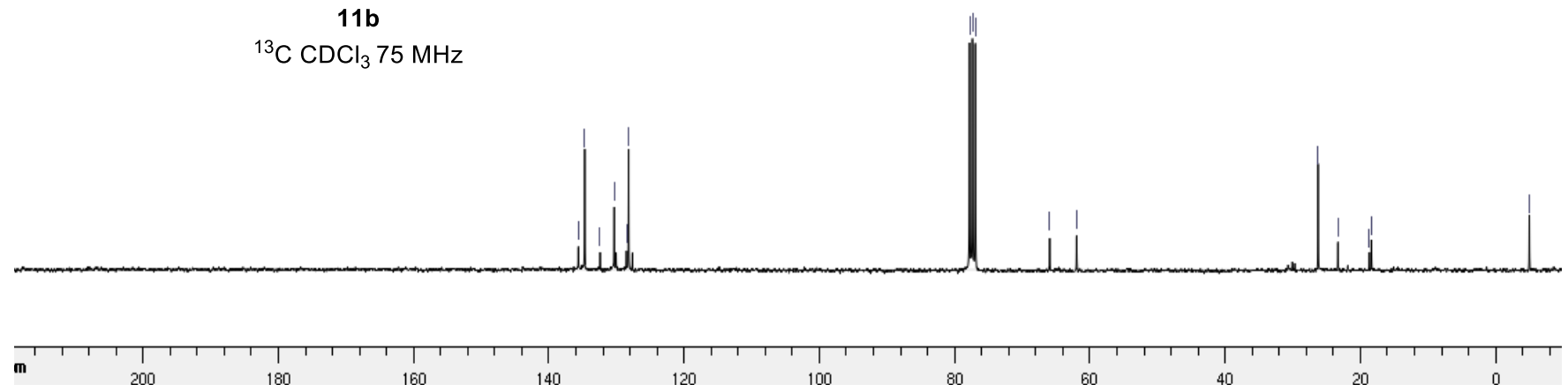
言

|

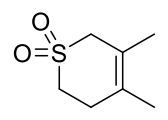

$12 \mathrm{a}$

${ }^{1} \mathrm{H} \mathrm{CDCl}_{3}, 400 \mathrm{MHz}$

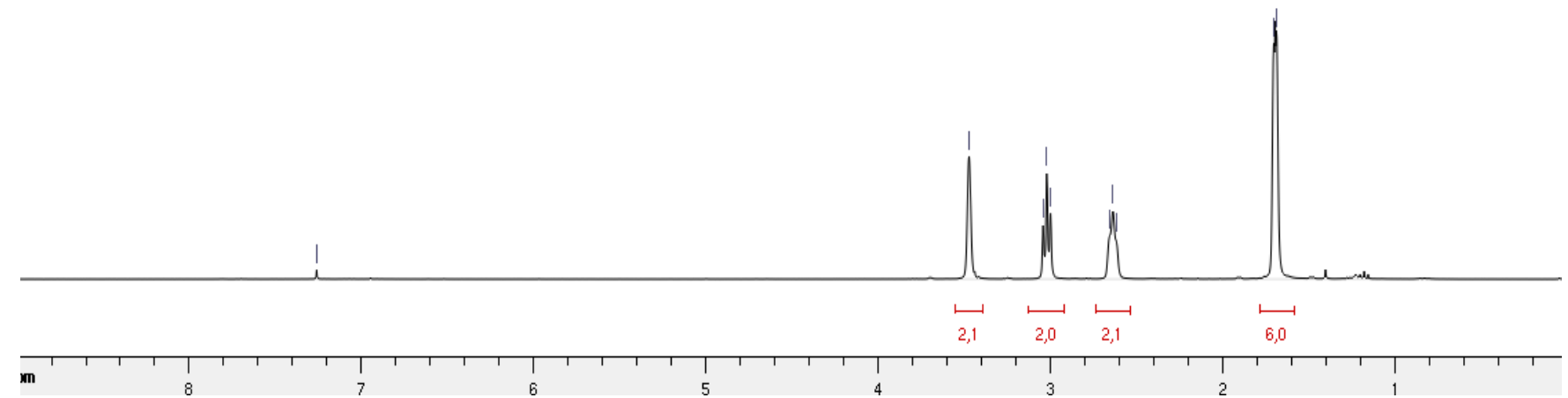

言

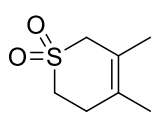

12a

${ }^{13} \mathrm{C} \mathrm{CDCl}_{3} 75 \mathrm{MHz}$

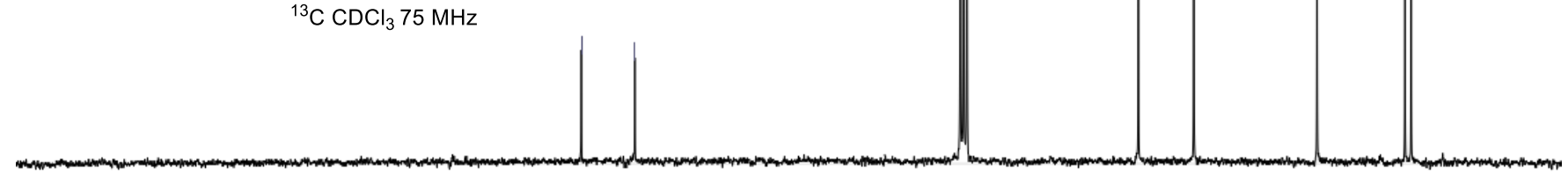

m 


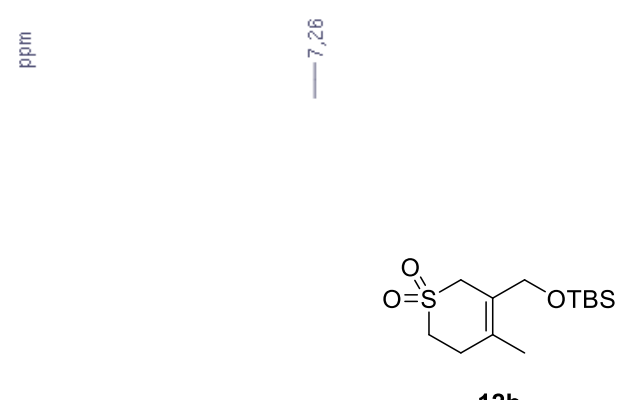

|

${ }^{1} \mathrm{H} \mathrm{CDCl}_{3} 300 \mathrm{MHz}$

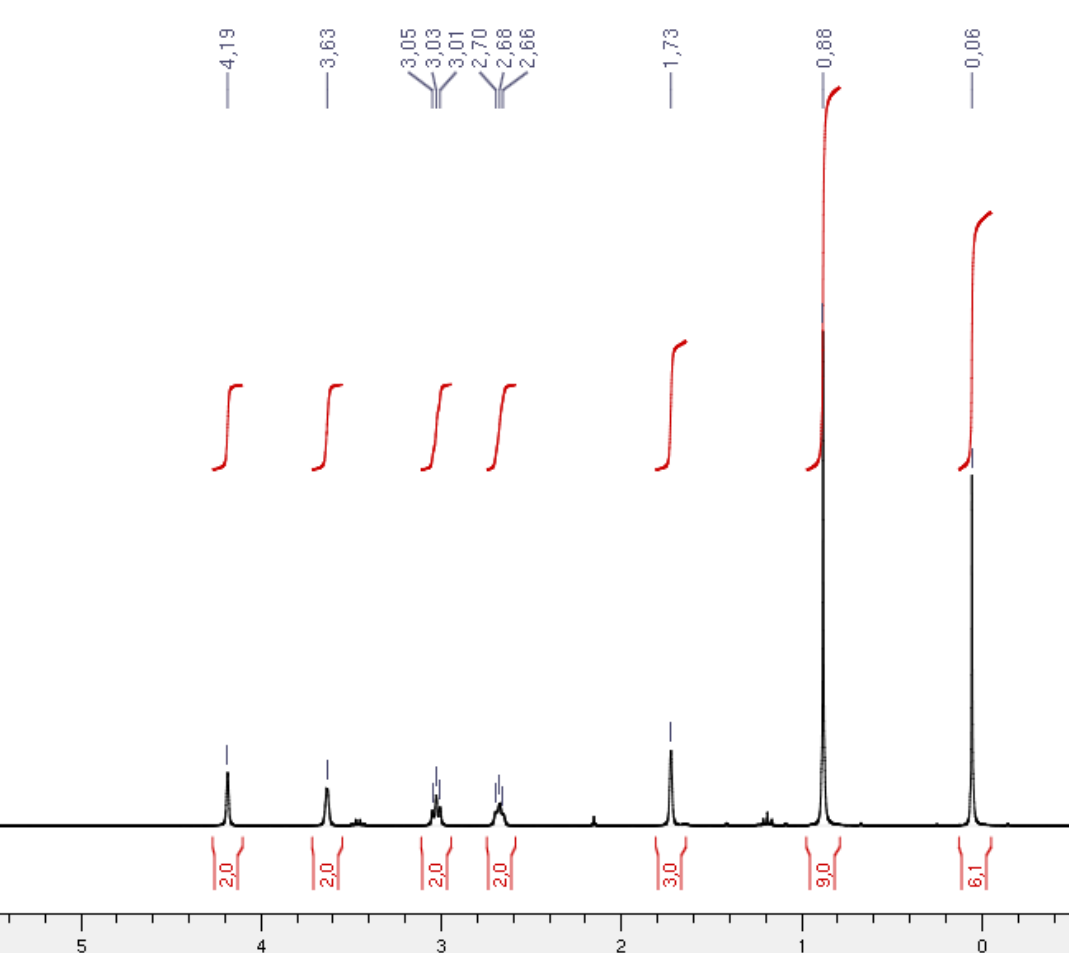

言

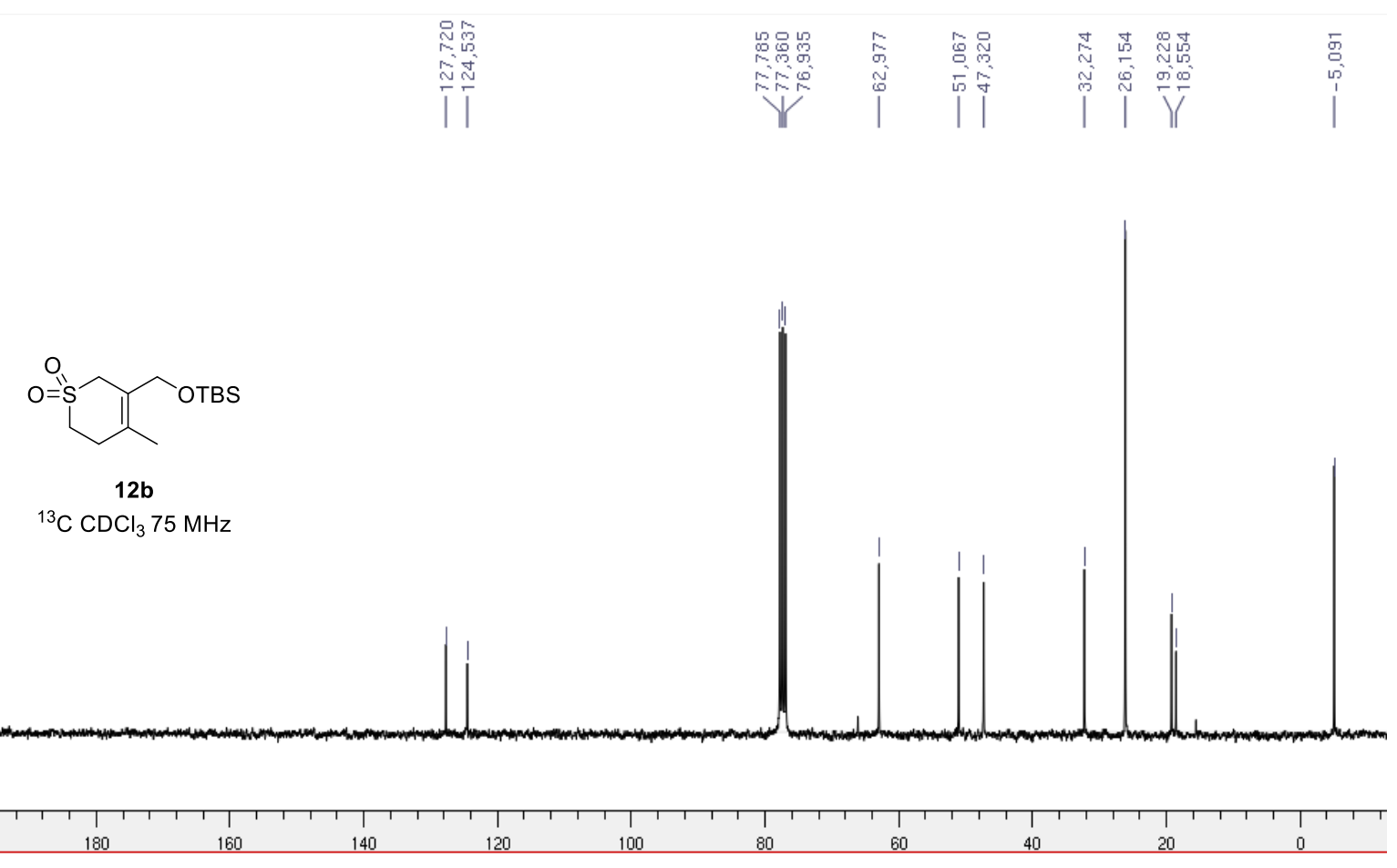



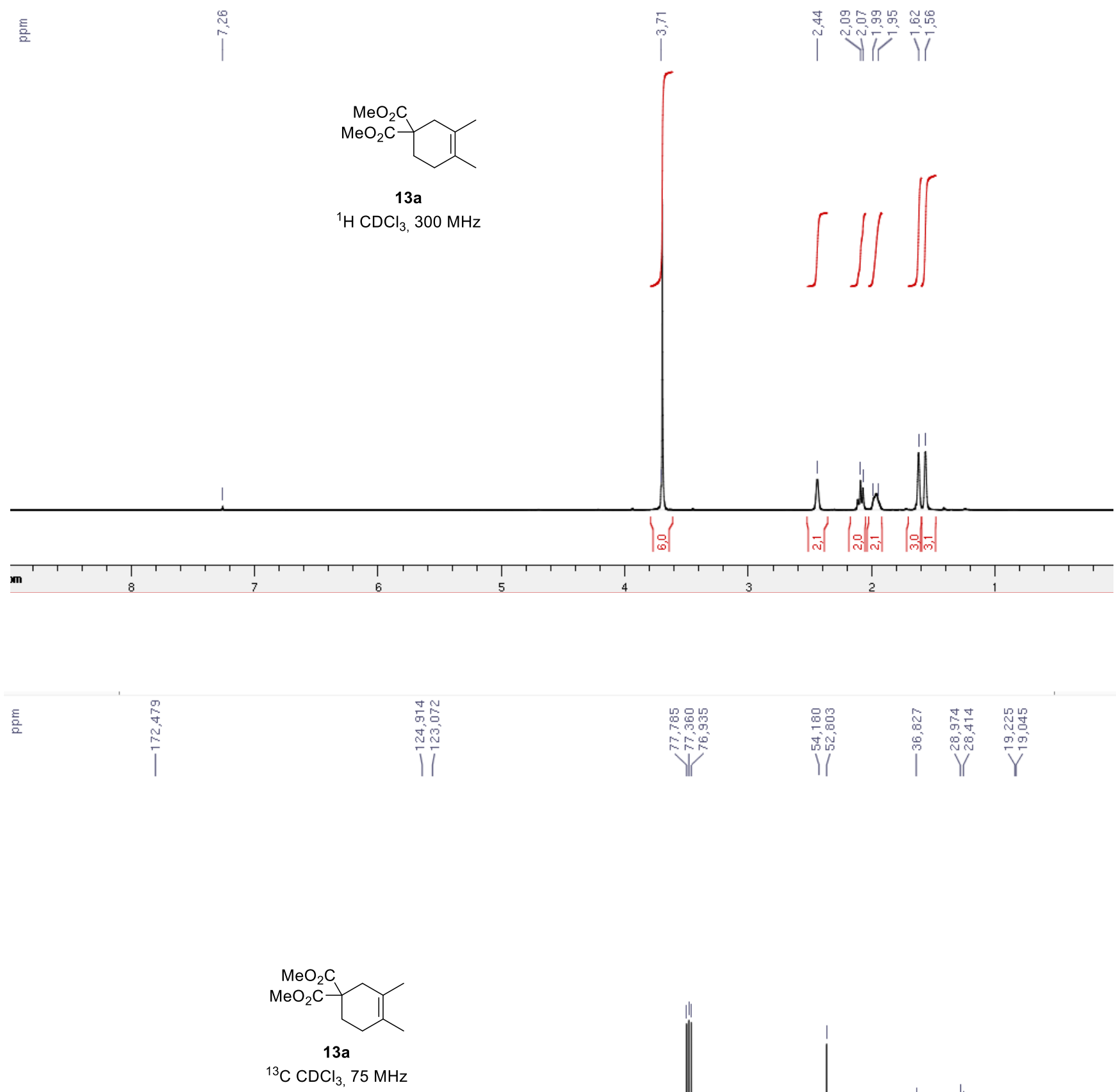

m
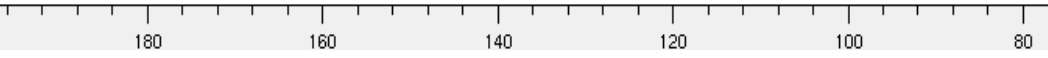

60

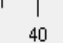



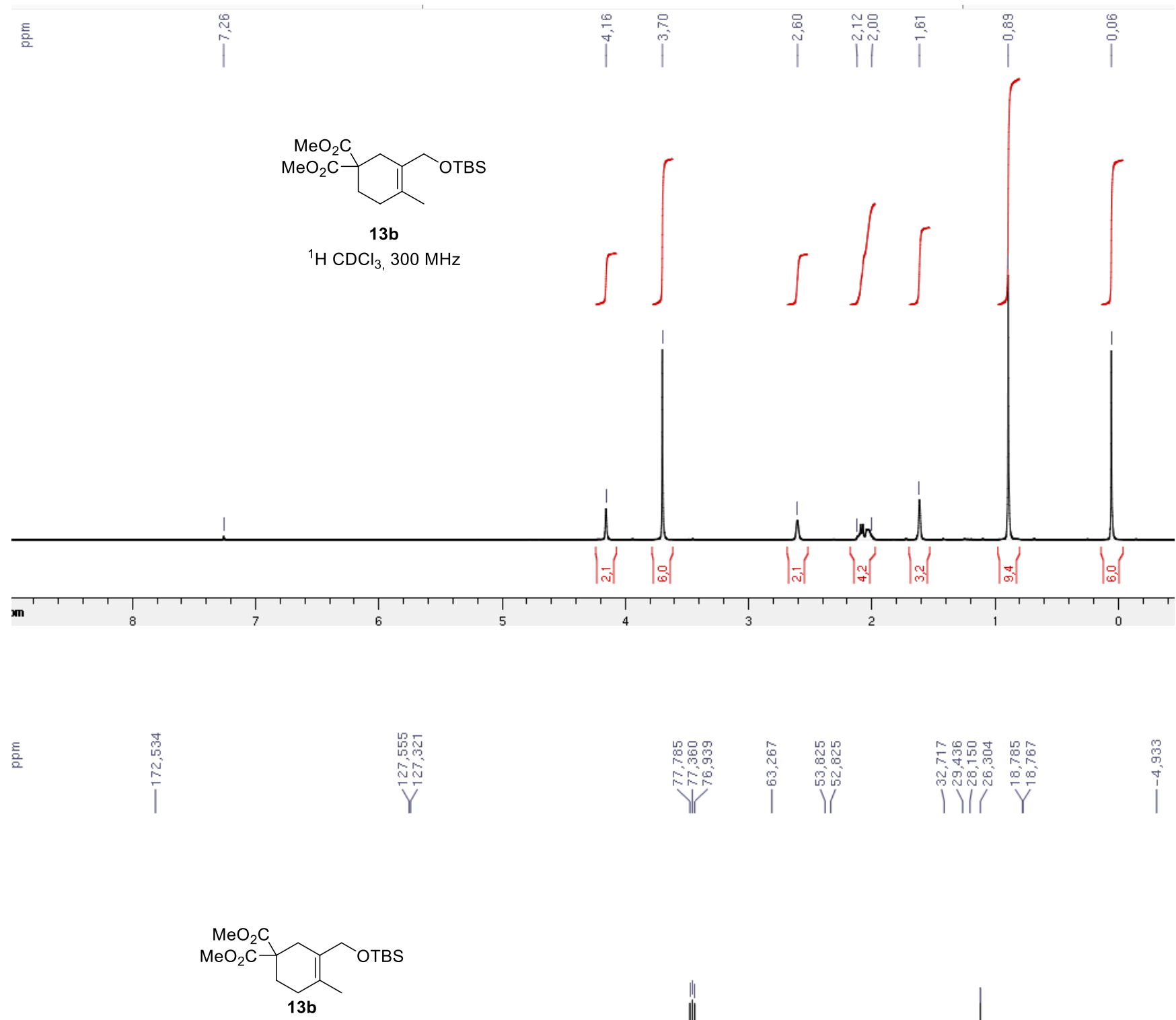

${ }^{13} \mathrm{C} \mathrm{CDCl}_{3}, 75 \mathrm{MHz}$
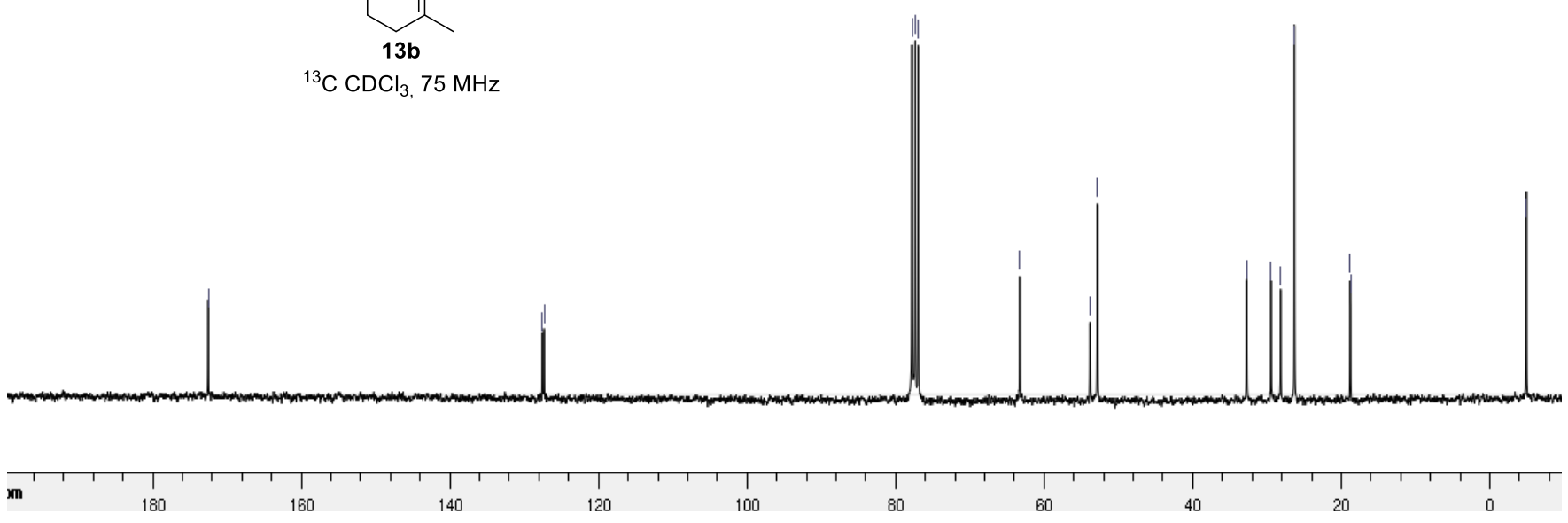

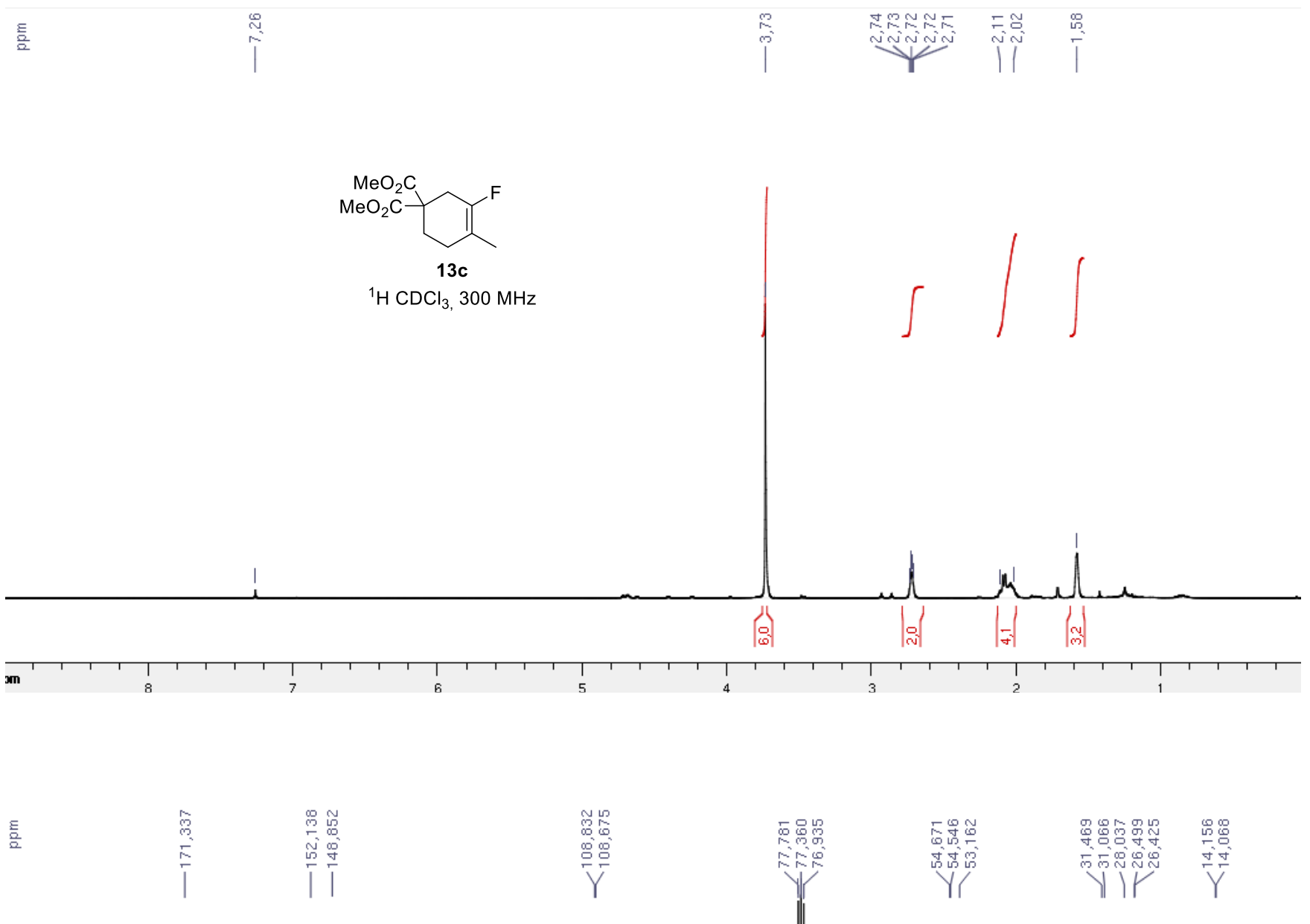

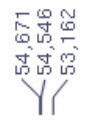

ل1

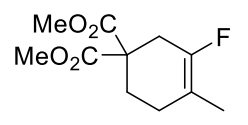

$13 \mathrm{c}$

${ }^{13} \mathrm{C} \mathrm{CDCl}_{3}, 75 \mathrm{MHz}$

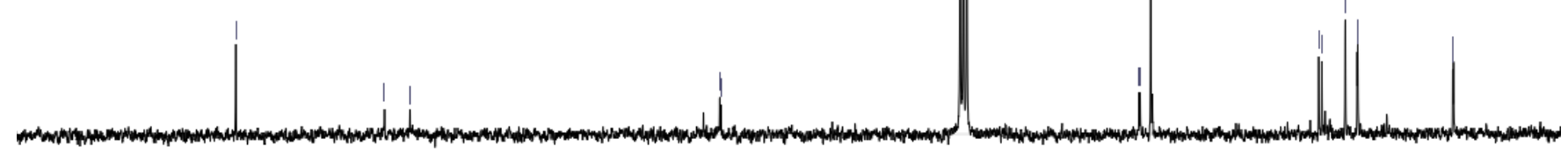

m 


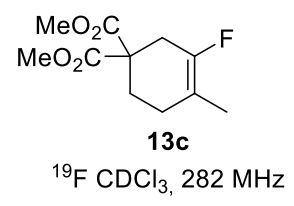

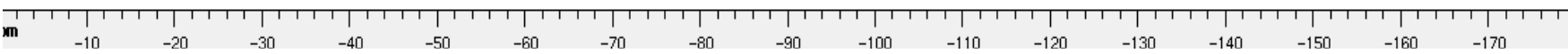



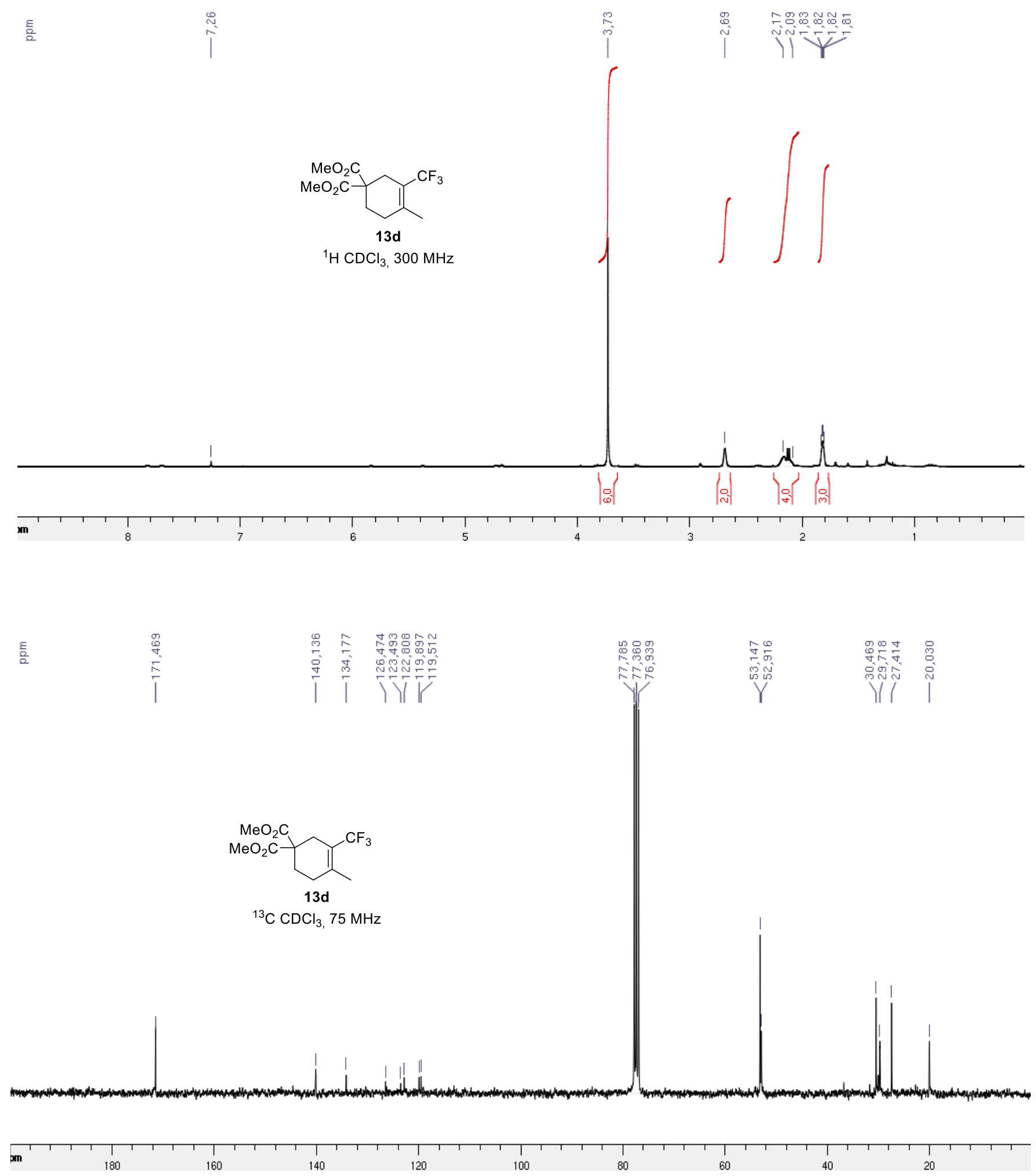
흘
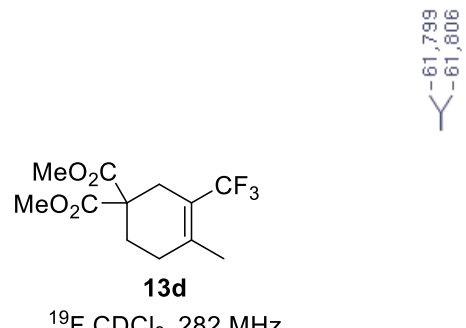

${ }^{19} \mathrm{~F} \mathrm{CDCl}_{3}, 282 \mathrm{MHz}$

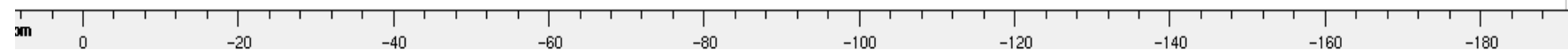



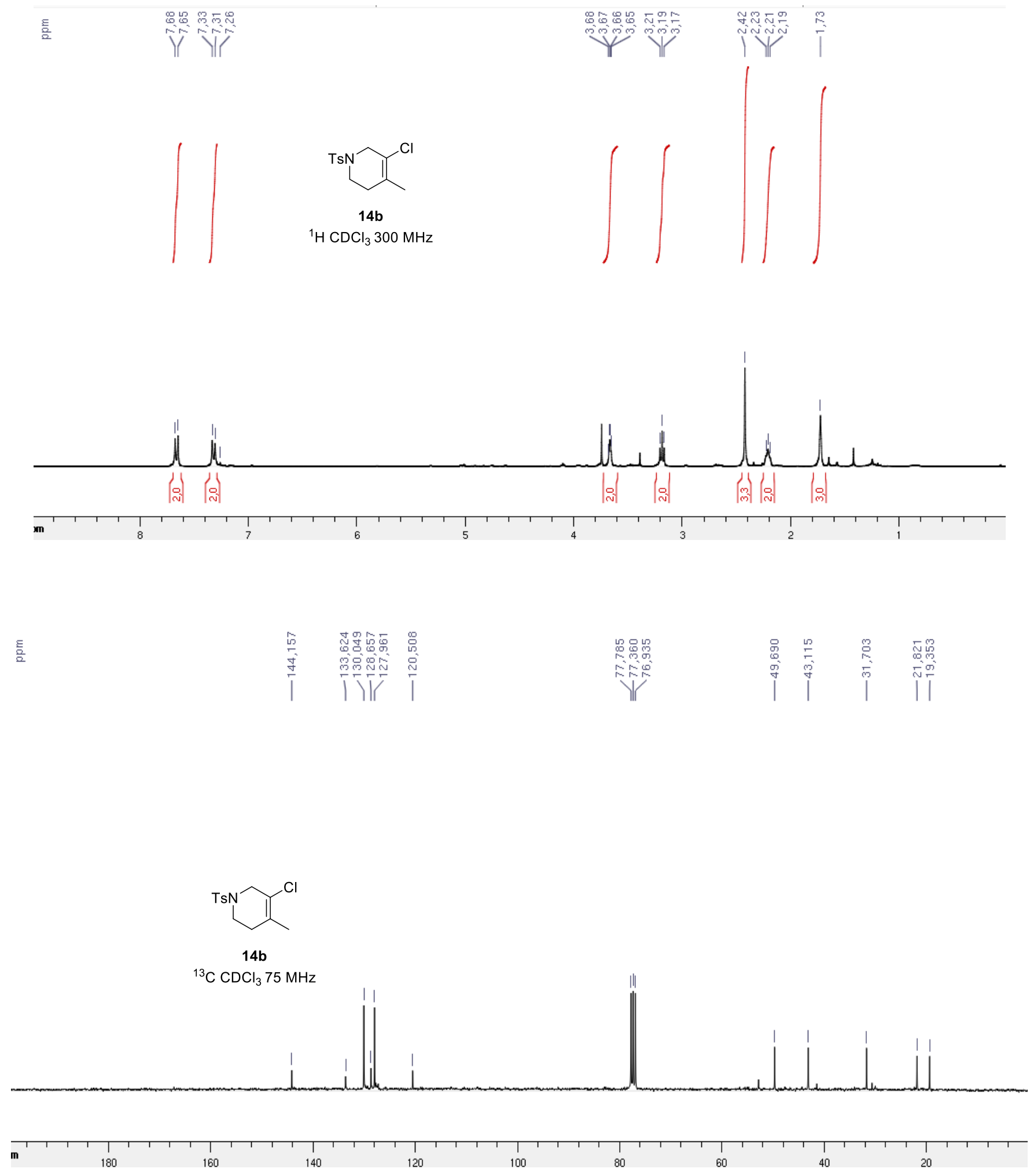


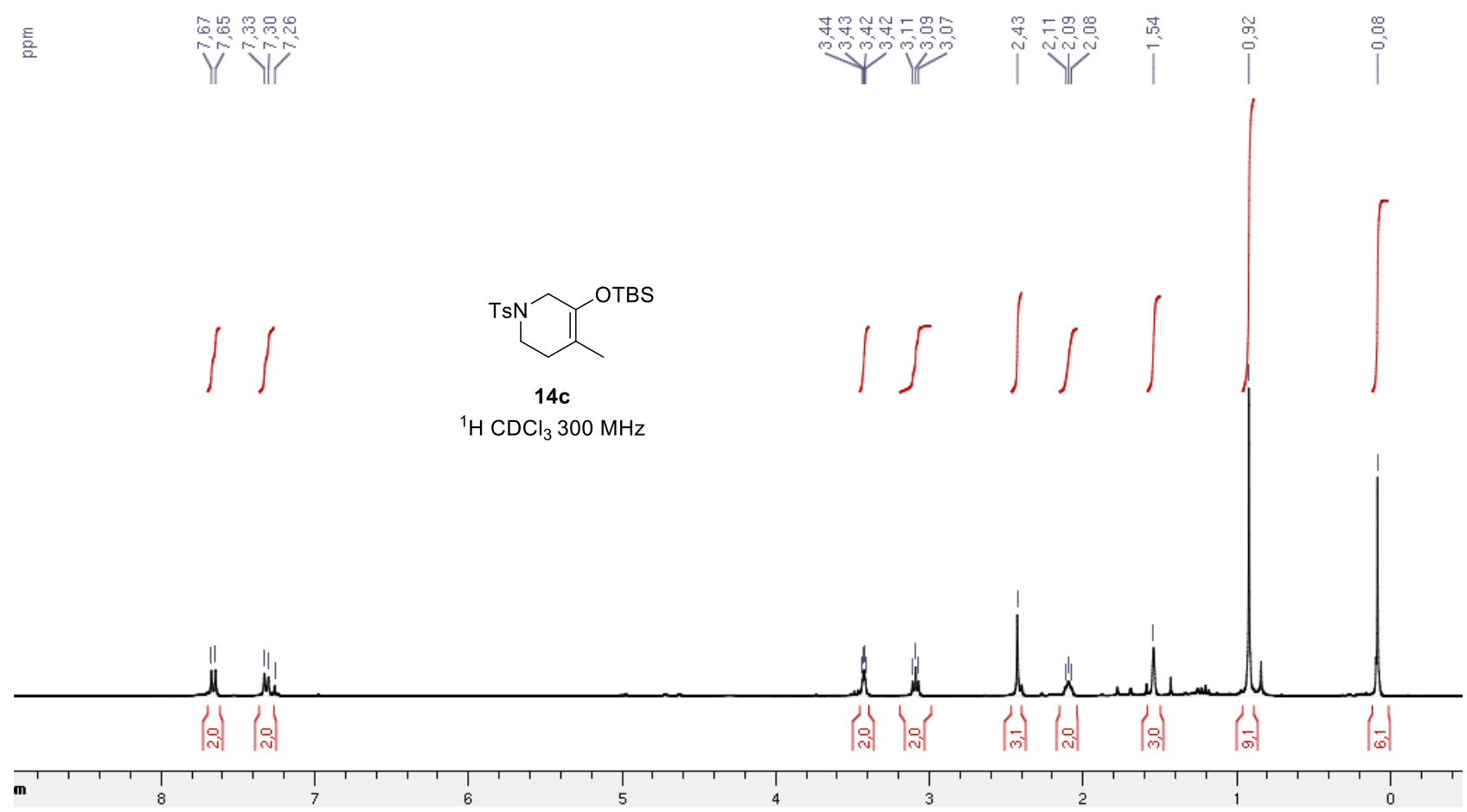

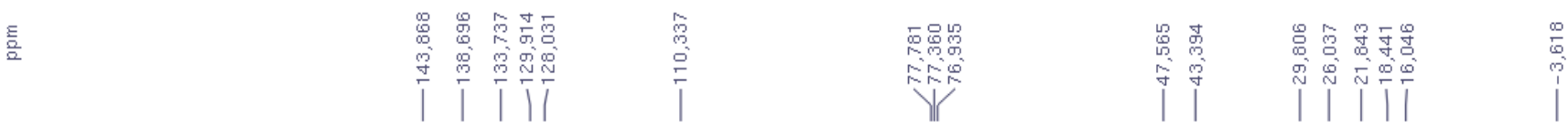

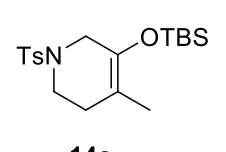

${ }^{13} \mathrm{C} \mathrm{CDCl}_{3} 75 \mathrm{MHz}$

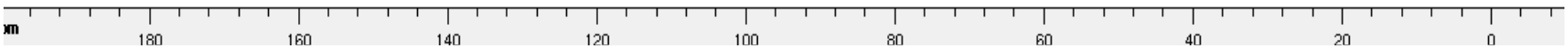




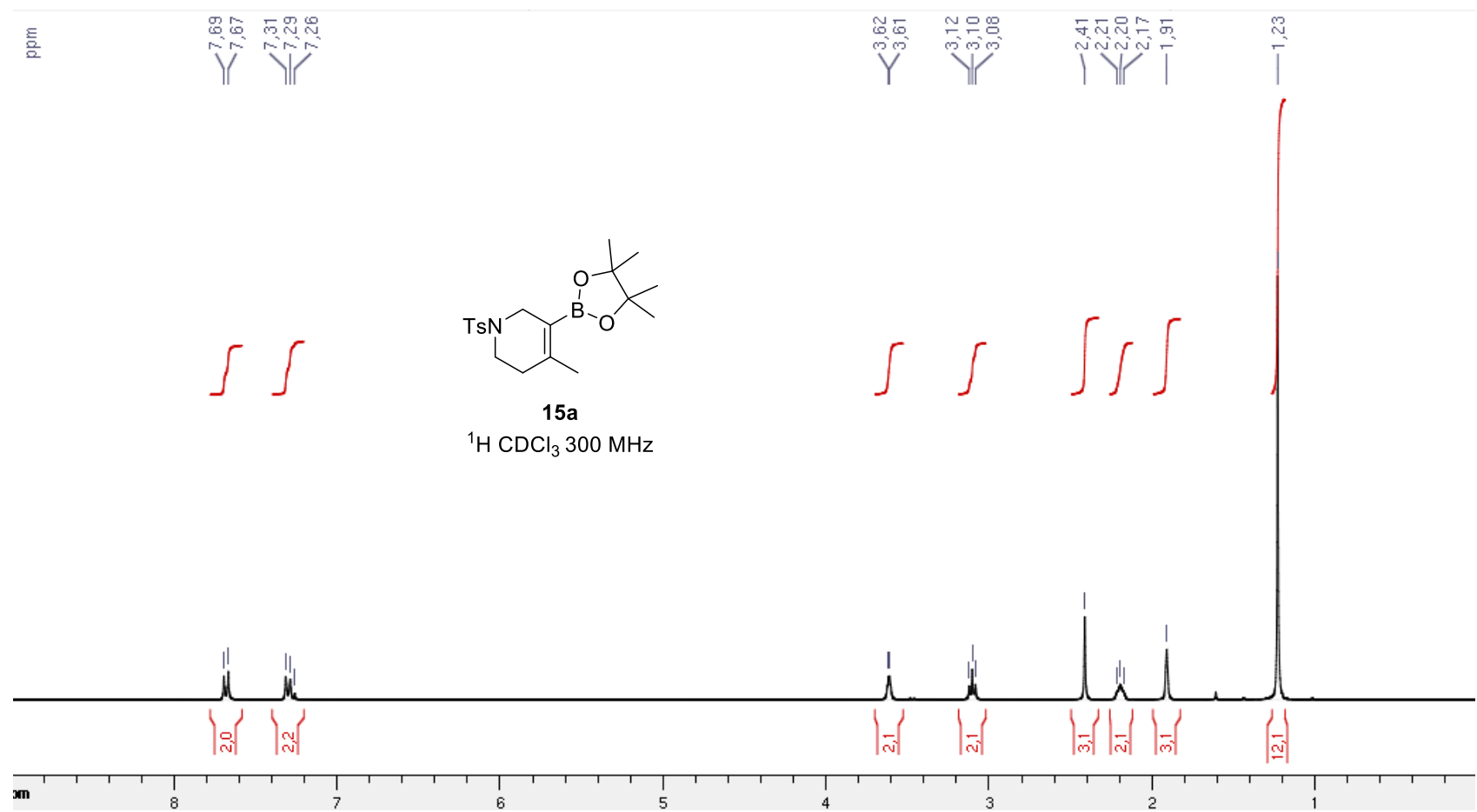

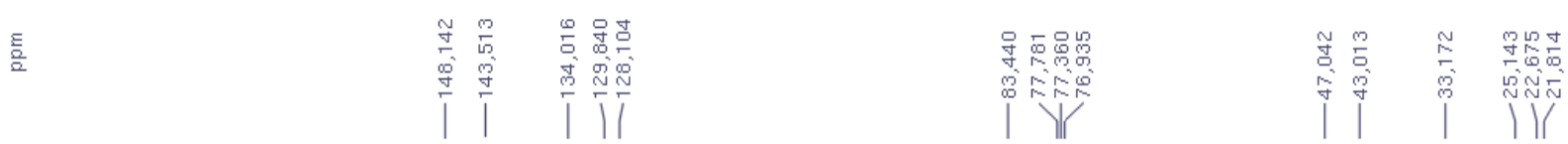

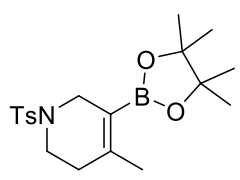

$15 a$

${ }^{13} \mathrm{C} \mathrm{CDCl}_{3} 75 \mathrm{MHz}$ 

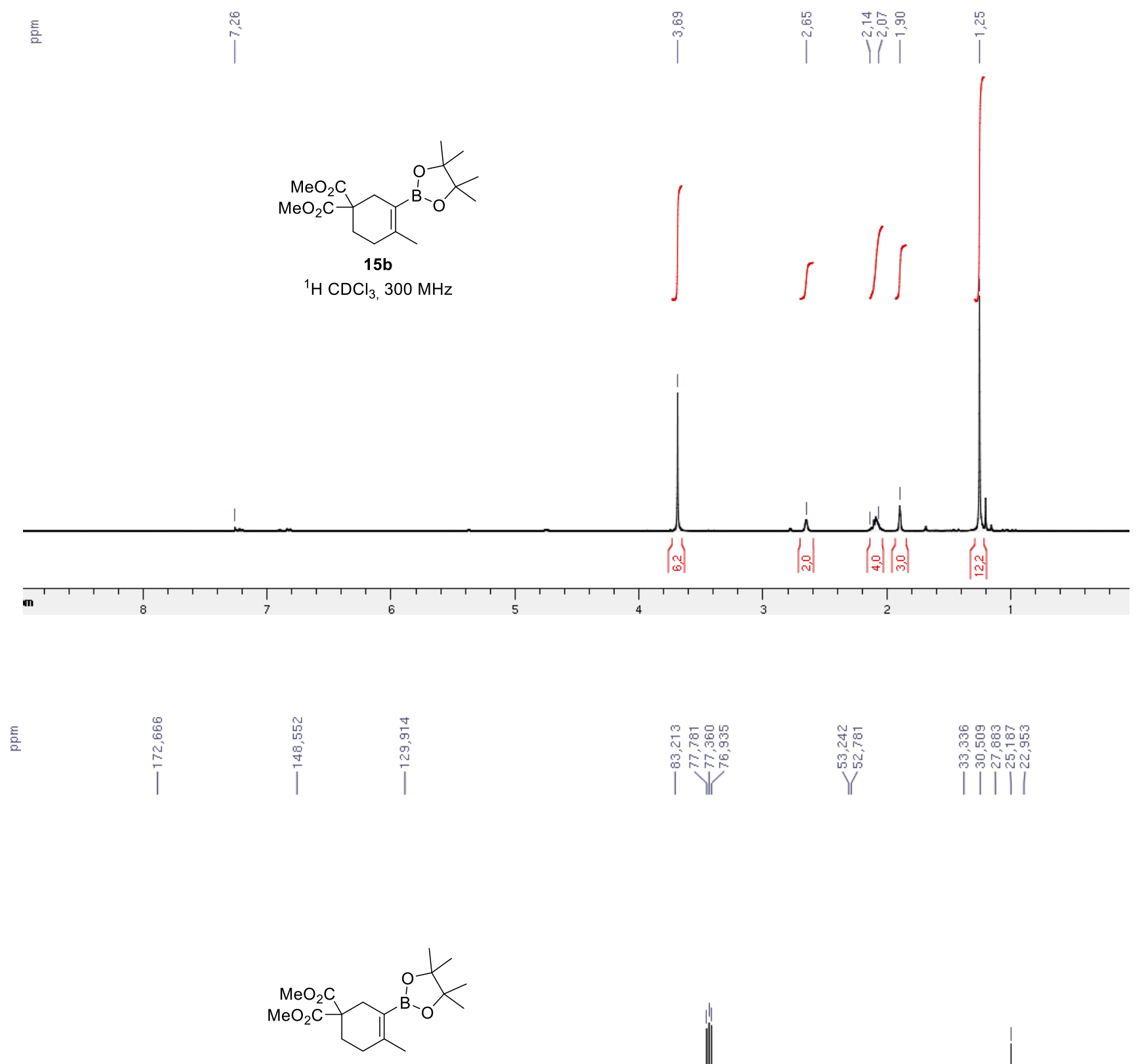

15b

${ }^{13} \mathrm{C} \mathrm{CDCl}_{3}, 75 \mathrm{MHz}$ 


\section{${ }^{1} \mathrm{H}$ and ${ }^{13} \mathrm{C}$ spectra for compounds $16 \mathrm{a}-\mathrm{b}, 17$ and $18 \mathrm{a}-\mathrm{b}$}
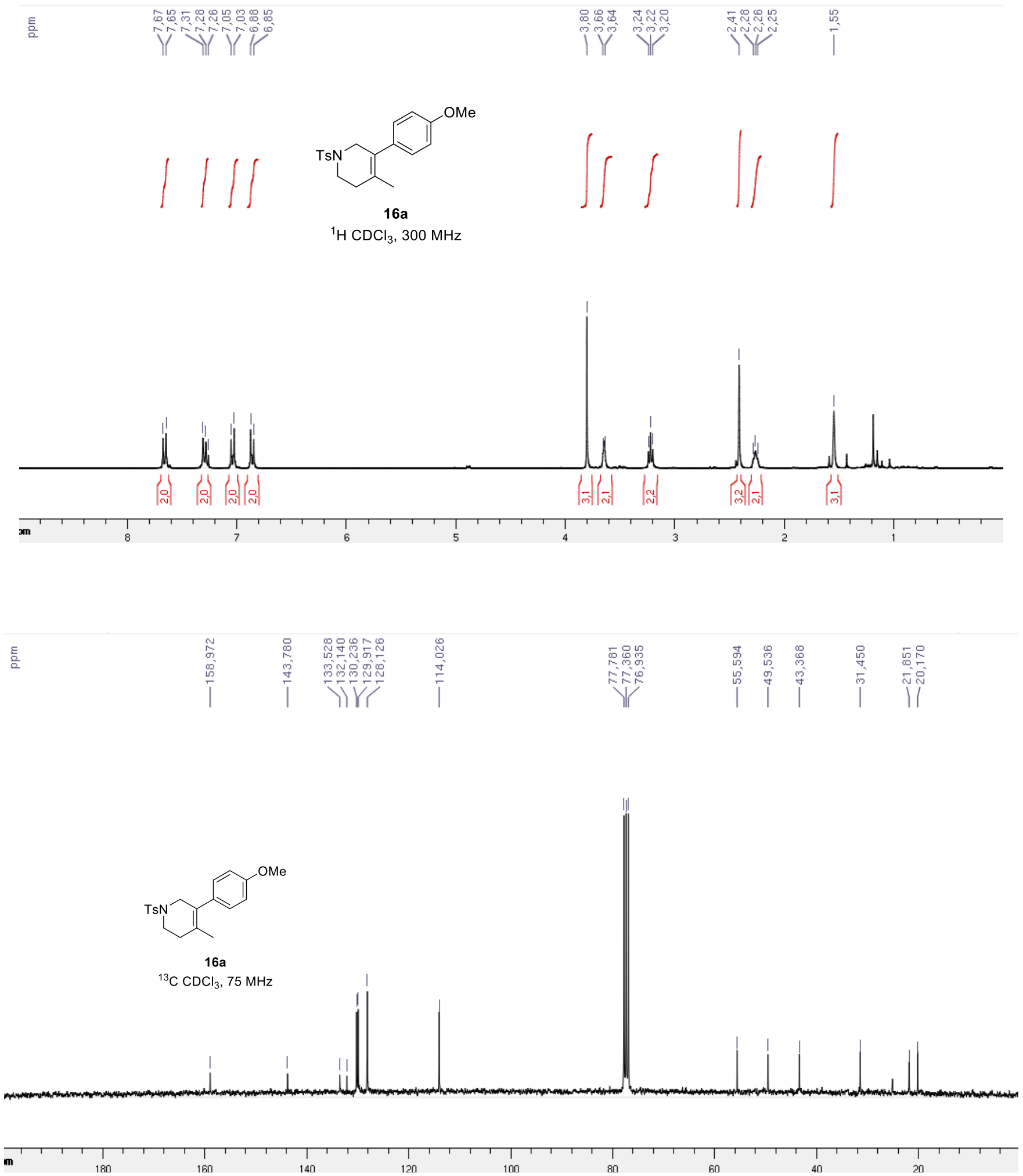
言<smiles>CC1=C(c2cccc(C(F)(F)F)c2)CN([135I])CC1</smiles>

$16 \mathrm{~b}$ ${ }^{1} \mathrm{H} \mathrm{CDCl}_{3}, 300 \mathrm{MHz}$ $4^{\circ}$

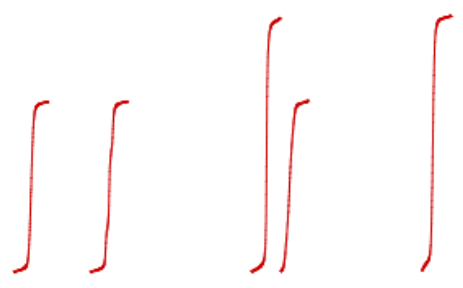

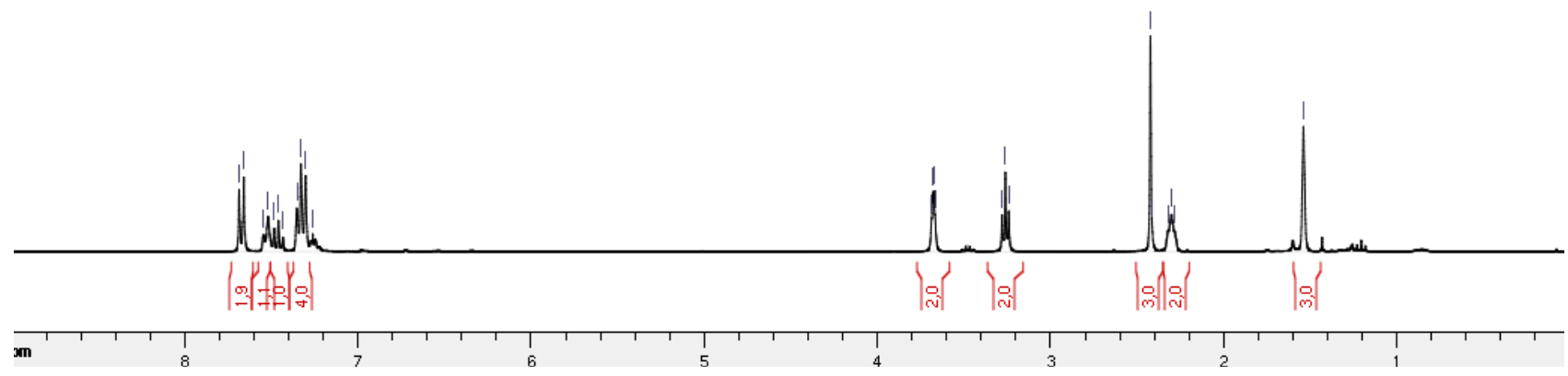

흘

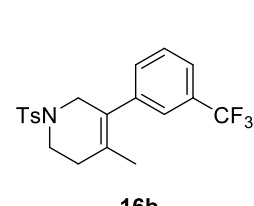

$16 \mathrm{~b}$

${ }^{13} \mathrm{C} \mathrm{CDCl}_{3}, 75 \mathrm{MHz}$

mn

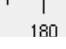

160

140

120

100

80

60

$\prod_{40}^{1}$

20 


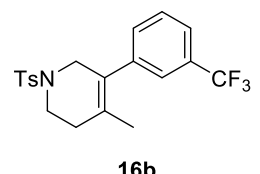

${ }^{19} \mathrm{~F} \mathrm{CDCl}_{3}, 282 \mathrm{MHz}$

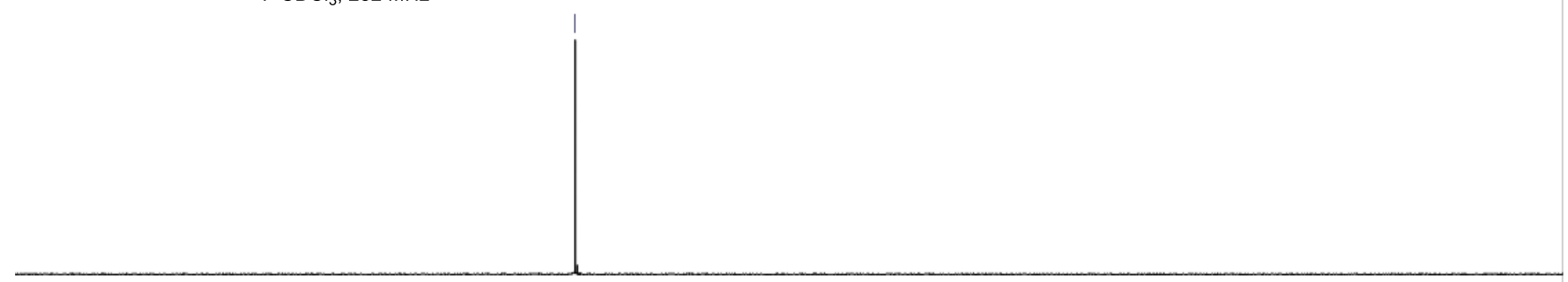

$$
\text { m }
$$

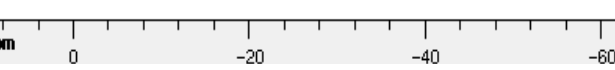

$-80$

$-100$

$-120$

$-140$

$-160$ 

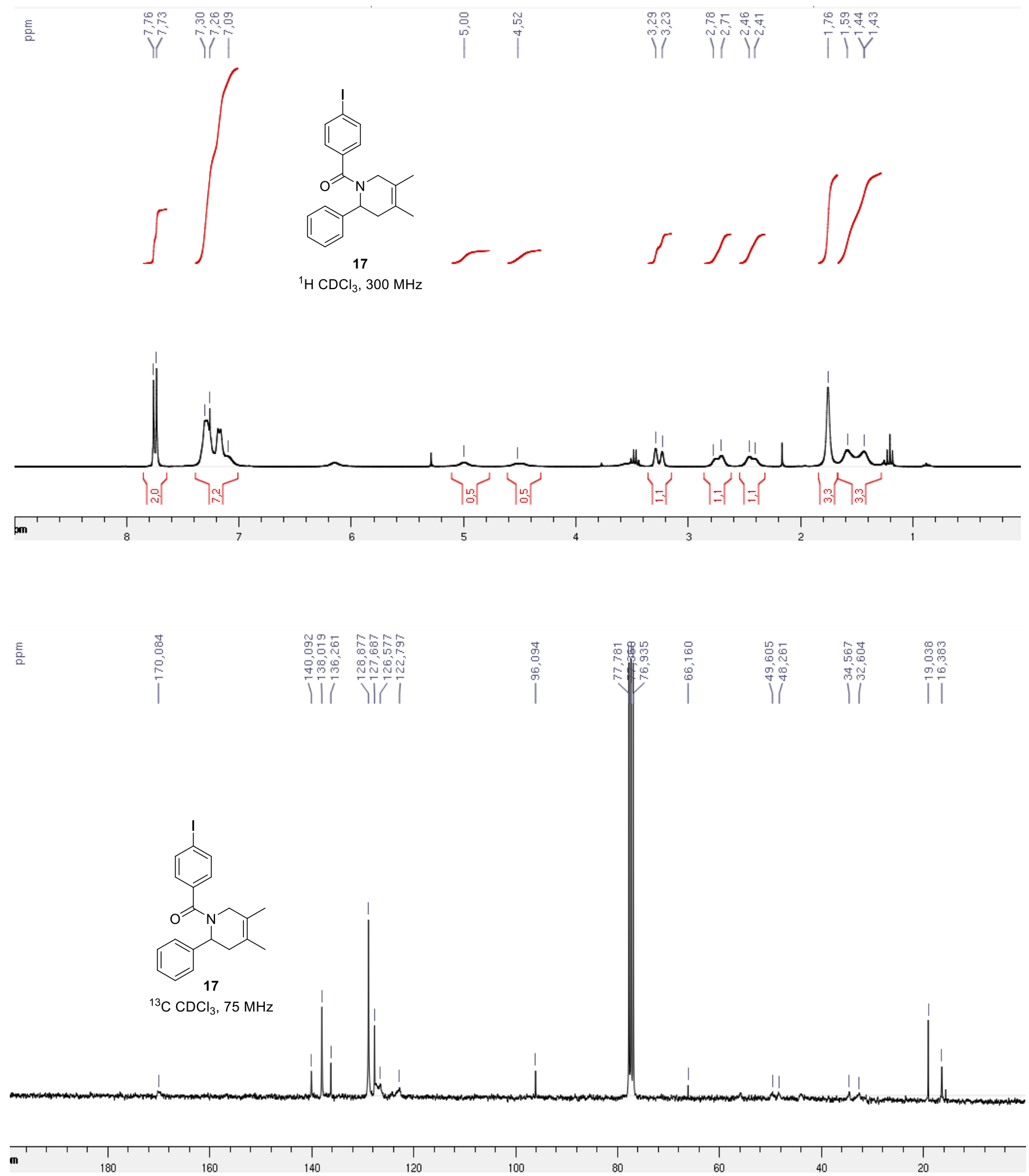

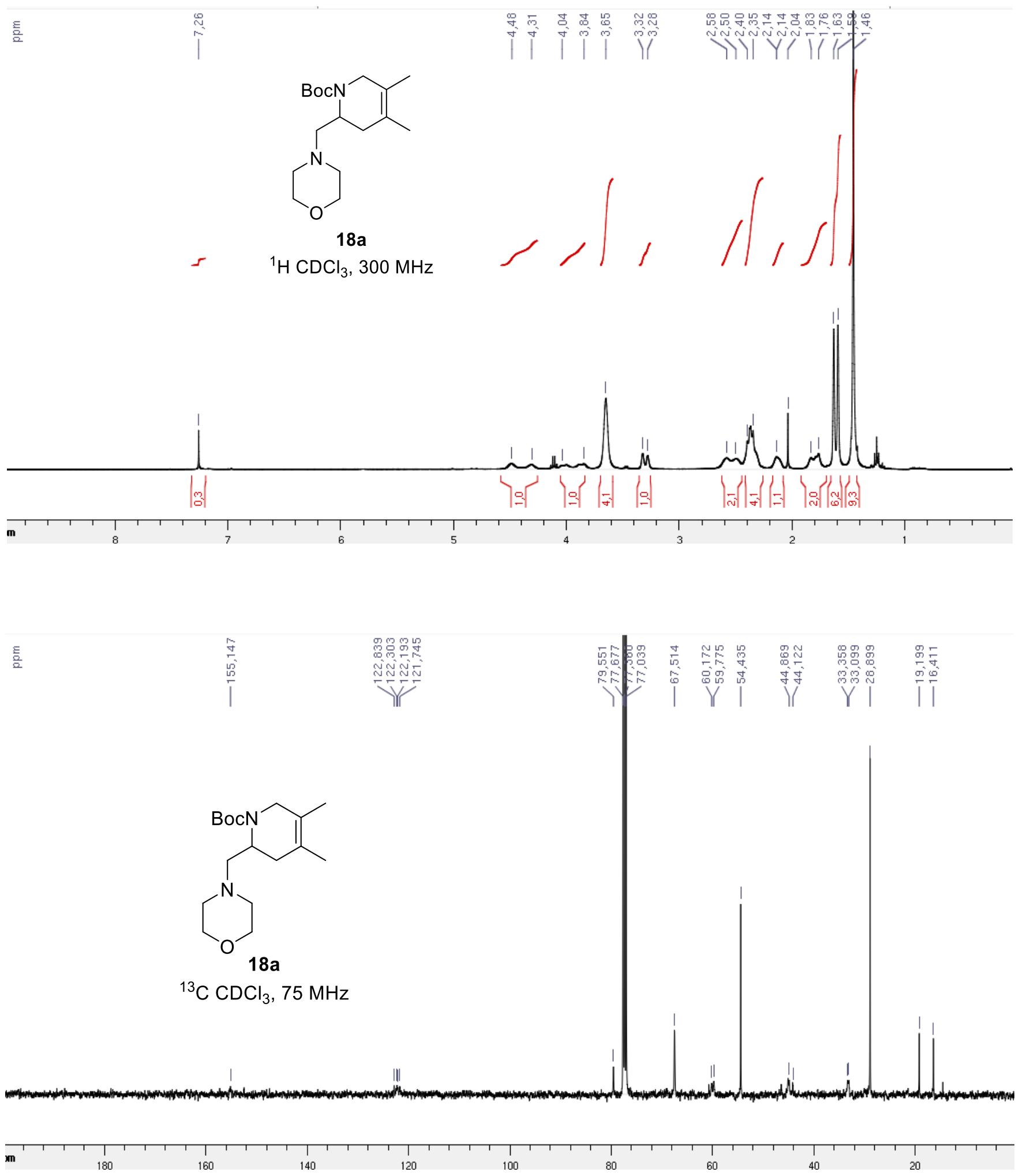


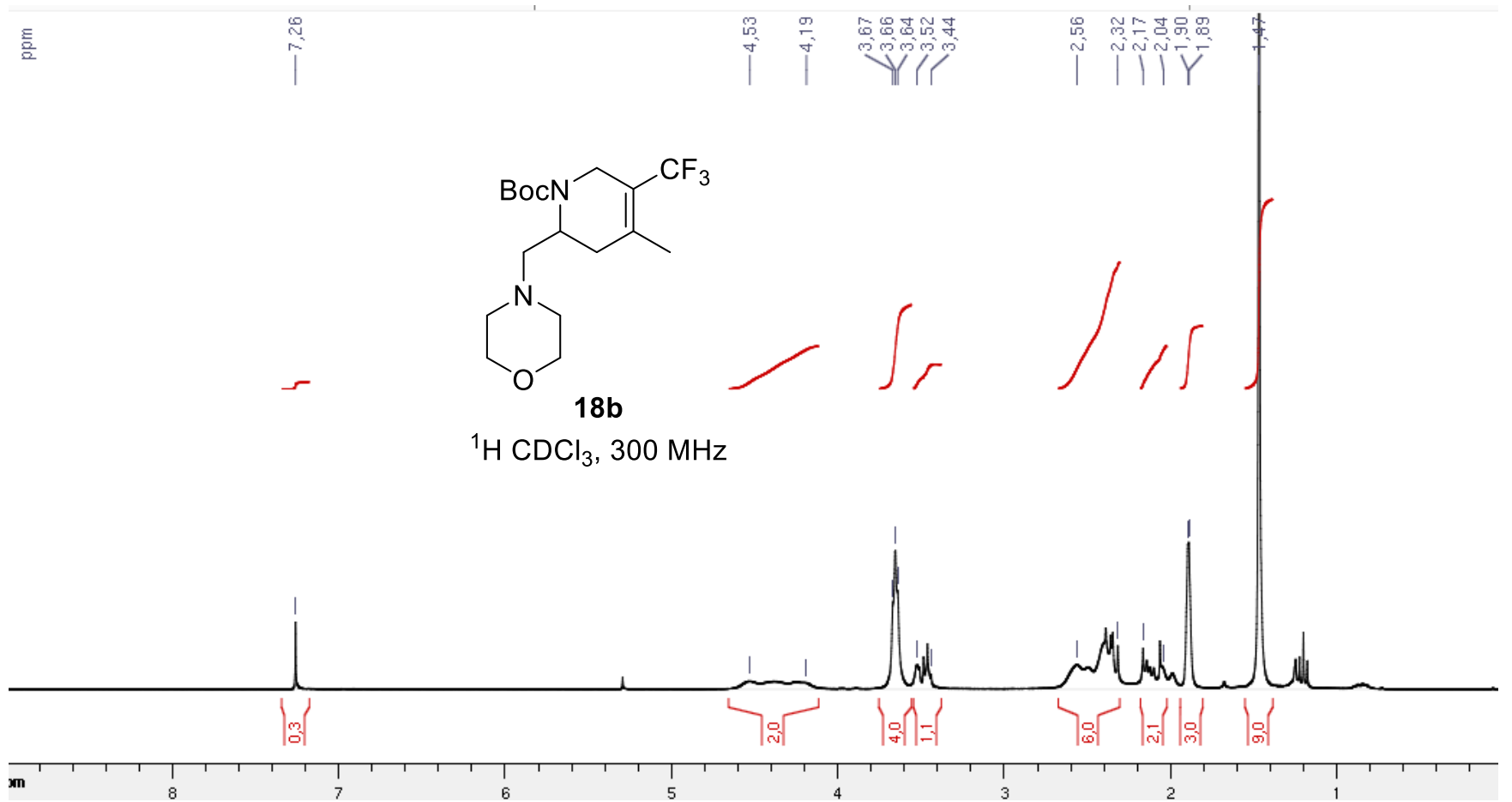

흘

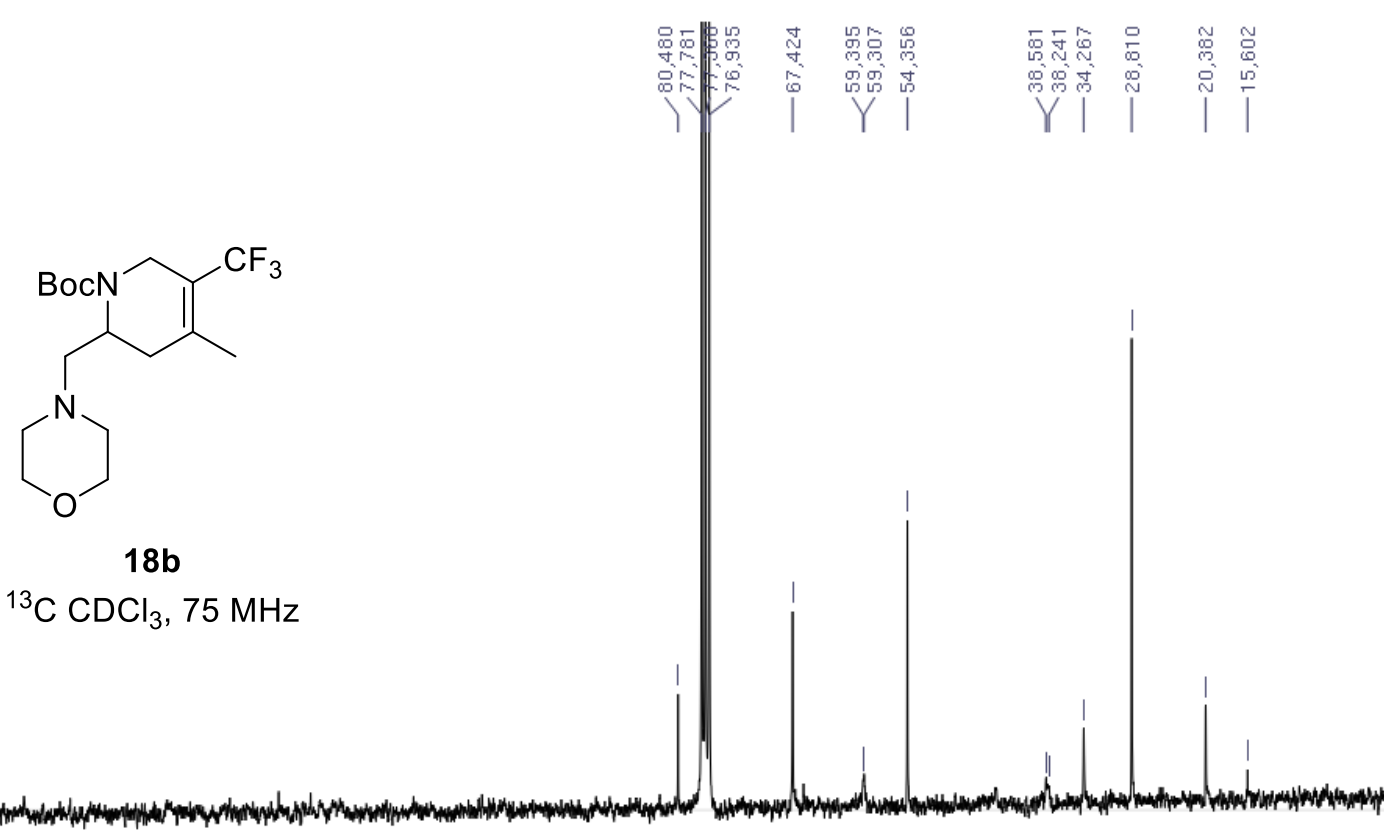

m
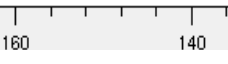

120

100

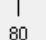

60

40

20 
言<smiles>CC1=C(C(F)(F)F)CN(C(=O)OCc2ccccc2)C(CN2CCOCC2)C1</smiles>

$18 \mathrm{~b}$

${ }^{19} \mathrm{~F} \mathrm{CDCl}_{3}, 282 \mathrm{MHz}$

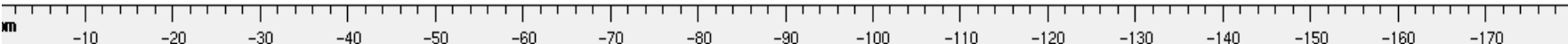

